ATL-A-108

INFORMAL AEC RESEARCH AND DEVELOPMENT REPORT UC-81, Reactors-Power SPECIAL DISTRIBUTION

Quarterly Progress Report No. 4

VARIABLE MODERATOR REACTOR

DEVELOPMENT PROGRAM

ATL Job 45003

31 May 1960

Prepared Under

Contract No. AT(04-3)-250

Project Agreement No. 3

for the U. S. Atomic Energy Commission

Division of Reactor Development

\title{
ADVANCED TECHNOLOGY LABORATORIES
}

A Division of American-Standard

369 Whisman Road

Mountain View, California

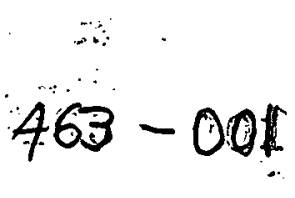

ADVANCED Techuology LABORATORIIS a oivision of American-siandard 


\section{DISCLAIMER}

This report was prepared as an account of work sponsored by an agency of the United States Government. Neither the United States Government nor any agency Thereof, nor any of their employees, makes any warranty, express or implied, or assumes any legal liability or responsibility for the accuracy, completeness, or usefulness of any information, apparatus, product, or process disclosed, or represents that its use would not infringe privately owned rights. Reference herein to any specific commercial product, process, or service by trade name, trademark, manufacturer, or otherwise does not necessarily constitute or imply its endorsement, recommendation, or favoring by the United States Government or any agency thereof. The views and opinions of authors expressed herein do not necessarily state or reflect those of the United States Government or any agency thereof. 


\section{DISCLAIMER}

Portions of this document may be illegible in electronic image products. Images are produced from the best available original document. 


\section{LEGAL NOTICE}

This report was prepared as an account of Government sponsored work. Neither the United States, nor the Commission, nor any person acting on behalf of the Commission:

A. Makes any warranty or representation, expressed or implied, with respect to the accuracy; completeness, or usefulness of the information contained in this report, or that the use of any information, apparatus, method, or process disclosed in this report may not infringe privately owned rights; or

B. Assumes any liabilities with respect to the use of, or for damages resulting from the use of any information, apparatus, method, or process disclosed in this report.

As used in the above, "person acting on behalf of the Commission" includes any employee or: contractor of the Commission, or employee of such contractor, to the extent that such employee or contractor of the Commission, or employee of such contractor prepares, disseminates, or provides access to, any information pursuant to his employment or contract with the Commission, or his employment with such contractor.

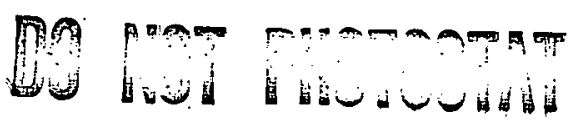




\section{CONTENTS}

Forward $\quad 1$

Program Objectives ..

Status of Program $\quad 3$

A. Core Designs and Parametric Studies 3

B. Kinetics 3

C. Physics 3

D. Mechanical and System Design 3

E. Economic Evaluation 3

F. Critical Experiment $\quad 3$

Summary of $:$ Results .

A. Core Designs, Parametric Studies, and Economic Evaluation 4

B. Kinetics

C. Physics. 4

D. Critical Experiment 4

I. Core Designs and Fuel-Cycle Cost Analysis $\quad$ $\quad 5$

A. Core Designs and Parametric Studies $\quad 5$

B. Results of VMR Fuel-Cycle Cost Analysis 7

C. Effect of Control Requirements on Fuel-Cycle Costs 10

1. Reactivity Effects 10

2. Moderator-Level Variation with Load 13

D. Comparison of Fuel-Cycle Costs for "Conventional"

$\begin{array}{ll}\text { Boiling-Water Reactors and the VMR } & 14 \\ \text { 1. Prototype Boiling Water Reactor } & 15\end{array}$

2. 50-mw BWR Designed by General Nuclear Engineering Corporation 17

3. 40-mw Process-Steam BWR 18

4. General Discussion of VMR and Conventional BWR Fuel-Cycle-Cost Differences 19

E. Method of Computing Fuel-Cycle Costs 20

$\begin{array}{ll}\text { 1. Reactivity } & 20\end{array}$

2. Beginning- and End-of-Life Uranium and Plutonium Concentrations

3. Reactor Power Output 21

4. Fabrication Costs 21

5. Reprocessing Fuel to Nitrates $\quad 21$

6. Burnup Cost . - . 21

7. Pu Credit 21

8. Conversion Nitrates to $\mathrm{UF}_{6} \quad 21$

9. Losses 22

10. Use Charges $\quad 22$

11. Shipping 22

12. Interest on Fabrication Capital 22 


\section{CONTENTS}

II. MSBU Fuel-Burnup Code $\quad \cdot \quad 27$

A. General Description of Code $\quad 27$

B. "Batch" Loading Calculation Procedure 31

C. "Three Region" Loading Calculation Procedure 31

D. Discussion of "Batch" Loading Versus "Three Region"

\begin{tabular}{ll} 
Fuel Loading & 32 \\
\hline
\end{tabular}

III. Kinetics . $\quad 34$.

$\because \quad$ Nomenclature $\quad 39$

IV. PUREE' Physics Analysis, Thermal Group 53

A: Blackness Computation $\quad 53$

B. Spectral Shift Between Coolant and Fuel 53

C. Conclusion $\quad 54$

V. VMR Mechanical and Systems Design $\quad 55$

A. Reactor Arrangement $\quad 55$

1. Fuel - 55

2. Moderator Barrel . $\quad 55$

3. Coolant Riser $\quad 56$

4. Pressure Vessel 56

B. Reactor Component Stress Analysis $\quad 57$

1. Core Support Plate $\quad 57$

2. Shrouds $\quad 57$

3. Moderator Inlet Pipe $\quad 58$

4. Pressure Vessel . 58

C. Economic Evaluation $\quad 58$

D. Cleanup System For VMR Moderator Region $\quad 59$

VI. Thermal Design of Fuel Assemblies $\quad 60$

VII. Critical Experiment $\quad$. $\quad 63$

A. Initial Critical Experiments 63

B. Current and Future Program $\quad 65$

C. Deviations of the PUREE' Physics Code from Experimental Data 66

Appendix A - Materials Balance $\quad$ 、 69

Appendix.B - Heat Balance $\quad 72$

Appendix C - Equipment Sizes $\quad 73$

Distribution 


\section{FOREWORD}

Development of the Variable Moderator Reactor (VMR) is conducted under Contract No. AT(04-3)-250, Project Agreement No. 3; by Advanced Technology: Laboratories, a Division of American-Standard, for the U.: S. Atomic Energy Commission. This fourth quarterly technical progress report covers the continuation of work under Phase $I$ of the contract, "Physics and Kinetics Analysis and Initial Evaluation," and the continuation of work under Phase II, "Critical Experiment and Analysis of Results."

The information contained in this progress report is preliminary and subject to change as the program evolves. 


\section{PROGRAM OBJECTIVES}

The objectives of the work currently being performed, and of the work to be performed during the next quarter (16 May 1960 through 15 August 1960), in accordance with the agreed upon scope, ${ }^{1}$ is as follows:

1. To compare the core physics model PUREE' ${ }^{2}$ with the VMR critical experiment and to modify or apply corrections if the experimentall data indicate that adjustments should be made. $\therefore 2$. To use the hydrodynamic code $B O C H{ }^{3}$ and the physics codes PUREE' and VAL PROD 4 to complete the detailed analysis of core designs determined to be attractive by the completed parametric study.

3. To use the analog representation of the VMR core kinetics to study specific core designs found to be attractive by the completed parametric study, and to complete the comparison of the analog representation with existing reactor. transient response data.

4. To complete the mechanical and system design and cost analysis of specific VMR cores that have been examined for nuclear and hydrodynamic feasibility.

5. To continue with the critical experiments.

6. To prepare an initial technical and economic feasibility report and thus complete Phase I of the contract.

1. "Program for Evaluation of the Variable Moderator Reactor under the New Reactor Concepts Program for the Atomic Energy Commission, "Atomic Energy Division of American-Standard, Proposal P-470A, December 17, 1958.

2. PUREE' is a non-dimensional physics code which computes homogenized constants for use in neutron-balance equations (see Quarterly Progress Report No. 3 for description).

3. $\mathrm{BOCH}$ is a two-dimensional hydrodynamic code which computes the non-uniform void distribution in the core (see Quarterly Progress Report No. 3 for description).

4. R. H. Stark and C. H. White, "VAL PROD, a Revision of the PROD II 630 Multigroup," General Electric, Atomic Power.Equipment Division, GEAP-0952, January 9, 1957 (a .one-dimensional physics code for solving criticality and reactivity).

$$
-2-\quad .03 .095
$$




\section{STATUS OF PROGRAM}

\section{A. Core Designs and Parametric Studies}

The hydrodynamics code BOCH, the physics code PUREE', and the fuel burnup code

MSBU $^{5}$ have been used in the analysis of VMR cores for the parametric study. This study is largely complete, and based upon its results, attractive core designs have been selected for more detailed analysis. In particular, control requirements on these attractive designs are being investigated.

\section{B. Kinetics}

The analog representation of the VMR kinetics has been applied to the analysis of the VMR over a range of parameters.for both positive and negative void coefficients of reactivity. It is presently being applied to reactor experimental data.

C. Physics

The blàckness method of computing the PUREE' thermal group constants has been checked against experimental data to determine the effect of the change in fuel-pin blackness due to incident neutron distortion by neighboring fuel pins.

D. Mechanical and System Design

Design of the fuel assembly has been completed, and specifications and drawings have been prepared for release to vendors for quotation. Cost data obtained from these quotations will be used in the economic evaluation of the VMR. Stress analyses of the pressure vessel and core structure have been completed, and drawings and specifications are being prepared. A moderator cleanup system has been designed.

E. Economic Evaluation

The fuel-cycle cost analysis is nearly complete. Modifications to the analysis will be made as required by the results of the critical experiment and vendor quotations.

F. Critical Experiment

The first of a series of core arrangements has achieved criticality and macroscopic and microscopic measurement of its nuclear properties are being made.

5. See section $I I$ for description of MSBU. 


\section{SUMMARY OF RESULTS}

\section{A. Core Designs, Parametric Studies, and Economic Evaluation}

Work to date on the parametric studies, coupled with the partially. completed economic evaluation, has shown the following:

1. A moderator-to-coolant volume ratio of at least 0.45 is required in order to obtain sufficient reactivity worth in the moderator-reflector region of the VMR to control the reactor.

2. Stainless-steel-clad fuel appears to be slightly more attractive economically than Zircaloy-clad fuel, based upon present day fabrication costs for the VMR core.

3. Fuel-cycle.costs are considerably more sensitive to reductions in specific power brought about by reductions in coolant-to- $\mathrm{UO}_{2}$ ratios than they are to changes in conversion ratio brought about by changes in total water-to- $\mathrm{UO}_{2}$ ratios.

\section{B. Kinetics}

The VMR analytical model of the kinetics of the reactor system shows that the reactor can be made to be stable and load-following for both positive and negative void reactivities with a simple control system.

\section{Physics}

The blackness method of computing the PUREE' thermal group constants produces negligible differences for lattices of interest, as compared to those determined by the $\mathbf{P}_{3}{ }^{-}$ POP method described in the last quarterly report. ${ }^{6}$

\section{Critical Experiment}

The value of $\mathrm{k}_{\text {effective }}$ computed by the present PUREE' techniques appears to be approximately: $3 \%$ higher than the experimental values obtained on VMR-type lattices.

6. "Variable Moderator Reactor Development Program," Advanced Technology Laboratories, a Division of American-Standard, Quarterly Progress Report No. 3, ATL-A-107, 29 February 1960. 


\section{CORE DESIGNS AND FUEL-CYCLE COST ANALYSIS}

\section{A. Core Designs and Parametric. Studies}

The data for various core designs were tabulated in the previous quarterly progress report. ${ }^{6}$ The analysis of most of these core designs has been completed, and the majority of the results are presented herein. Table I shows the significant core design parameters, and some of the computed power and thermal flux "peaking" factors. Figures 1 through 6 illustrate. various relationships among the computed parameters. Some of the reported information differs from that reported previously. ${ }^{6}$ These differences represent corrections to the earlier preliminary data.

Referring to Table I and to Figures 1, 2, and 3, it will be found that the radial peaking factors (maximum flux/average flux and maximum flux/minimum flux) are sensitive to changes in moderator/coolant volume ratios. An increase in the moderator/coolant ratio by a factor of 3 , for instance, results in an increase in the large cell peak/minimum thermal neutron flux ratio by approximately a factor of 2 . ("Small Cell" is defined as a single fuel pin and its associated coolant. "Large Cell" is defined as a complete fuel assembly with its associated coolant, shroud, and moderator.). Figure .4 shows that increasing the moderator/coolant ratios decreases the distortion in the axial powerdistribution curve produced by the axial void distribution, and hence the peak/average power ratio. However, the reduction in the axial power-peaking factor is not as sensitive to changes in moderator/coolant ratios as is the radial peaking factor (and is in the opposite direction); hence, there is a slight increase in the over-all flux peaking factor as the moderator/coolant ratio is increased. The effect of the variation in moderator/coolant ratios on flux and power-peaking factors is an important parameter in the VMR design, since a certain minimum moderator/coolant ratio must be maintained in order to properly control the reactor (see section I. C, "Effect of Control Requirements on 'Fuel-Cycle Costs").

Figure 5 shows the variation in $\mathrm{k}_{\text {effective }}$ with "average" coolant density. for various ratios of coolant and moderator to $\mathrm{UO}_{2}$. As the moderator $/ \mathrm{UO}_{2}$ ratio is increased, the slope of the reactivity-density curve becomes less positive with increasing coolant density (decreasing steam voids). However, within the range investigated, it does not become negative. The VMR kinetics analysis (section III) includes an investigation of the transient operation of the reactor with both positive and negative reactivity-void curves. 
TABLE I

VMR CORE DESIGN DATA

Core Design Number

\begin{tabular}{|c|c|c|c|c|}
\hline 1 & 2 & 3 & 4 & 5 \\
\hline 0.030 & & & & \\
\hline $\mathrm{Zr}$ & & & & \\
\hline 0.005 & & & & \\
\hline 0.050 & & & & \\
\hline 1. 61 & & $\rightarrow$ & 1. 24 & \\
\hline 0.892 & 2.0 & 3.0 & 3.0 & 1. 0 \\
\hline 2.502 & 3.61 & 4. 61 & 4.24 & 2. 24 \\
\hline 0.553 & 1. 24 & 1. 86 & 2.42 & 0.806 \\
\hline
\end{tabular}

No. of fuel pins/element: 61

No. of elements/core $\quad 121$

$\mathrm{UO}_{2}$ in core, $\mathrm{kg}$

$12 ; 560$

Density of $\mathrm{UO}_{2}, \mathrm{gm} / \mathrm{cc} \quad 10.41$

Fuel-pellet diameter, in. $\quad 0.420$

Fuel-pin diameter, in. $\quad 0.485$

Fuel-pin centerline spacing, in. $\quad 0.676$

Fuel-pin spacing/diameter (S $/ D) \cdot 1.393$

Fuel-element centerline spacing, in. 6.20

Moderator gap between shrouds, in. $\quad 0.75$

Shroud internal distance between flats, in. 5.35

Active fuel height, in.

72

Core axial peak power/avg. power

$1.50 \quad 1.45$

Core radial peak power/avg. power (volume-weighted)
1. 82
1.88

Small-cell peak thermal neutron flux/ minimum thermal neutron flux

1. 233

1. 241

1. 260

1. 265

Large-cell peak thermal neutron flux/ minimum thermal neutron flux

1.963

3. 122

4. 09

4. 61

* Coolant volume computed with zero voids. 

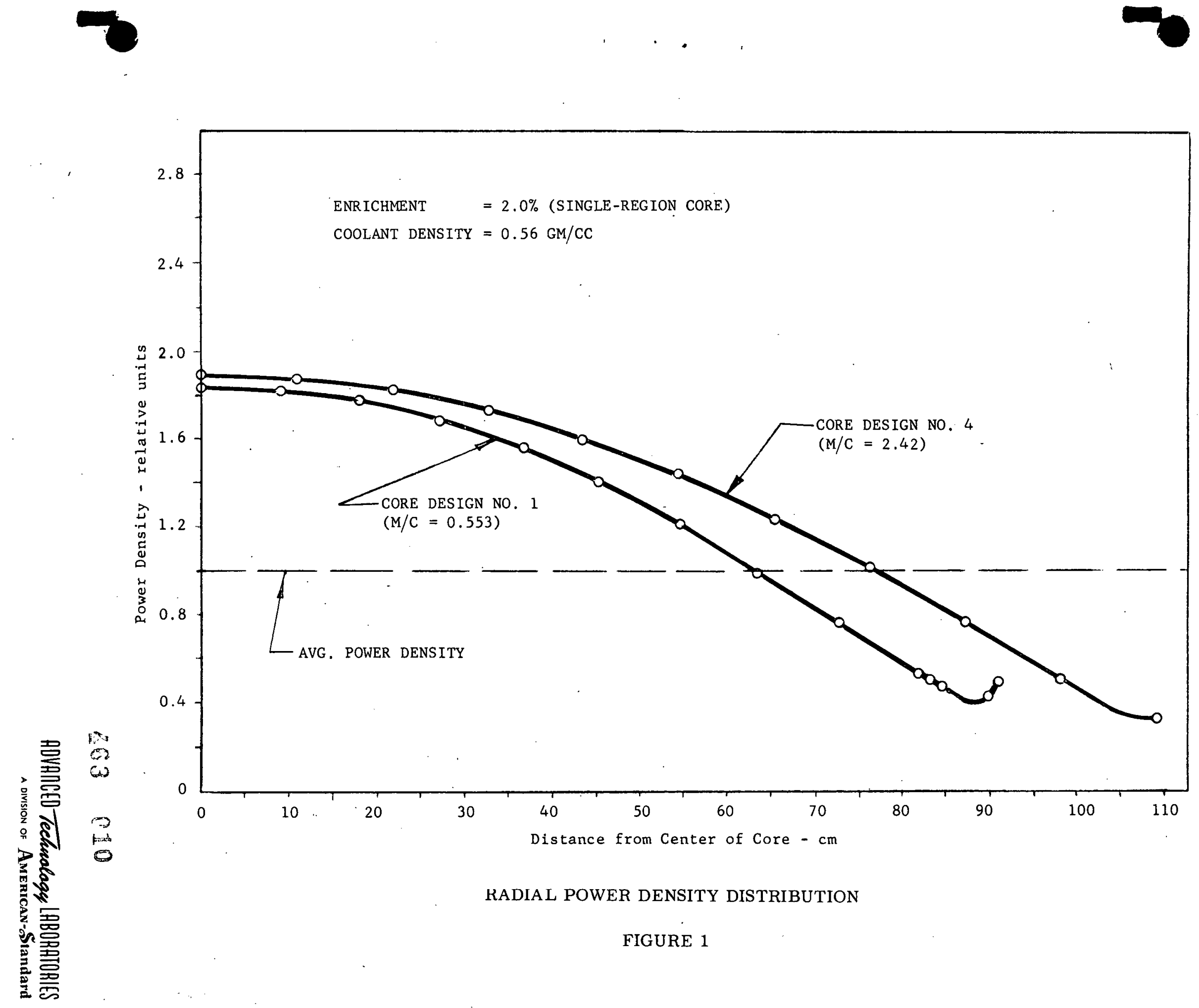

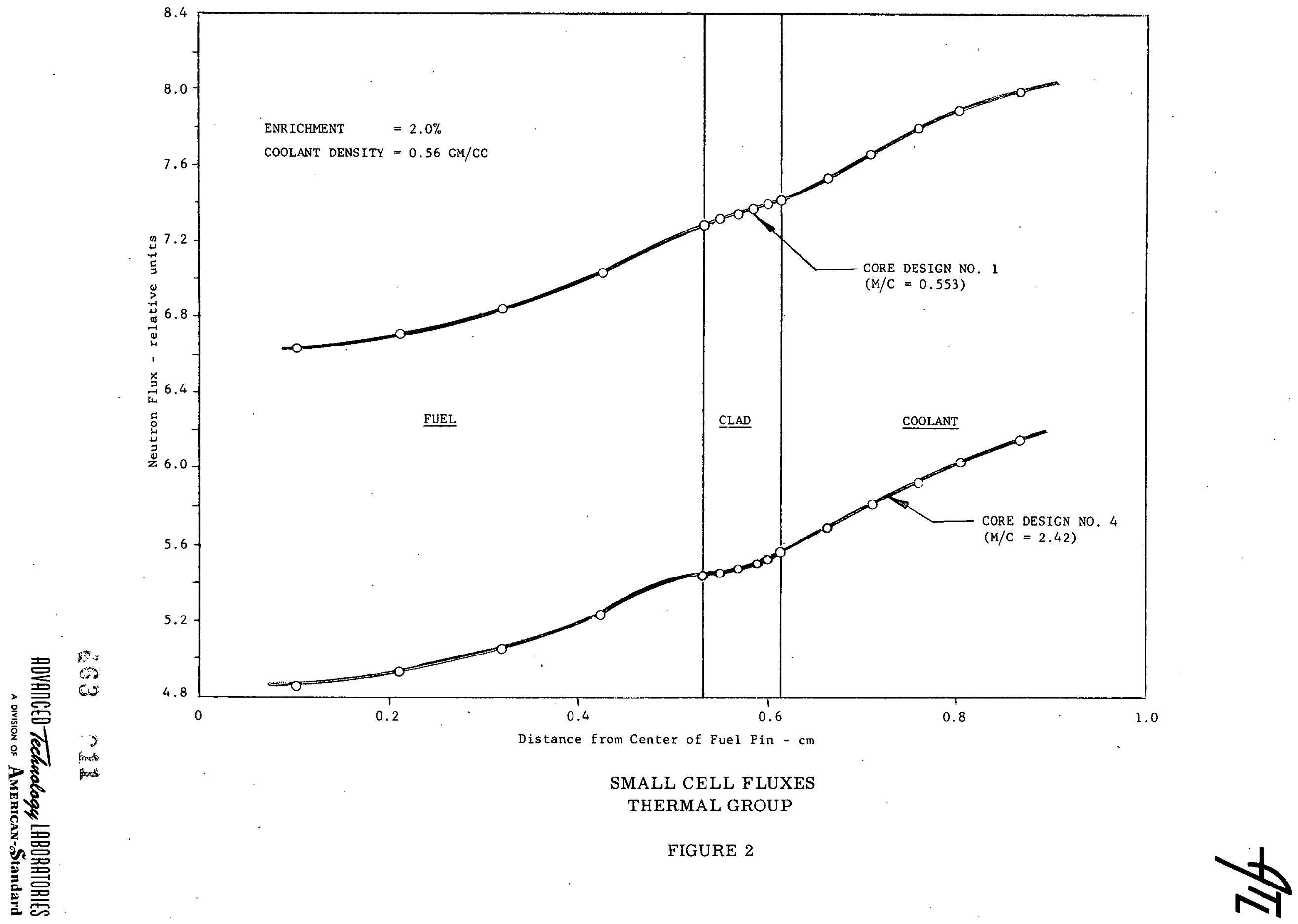


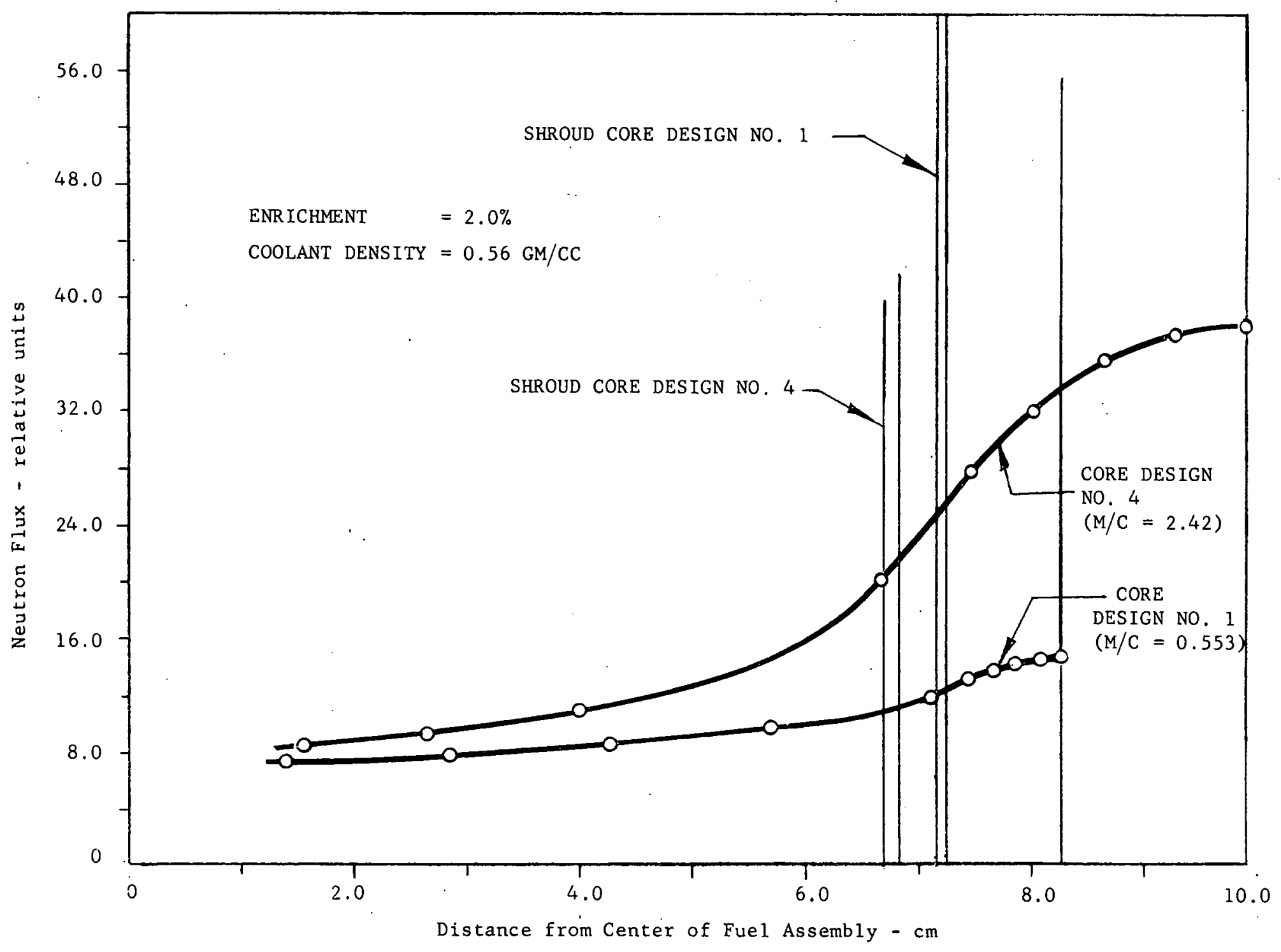

\section{LARGE CELL FLUXES \\ THERMAL GROUP}

FIGURE 3 


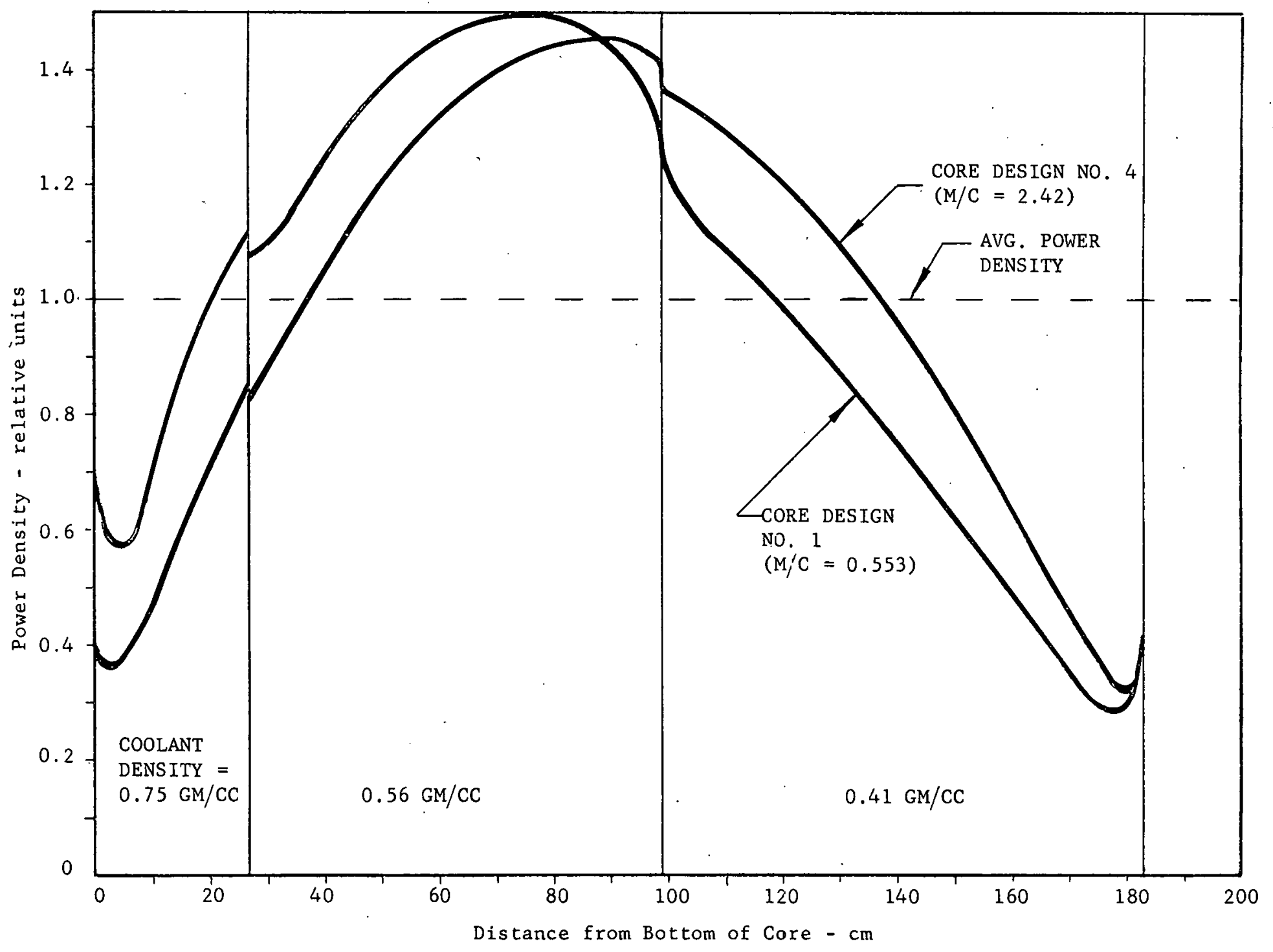

AXIAL POWER DENSITY DISTRIBUTION

FIGURE 4 


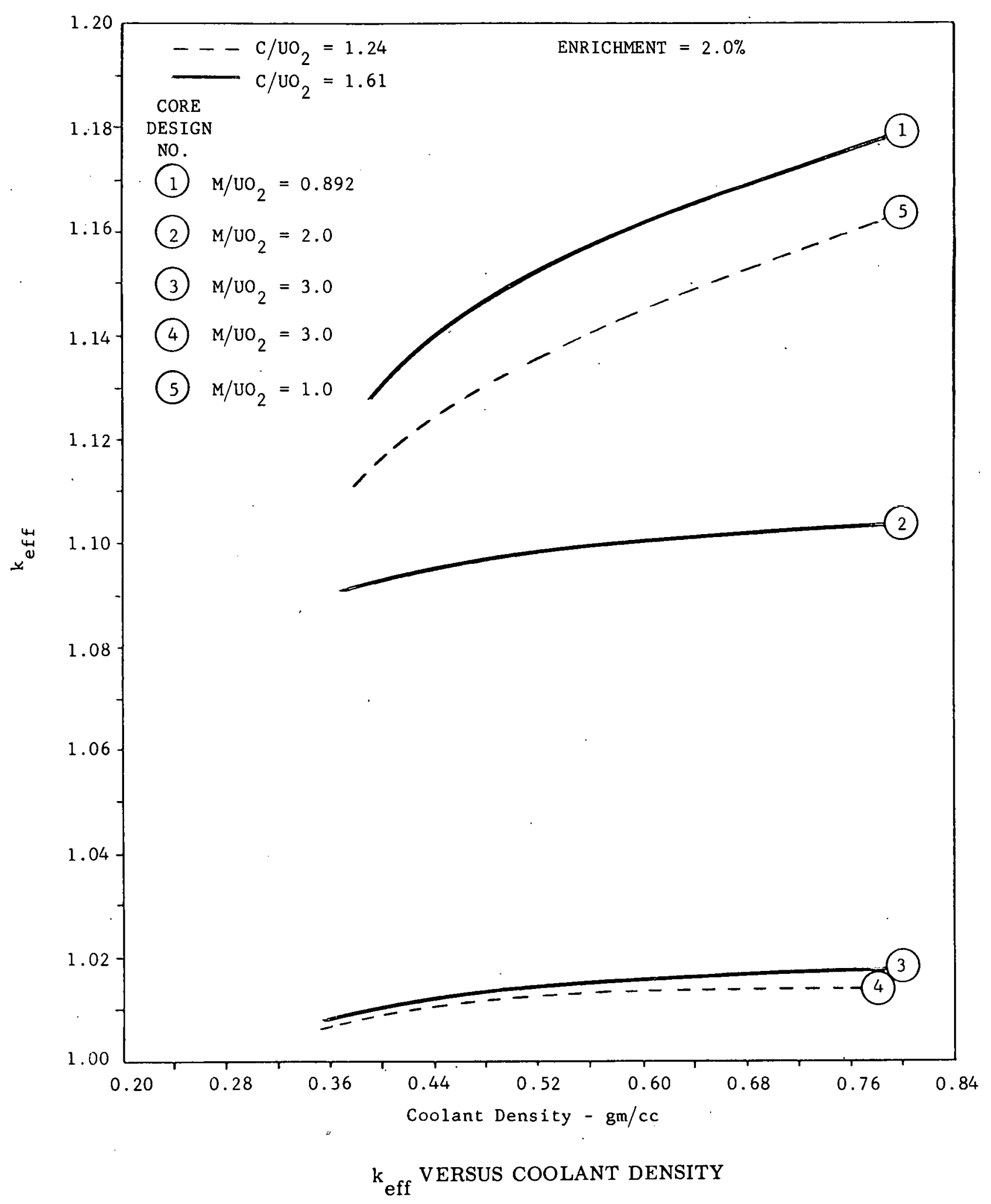

FIGURE 5 


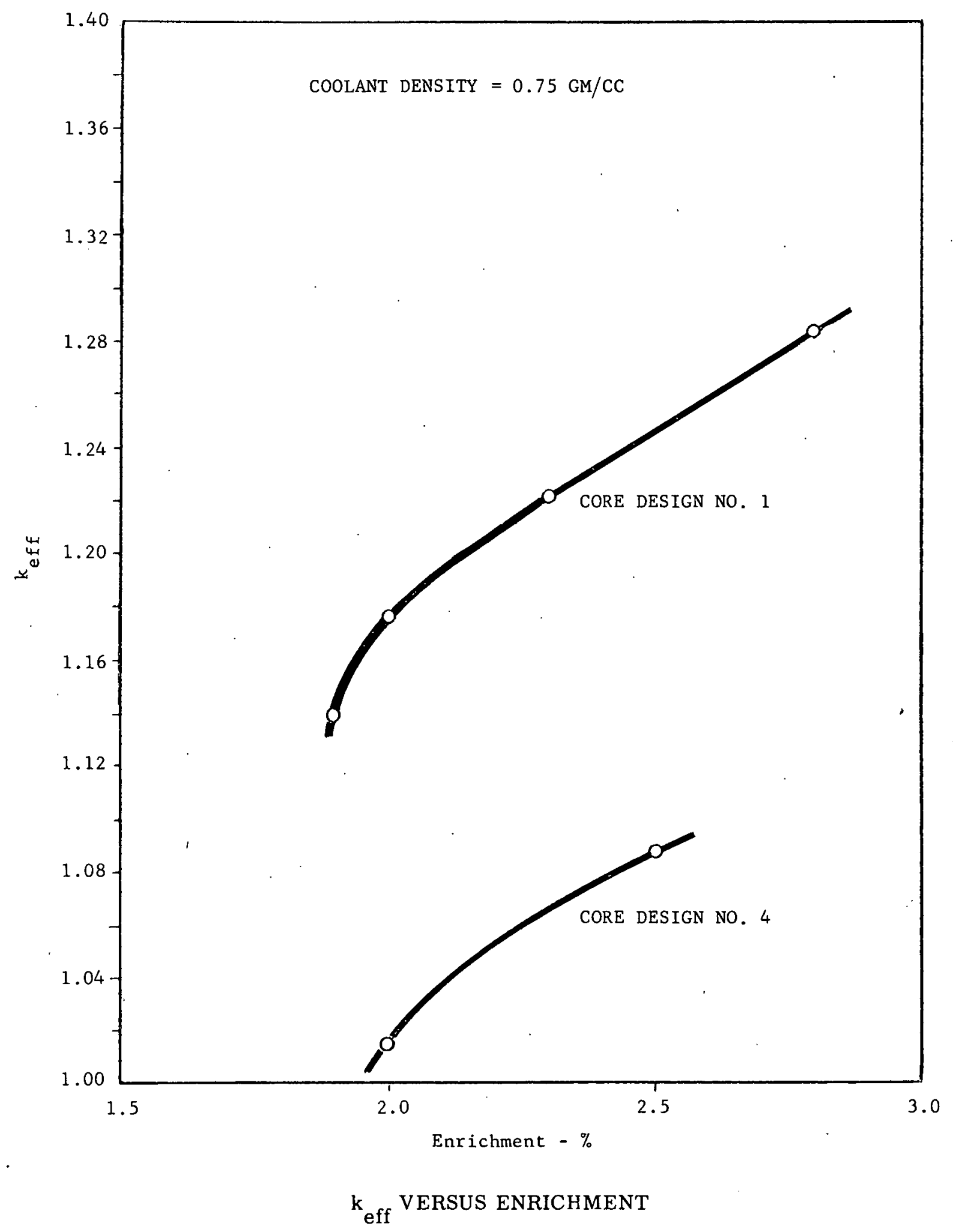

FIGURE 6

$$
803 \quad 015
$$


B. Results of VMR Fuel-Cycle Cost Analysis

In order to determine the economic attractiveness of the VMR, it is necessary that three items of the reactor plant be.cost estimated and compared with "conventional." controlrod boiling-water reactors. These three items are:

1) Reactor-plant capital costs.

2) Reactor-plant maintenance and operating costs.

3) Fuel-cycle cost.

The preliminary results of the fuel-cycle cost analysis are given in this'section of the report.

The data used to develop the fuel-cycle costs were obtained from AEC-published cost schedules and from preliminary cost estimates of fuel manufacturers. The VMR design reflects current design techniques. No design credit was taken for items considered to be unusually developmental in nature. A significant item of this nature would be fuel-element shrouds constructed of Zircaloy instead of stainless steel. Since the integrity of the VMR moderator region is important, the stainless steel joints at the grid plates must be welded or brazed. To date, large grid plates have not been constructed of Zircaloy because of the expense, and Zircaloy to stainless steel joints are still.in the developmental stage. It is recognized, however, that the Commission is supporting a Zircaloy development program, which could successfully solve these particular problems by the time a full-scale VMR is ready for construction. For this reason, a cost estimate will probably be attempted (factoring out developmental costs) to determine the effect of using Zircaloy shrouds in the VMR. Cost estimates will thus be available for a VMR based on current technology and the potential reduction in costs obtained by using advanced metallurgical techniques.

Three separate studies of "conventional" reactors were used to compare fuel-cycle costs with those of the VMR. Two of these studies were successfully reduced to an approximately common base with the VMR, but the uncertainties are still rather large. To reduce these uncertainties, additional work is in progress. All of the cost data.shown in this and in other sections of the report may be modified as the final design data is firmed up.

Table II includes the significant core design data used to compute fuel-cycle costs. The methods used to compute these costs are described in section I. E, "Methods of Computing, Fuel Cycle Costs, " and in section II, "MSBU Fuel Burnup Code." 
TABLE II

VMR FUEL-CYCLE CORE DESIGN DATA

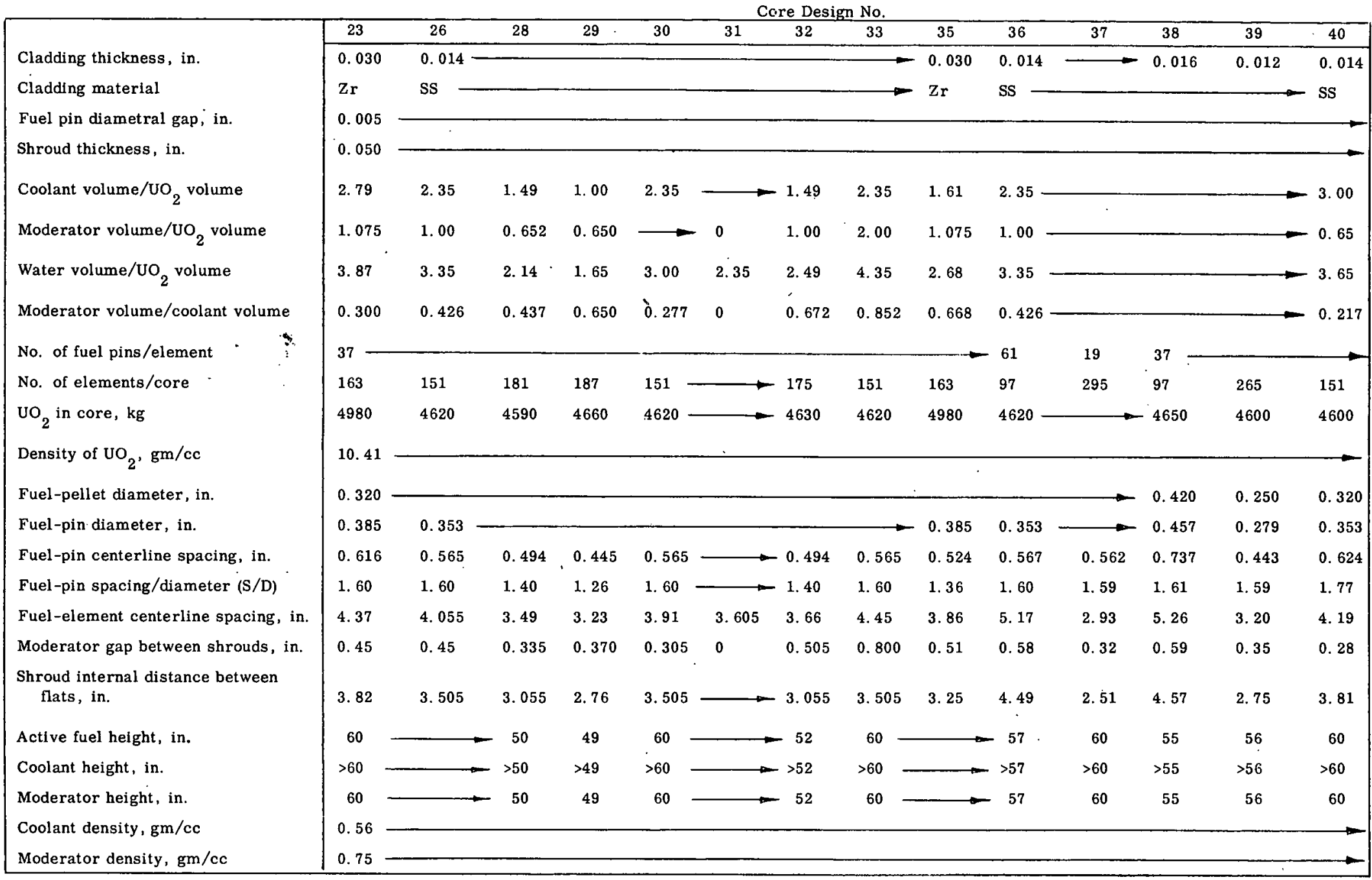


Figure 7 shows how fuel-cycle costs vary with coolant/ $\mathrm{UO}_{2}$ ratio and moderator $/ \mathrm{UO}_{2}$ ratio. The effects of natural and forced circulation are also shown in the graph, as are the differences between stainless-steel-clad and Zircaloy-clad fuel pins. It is clear that, for natural-circulation cores, minimum fuel-cycle costs occur at coolant/UO 2 ratios between 2.0 and 2.5. Increasing moderator $/ \mathrm{UO}_{2}$ ratios results in increasing costs for. constant coolant $/ \mathrm{UO}_{2}$ ratios. At coolant $/ \mathrm{UO}_{2}$ ratios above 2.5 , the power density becomes limited by central fuel-element temperature requirements and hence remains constant at a maximum of $10 \mathrm{kw}$ per foot of fuel pin. This results in increased fuel costs, because of the approximately constant fuel-use charges and decreasing conversion ratios. As coolant/UO 2 ratios are decreased below 2.0 , the area available for coolant flow in the fuel channel becomes smaller, and, for natural-circulation reactors, the power density decreases. Despite slight increases in conversion ratios at low coolant/ $\mathrm{UO}_{2}$ ratios, the fuel-cycle costs increase because of the very marked dependence of fuel-use charges on power density.

Figure 7 also illustrates that at the minimum fuel-cost point, Zircaloy-clad fuel is approximately 1.3.cents per million Btu more expensive than stainless-steel-clad fuel. If the fabrication costs of the Zircaloy-clad elements are decreased by approximately $\$ 17 / \mathrm{kg} \mathrm{U}$, the cost differential is zero. Due to control requirements (discussed in section I. C, "Effect of Control Requirements on Fuel Cycle.Costs"), an additional 2 to 3 dollars per $\mathrm{kg} \mathrm{U}$ is required for Zircaloy, resulting in a total requirement of approximately $\$ 19 / \mathrm{kg}$ U to reduce the cost differential to zero. As Zircaloy fabricators gain experience, it is likely that Zircaloy will become more attractive than stainless steel as a cladding for the VMR fuel elements. The fabrication costs for both Zircaloy- and stainless-steel-clad fuel elements are based upon preliminary quotations received from fuel vendors. These quotations will be firmed-up and the costs adjusted accordingly for the initial technical and economic feasibility report.

Figure 8 shows the variation in fuel-cycle.costs with moderator/coolant ratio. This graph is discussed more fully in section I. C in connection with the control requirements of the reactor.

Figure 9 shows the effect of fuel-pin diameter on fuel-cycle.costs. The diameter selected for. Core Design No. 26 (0.353 inch) is seen to be an optimum for stainless-steelclad pins. In addition to the 1 cent per million Btu difference between Core Design No. 26 
CONDITIONS :

NO. OF FUEL PINS PER ASSEMBLY FUEL PIN OD, IN.

CLADDING THICKNESS, IN. BURNUP, MWD/SHORT TON U

KG UO 2 PER CORE

OXIDE PELLET OD, IN.

\section{STAINLESS STEEL CLADDING}

37
0.353
0.014
15,000
$4590 \geq \mathrm{KG} \mathrm{UO} 2 \geq 4660$
0.320

\section{ZIRCALOY CLADDING}

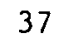

0.385

0.030

15,000

4980

0.320

LEGEND:- STN. STL. CLAD, NATURAL CIRCULATION - - - STN. STL. CLAD, FORCED CIRCULATION ZIRCALOY CLAD, NATURAL CIRCULATION (30) CORE DESIGN NO. 30 (TYP.)

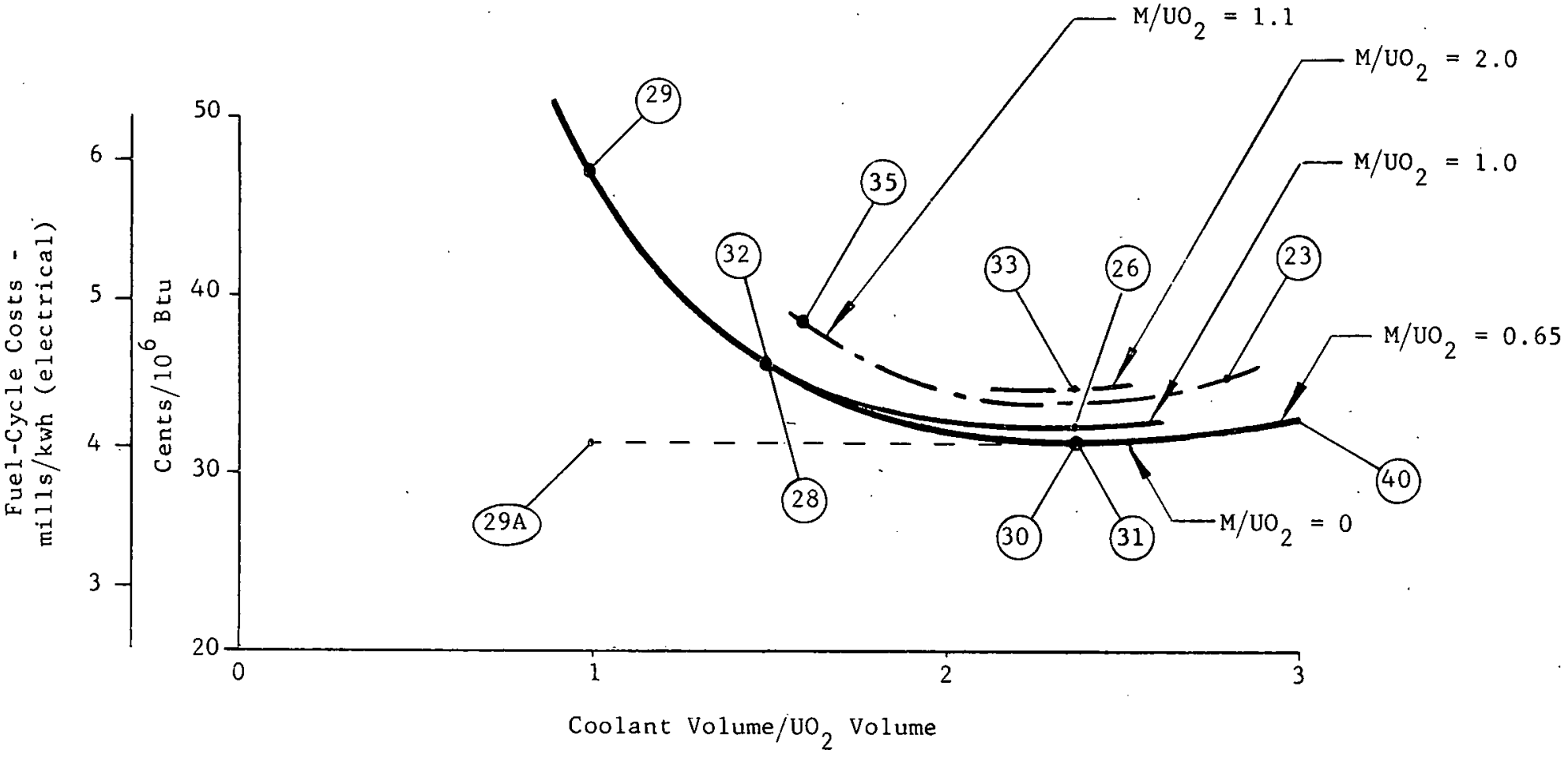

VMR FUEL COST VERSUS MODERATOR/UO 2 AND

COOLANT/UO 2 RATIOS

FIGURE 7 
CONDITIONS :

NO. OF FUEL PINS PER ASSEMBLY $=37$.

FUEL-PIN CLADDING

FUEL-PIN OD, IN.

$=0.014^{\prime \prime}$ THICK STN. STL.

OXIDE PELLET, OD, IN.

$=0.353$

BURNUP, MWD/SHORT TON U

KG UO ${ }_{2}$ PER CORE

$=0.320$

$=15,000$

= BETWEEN 4590 AND 4660

LEGEND :

STN. STL. CLADDING, NATURAL CIRCULATION

STN. STL. CLADDING, FORCED CIRCULATION

(29) CORE DESIGN NO. 29 (TYP.)

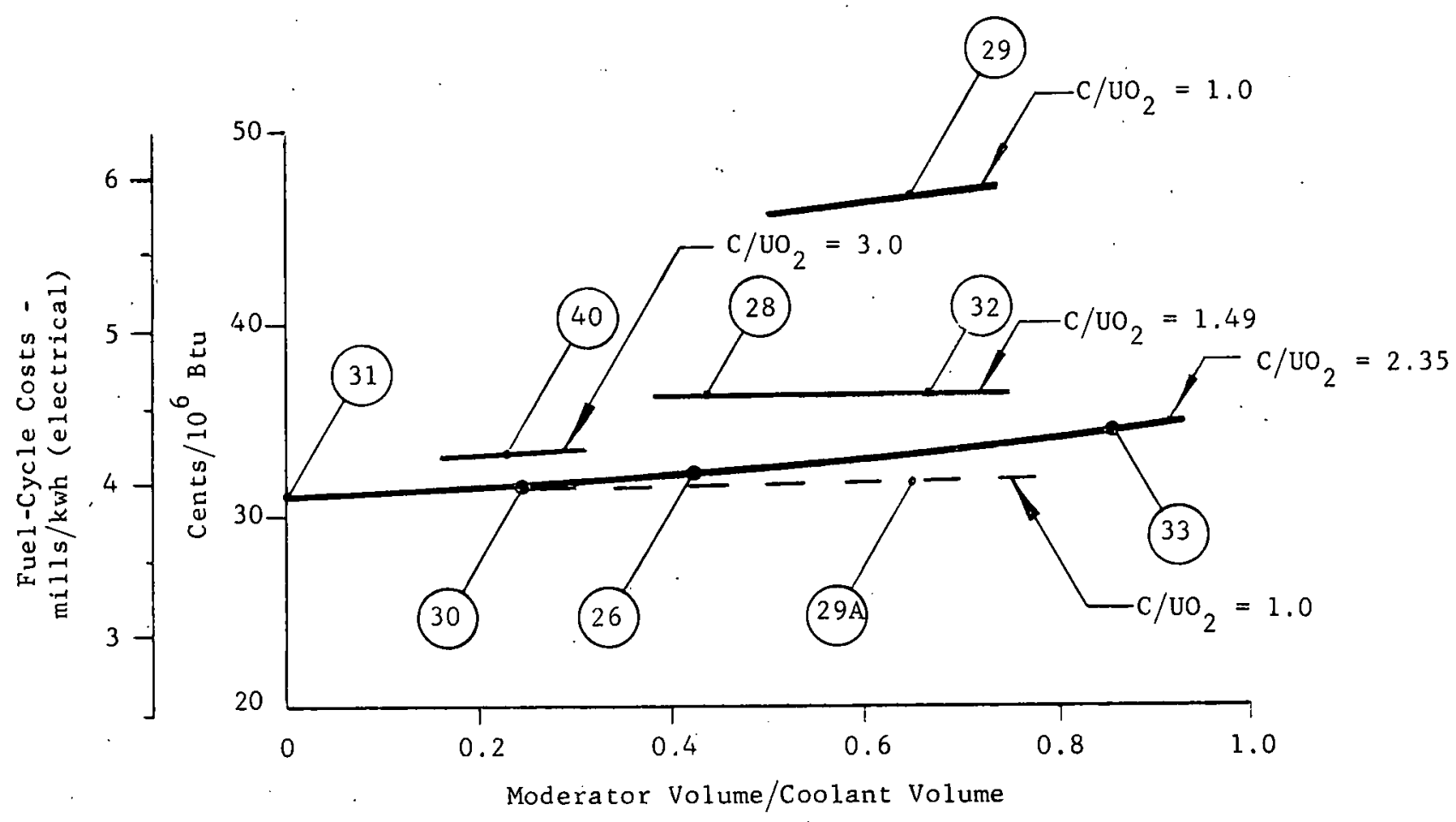

VMR FUEL COSTS VERSUS MODERATOR/COOLANT AND COOLANT/UO 2 RATIOS

FIGURE 8 


\section{CONDITIONS}

$\begin{array}{ll}\text { FUEL-PIN CLADDING } & =\text { STN. STL. } \\ \text { COOLANT VOLUME/UO }{ }_{2} \text { VOLUME } & =2.35 \\ \text { MODERATOR VOLUME/UO VOLUME } & =1.00 \\ \text { BURNUP } & =15,000 \text { MWD/SHORT TON U } \\ \text { KG UO }{ }_{2} \text { PER CORE } & =4630\end{array}$

LEGEND :

(39) CORE DESIGN NO. 39 (TYP.)

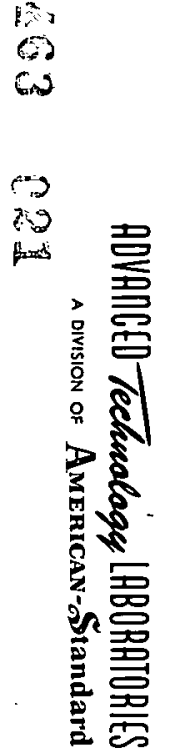

VMR FUEL COSTS VERSUS FUEL-PIN DIAMETER

FIGURE 9 
and No. 39, the latter design requires approximately, 114 additional fuel-channel shrouds for the same quantity of fuel. This results in an estimated $\$ 20,000$ increase in the capital cost of the core structure, (an amount not included in the fuel-cycle cost analysis). Core Design No. 39 is also considered unattractive because of control problems, which are discussed in section I.C. It is noted that the 4 cents per million Btu differential between Core Design No. 38 and No. 26 is considerably in excess of the equivalent decreased capital costs resulting from fewer shrouds in Core Design No. 38.

Figure 10 shows the effect of the number of fuel pins per assembly on fuel-cycle costs. Core Design No. 36 with 61 pins per assembly and Core Design No. 37 with 19 pins per assembly are both slightly less expensive than Core Design No. 26 with 37 pins per assembly. Core Design No. 37 accrues a penalty. which offsets the slight fuel-cycle advantage, however, because it requires approximately twice as many fuel shrouds for a given quantity of fuel as Design No. 26. As discussed in section I.C, Design No. 36 has approximately the same control characteristics as No. 26 and in addition requires approximately $50 \%$ fewer shrouds.

Because of reactivity control requirements (see section I. C), moderator/UO 2 ratios less than 1.0 are not attractive. From the above discussion it appears that designs 26 and 36 are near the minimum for natural-circulation VMR cores. A discussion of a forcedcirculation core is included in section $\mathrm{C}$ below.

C. Effect of Control Requirements on Fuel-Cycle Costs

1. Reactivity Effects

The following table of reactivity requirements has been developed from calculations and preliminary estimates. These data may undergo modifications as final calculations of parameters are completed.

Table.III

Estimate of VMR Reactivity Effects for Core Design No. 26

$\underline{\text { Item }} \quad \cdots \quad \ldots \quad \underline{\% \Delta \mathrm{k}}$

Doppler

Temperature

Voids

$\mathrm{Xe}$ and $\mathrm{Sm}$

Burnup (for ss-clad fuel)

Shutdown margin

Total
1.2

1.0

1.8

3.3

5.8

2.0

$\underline{15.1}$ 
CONDITIONS :

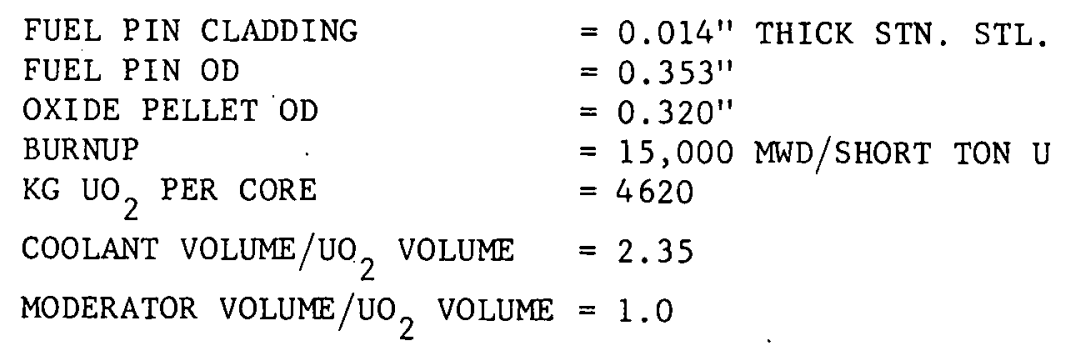

LEGEND:

(37) CORE DESIGN NO. 37 (TYP.)

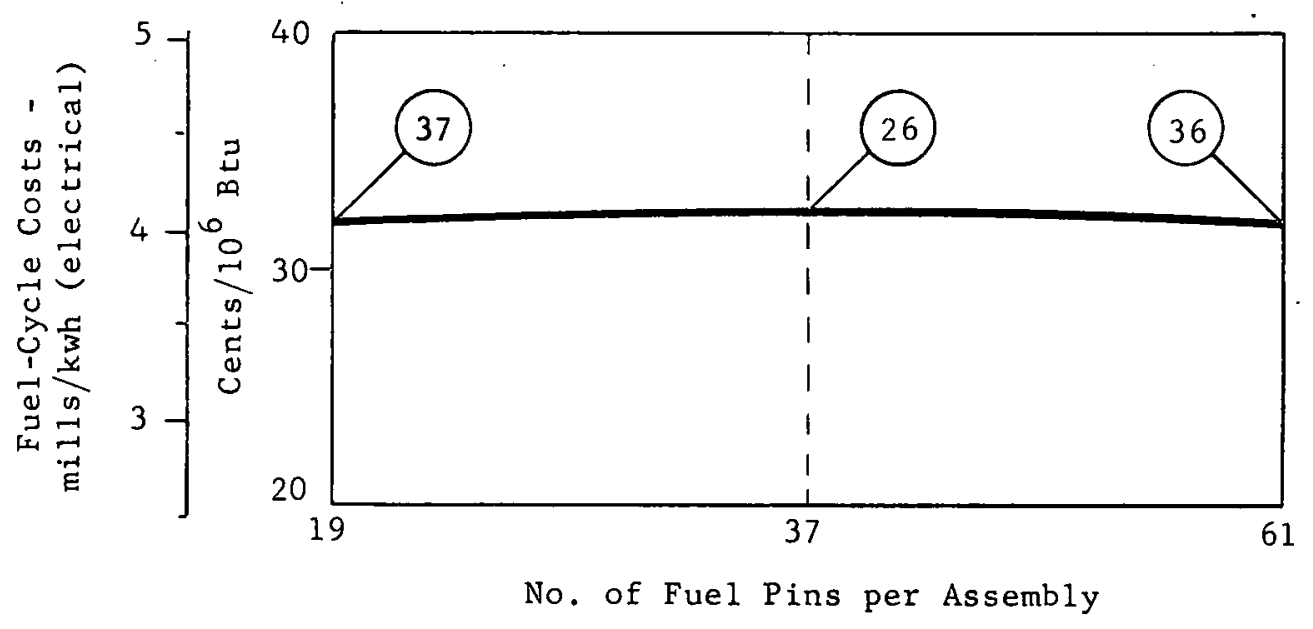

VMR FUEL COSTS VERSUS NUMBER OF

PINS PER ASSEMBLY

FIGURE 10 
It can be seen from the above that to have a satisfactory design, moderator must control $15.1 \% \Delta \mathrm{k}$, or $\frac{15.1}{1.151}=13.1 \% \Delta \mathrm{k} / \mathrm{k}$. Figures 11,12 , and 13 present the $\Delta \mathrm{k} / \mathrm{k}$ available from the moderator-reflector region. Since the curves were computed using the axial "average" density of the coolant, they do not reflect the effects of non-uniform density distribution in the fuel channels, nor do they reflect the control requirements with the reactor in the "cold" condition. These effects, and others, are presently being determined and will be included in the initial VMR feasibility report.

Figure 11 indicates that the $\Delta \mathrm{k} / \mathrm{k}$ available from the moderator-reflector region is a. sensitive function of moderator volume/coolant volume ratio. Therefore, for a given coolant/UO $\mathrm{U}_{2}$ ratio (determined by hydrodynamic.considerations), it is necessary to select a shroud spacing which results in the moderator/coolant ratio required for control: For the reactivity. effects shown in Table III, this moderator/coolant ratio is approximately equal to 0.45 . It is noted, however, that the control requirements with the reactor in the cold condition (e.g. , zero voids and ambient temperature) are likely to necessitate a larger moderator/coolant ratio. If so, this will have the effect of increasing the economic attractiveness of a forced-circulation reactor (see discussion below).

Figure 8 in section I. B also can be used to compare forced-and natural-circulation reactors. At low coolant/fuel ratios, forced circulation permits high power densities to be retained. Thus, for a given moderator/coolant ratio, it is possible to select a forcedcirculation core with a coolant/ $\mathrm{UO}_{2}$ ratio smaller than a natural-circulation core and to obtain lower fuel costs. At a moderator/coolant ratio of 0.45 , a forced-circulation core (with $\mathrm{C} / \mathrm{UO}_{2}=1.0$ ) has a fuel cost approximately 1 cent per million Btu lower than the optimum natural-circulation core. This represents approximately $\$ 18,000$ per year. However, the forced-circulation system is estimated to cost. $\$ 200,000$ or at 0.15 capitalization, $\$ 30,000$ per year. The smaller pressure vessel for forced circulation is estimated to save $\$ 40,000$ or $\$ 6,000$ per year. Thus, a forced-circulation system appears to show a loss of $\$ 6,000$ per year over the selected natural-circulation system (exclusive of building and shielding cost differentials between natural-and forced-circulation systems). If the detailed core design analysis indicates that a significantly higher moderator/coolant ratio is required for control, Figure 8 shows that these requirements can be met without a significant economic penalty by using a forced-circulation system. 


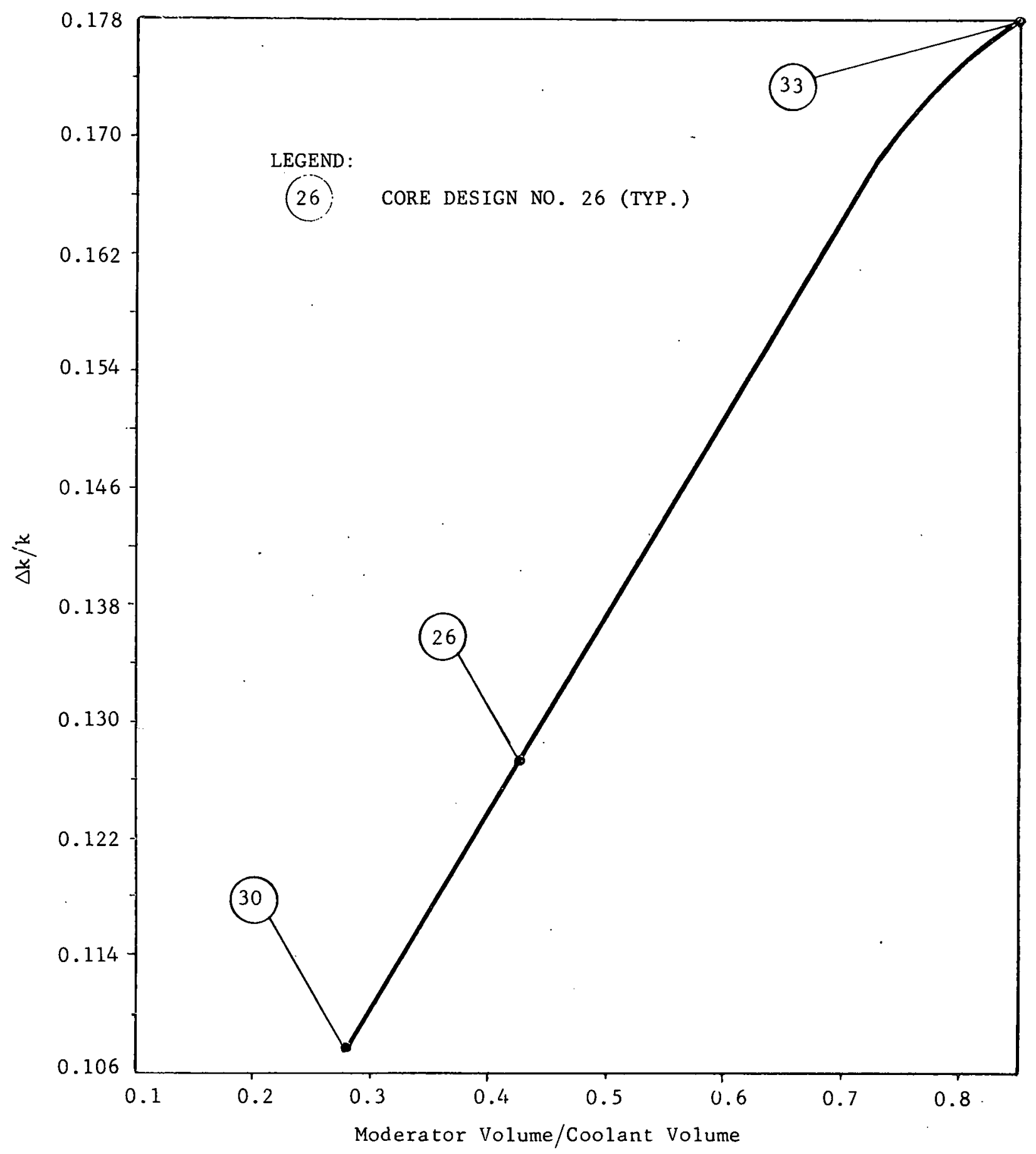

$\triangle \mathrm{k} / \mathrm{k}$ FOR MODERATOR AND REFLECTOR REMOVAL VERSUS MODERATOR/COOLANT RATIO

FIGURE 11 



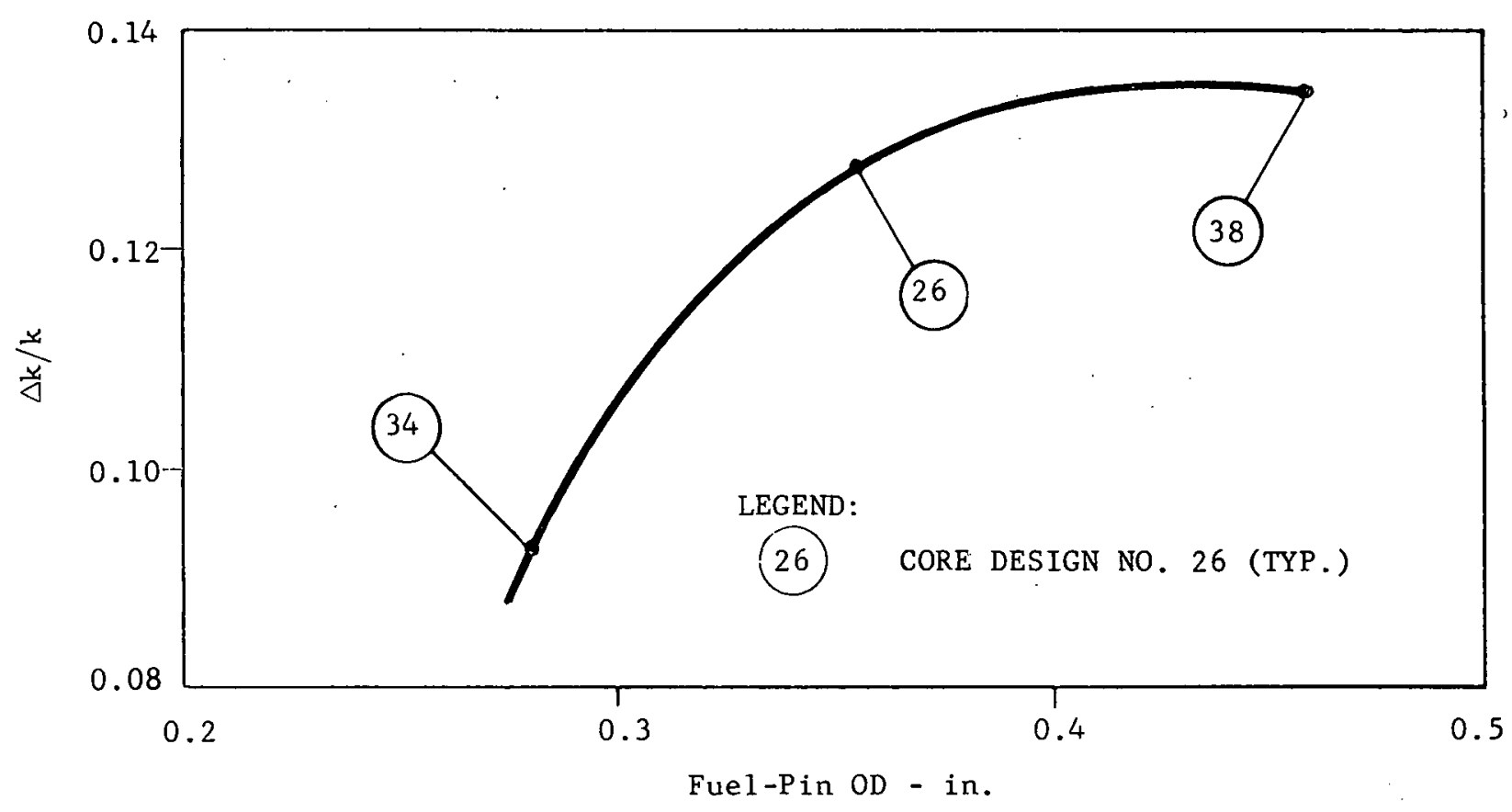

$\triangle \mathrm{k} / \mathrm{k}$ FOR MODERATOR AND REFLECTOR REMOVAL VERSUS FUEL-PIN DIAMETER

FIGURE 13 
Figure 12 shows that the $\Delta \mathrm{k} / \mathrm{k}$ available from the moderator-reflector region does not change rapidly as the number of pins per fuel assembly is changed.

Figure 13 indicates that the moderator-reflector reactivity worth increases markedly with increasing pin diameter in the range of 0.28 and 0.35 inch oD for the same moderator/ coolant ratio. This is probably due to the increasing effectiveness of the moderator region compared to the coolant region as the fuel-pin size increases and the number of stainless steel shrouds in the core decreases. It would be expected that the curve would go through a maximum and decrease as the pin diameter continued to increase and the number of shrouds continued to decrease.

It is noted that for Zircaloy-clad fuel, the reactivity required for burnup (shown in Table III) increases by an estimated $2 \%$ over that for stainless-steel-clad fuel. Zircaloyclad fuel cores thus require higher moderator/coolant ratios than stainless-steel-clad fuel. This increased reactivity required for burnup of the Zircaloy-clad fuel is principally due to the increased enrichment required for the stainless steel core. (Since there is more U 235 in the stainless-steel-clad core than in the Zircaloy-clad core, for a given burnup the change in $\mathrm{U} 235$ will produce a more marked change in $\mathrm{k}$ in the Zircaloy-clad than in the stainlesssteel-clad core.)

All fuel-cycle costs discussed in section $I_{0} B$ are based upon the assumption that the moderator-reflector height is retained near the top of the active region of the core throughout the life of the core. The power densities achievable over the core life are thus quite high. In order to make this possible, it is necessary to provide for control of the excess reactivity available in the moderator-reflector region when the core is initially put in service. This is accomplished by adding boron in the form of boric acid to the moderatorreflector water in order to reduce the worth of the water. Sufficient boric acid is added so that the moderator height can be maintained near the top of the active region of the fuel at full power. Load changes are accommodated by varying the level of the moderator-reflector. Long-term reactivity changes (e.g., burnup, , Xe, Sm) are accommodated by varying the concentration of boric acid poison.

With regard to the proposed boric acid system, such systems have been considered for use in other reactors but usually not for extended service. A significant disadvantage of their use in most reactors results from the requirement that boric acid fill the reactor 
primary system. Boric acid adjacent to the hot fuel assemblies may plate-out on the assemblies, the rapidly circulating primary water may have a rapid change in boric acid concentration as a slug of feedwater enters the core, and undesirable void-reactivity effects may occur as a result of adding boric acid to the primary system. These disadvantages do not exist in the VMR in which the relatively small moderator-reflector region is completely separate from the reactor primary system. The moderator-reflector cleanup system and boric acid.concentration control system are described in section V.D, "Cleanup System for Moderator-Reflector Region."

A thorough investigation has not yet been made of the effect of borating the moderator region on the moderator level coefficient of reactivity. It is possible that some core configurations could result in a positive level coefficient for the lower portion of the core but a negative level coefficient for the upper portions, especially with a highly poisoned moderator. This point is currently being investigated. If the level coefficient should change sign as moderator height increases, it would be necessary to operate only in the positive level coefficient region. This requirement could result in decreased permissible power densities and increased fuel-cycle costs. Preliminary calculations indicate that the level:coeffieient does not change sign for the core designs which are economically attractive. It is noted that this effect is important only for full power operation with the reactor at operating temperature and with non-uniform voids in the fuel channels. A changing levell... coefficient with uniform coolant density and with the reactor at low temperatures is un:important, since high power density is not necessary at low-power operation.

\section{Moderator-Level Variation with Load}

The moderator-level change required to accommodate a core thermal-output change from one steady-state to another steady-state level of operation at the same pressure can be simply computed by noting that the net reactivity change must be zero. The reactivity changes, $R$, accompanying the change in core thermal output are postulated to be due to a) moderator-level change, $R_{L} ;$ b) void change, $R_{\rho}$; and c) fuel temperature, $R_{T}$. Thus

or

$$
\begin{aligned}
& \mathrm{R}_{\mathrm{L}}=-\left(\mathrm{R}_{\rho}+\mathrm{R}_{\mathrm{T}}\right) \\
& \frac{\partial \mathrm{R}}{\partial \mathrm{L}} \Delta \mathrm{L}=-\left(\frac{\partial \mathrm{R}_{\rho}}{\partial_{1} \rho} \frac{\partial \rho}{\partial \Delta^{\mathrm{r}} \mathrm{Q}}+\frac{\partial \mathrm{R}_{\mathrm{T}}}{\partial \Delta^{\prime} \mathrm{Q}}\right) \Delta^{\prime} \mathrm{Q}
\end{aligned}
$$


in which $\rho$ is the average coolant density, $T$ the fuel temperature, $L$ the moderator level, and $\Delta^{\prime} Q$ the fractional change in core thermal output. (Changes in coolant mass rate through the core and the consequent void changes:are small and therefore ignored.) The reactivity derivatives $\partial \mathrm{R}_{\rho} / \partial \rho$ and $\partial \mathrm{R} / \partial \mathrm{L}$ have not been calculated but can be estimated for preliminary purposes (from EBWR data in the case of $\partial R_{\rho}, \partial \rho$, and from moderator control requirements for the VMR in the case of the $\partial \mathrm{R} / \partial \mathrm{L}$ derivative). For the EBWR operating at $20 \mathrm{mw}$ and $550 \mathrm{psi}$ the derivative $\partial \mathrm{R}_{\rho} / \partial \rho$ is $-1.2 \$ /\left(1 \mathrm{~b} / \mathrm{ft}^{3}\right)$. For the VMR, the derivative $\partial \mathrm{R}_{\mathrm{L}} / \partial \mathrm{L}$ is estimated to be of the order of $0.05 \$ / \mathrm{in}$. The values. of the derivatives with respect to changes in the core thermal output are obtained from Attachment I to the Quarterly Progress Report No. 3. Substituting these values in the foregoing equation gives as a preliminary estimate,

$$
\Delta \mathrm{L}=80 \Delta^{\prime} \mathrm{Q}
$$

Thus, if the thermal output is increased $1 \%\left(\Delta^{\prime} Q=0.01\right)$, the consequent moderatorlevel change must be 0.8 inch. It will be noted that the reactivity, controlled by the moderator will change during the life of the core. As a result, the factor (80.in the present calculation) will vary during core life.

D. Comparison of Fuel-Cycle Costs for "Conventional" Boiling-Water Reactors and the VMR

Three separate studies of small boiling-water reactors have been used to compare the fuel costs of "conventional" boiling-water reactors with the VMR. Since each of the studies used different criteria for establishing fuel-cycle costs, these costs were recomputed using the techniques described in section I. E. The values that were used without modification from the three reports were: initial enrichment, final enrichment, plutonium concentration, fuel burnup, quantity of fuel in reactor, and total power output from reactor. Since these values are dependent upon the physics techniques employed by the investigators and upon the thermal design of the reactor, a discussion of these items and their effect on fuel-cycle.costs is. included below. Table IV compares the computed fuel-cycle costs of these three reactors with the VMR; VMR ${ }_{1}$ and $\mathrm{VMR}_{2}$ are similar.except that VMR $\mathrm{VM}_{1}$ has stainless-steel-clad fuel and VMR 2 Zircaloy-clad fuel. To be meaningful, the data should be considered in conjunction with the following discussion. 
1. Prototype Boiling. Water Reactor ${ }^{7}$

Two boiling-water-reactor designs are described in ANL-6019. A "reference" reactor design having a thermal output of $165 \mathrm{mw}$ was selected, ind the data developed for this reference reactor were extended by Argonne to include a "full-scale" reactor of $825-\mathrm{mw}$ thermal capacity. The reference reactor was designed as a prototype for the larger reactor, and therefore certain design compromises were effected to provide faviorable economics for the full-scale reactor. Two unique schemes for shuffling the fuel during reloading cycles were developed, the most attractive of which has been selected for comparison with the VMR. The stated objective of the study was "to design a nuclear power plant of $50 \mathrm{mw}(\mathrm{e})$ capacity which could be used to demonstrate advanced performance concepts for boiling water reactors."

Examination of Table IV will show that the reference design selected by Argonne is a very "dry" lattice, high-specific-power core employing forced circulation. These factors tend to produce high conversion ratios (hence low burnup costs) and low inventory costs. However, several other factors tend to result in higher cycle costs than those of an "optimum" design. These factors are:

a. High neutron leakage due to small core. As pointed out by ANL, the tight lattice core is probably optimum for the larger reactor, not for the small prototype.

b. Conservative simplified techniques employed by Argonne for determining power distribution.

c. Burnup of $11,000 \mathrm{mwd} / \mathrm{T}$ instead of $15,000 \mathrm{mwd} / \mathrm{T}$.

It is estimated that the above factors might add 3 cents per million Btu to the calculated fuel-cycle costs.

To decrease the neutron leakage in the prototype reactor design, it would be necessary to increase the core size by either:

1) Adding additional fuel and decreasing specific power, or

2) Increasing the water $/ \mathrm{UO}_{2}$ ratio.

7. J. M. Harrer, "Prototype Boiling,Water Reactor, "Argonne National Laboratory Report ANL-6019, October 1959. 
TABLE IV

COMPARISON OF "CONVENTIONAL" BWR AND VMR FUEL-COST DATA

Thermal output, mw

Fuel cladding material

Operating pressure, psia

Water volume/ $\mathrm{UO}_{2}$ volume

Avg. specific power, $\mathrm{kw} / \mathrm{kg} \mathrm{U}$

Approx. avg. power density, $\mathrm{kw} /$ liter of coolant

Max. heat flux, Btu/hr-ft ${ }^{2}$

Burnup, $\mathrm{mwd} / \mathrm{T}$

$\mathrm{Kg} \mathrm{U} /$ core

Forced or natural circulation

Calculated fuel-cycle costs,

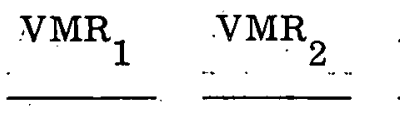

76

SS

1,000

3.4

18. 7

73

370,000

15,000

4,070

Natural

32.5

33.8

33.8

26. 1

45

312,000

15,000

3,796

Natural

Adjusted fuel-cycle costs;

$$
\text { e/ } 10^{6} \mathrm{Btu}
$$

32.5

33.8

$30.8-32.8$
Natural

30 (est.)

130,800

11,000

10,300

31.9

$29-31$
ANL -6009

BWR

40. 6

$\mathrm{Zr}$

333

0.8 
Alternative. "1" results in additional inventory charges, and alternative "2" results in increased burnup costs. It is noted also that a forced-circulation system is used. Even considering the decreased pressure drop.with core-size increase, the existing lattice is so tight it is doubtful that the present specific power could be maintained without a pumping system. It is estimated that the increased costs resulting from " 1 " or "2" above and the reduction in specific power obtained from a natural-circulation system would be approximately 1 cent per million Btu:

The net decrease in fuel costs, considering all of the effects outlined above is... estimated at 2 cents per million Btu. Since the calculated costs were 33.8 cents per $10^{6}$ Btu, $^{6}$ the adjusted costs are 31.8 cents per $10^{6}$ Btu. To allow for uncertainties, these adjusted costs are estimated at between 30.8 and 32.8. cents per million Btu; This would represent a decrease in fuel-cycle costs of 3 to $10 \%$ over the VMR Zircaloy-clad core. The VMR stainless-steel-clad core is between 0 to $5 \%$ more expensive than the conventional reactor Zircaloy-clad core.

2. $50-\mathrm{mw}$ BWR Designed by General Nuclear Engineering Corporation ${ }^{8}$

The reactor data shown in Table IV under TID-8510 BWR were extracted from reference 8 . The general objectives of the study were:

a. To review the state of the art of boiling water reactors in the 5 - to 40 -emw range.

b. To summarize anticipated problems having to do with boiling-water reactors in the 5 - to 40 -emw range.

c. To present economic data in the form of capital and operating cost breakdowns.

It is noted that a rather large discrepancy exists between the fuel-cycle costs shown for the reactor design obtained from TID-8510 and the fuel-cycle costs shown for the other reactors in Table IV. The source of this discrepancy is difficult to determine because of a lack of information in TID-8510 concerning the methods used to obtain the nuclear constants in the callculations and the method of operating the reactor. While this report describes the numerical results of the burnup calculations in considerable detail, it is not clear whether the

8. "A Brief Study. of Boiling Water Reactors in the 5 to 40 emw Range," TID-8510, October 1959. 
reactor operates under a continuous discharge, batch discharge, or some intermediate scheme, or what the power distribution is. Also, the source of the values, and the values used for relative-absorption cross sections, slowing-down cross sections, water densities, and age. are not specified. In addition, for the water $/ \mathrm{UO}_{2}$ ratio at which these reactors are designed, and for the $\mathrm{U} 235$ consumption and the $\mathrm{Pu}$ production obtained, there is some question as to whether the one-group burnup procedure described is adequate. For these reasons, it does not appear reasonable to compare the fuel costs obtained by GNEC with VMR fuel costs.

\section{40 -mw Process-Steam BWR ${ }^{9}$}

This study was undertaken by Argonne National Laboratory for the Atomic Energy Commission to determine the "feasibility of using nuclear reactors for process steam" and "to determine if the PWR, OMR, or BWR are particularly suitable for generation of $380^{\circ} \mathrm{F}$ saturated steam." It follows, from these objectives, that an attempt was probably made by Argonne to optimize each reactor type with regard to over-all economics. If this objective had been realized, it is apparent from examination of Table IV (discounting differences due to burnup) that the VMR fuel-cycle costs for the Zircaloy-clad core and the stainless-steelclad core are; respectively, $5 \%$ and $2 \%$ more expensive than the Argonne conventional BWR fuel-cycle costs.

Unfortunately, the BWR selected by Argonne may not really represent an optimized design with regard to economics. Although the extremely dry lattice (water volume $/ \mathrm{UO}_{2}=0.8$ ), coupled with the relatively large core (56-in. diameter) and the Zircaloy cladding, result in a high conversion ratio, the specific power is very low $(3.9 \mathrm{kw} / \mathrm{kg} \mathrm{U})$. This low specific power is obtained for two reasons: a) the tight lattice selected by Argonne imposes hydrodynamic restrictions on the core; and b) the low operating pressure (333 psia) imposes power-density restrictions because of stability considerations. It is difficult to ascertain the magnitude of these various effects, but the VMR has been shown to be more sensitive to specific power limitations brought about by hydrodynamic restrictions than it is to changes in fuel-cycle costs resulting from water $/ \mathrm{UO}_{2}$ volume.changes.

9. L. Link, "Study of 40-mw Pressurized Water, Boiling. Water, and Organic Moderated Reactors for Production of Process Steam, "Argonne National Laboratory Report, ANL 6009, June 1959. 
If the above effects (and the difference in burnup times) resulted in a net cost increase of 1.9 cents per million Btu, the "optimum" fuel-cycle cost would be 30 cents per $10^{6}$ Btu. Allowing 1 cent per $10^{6}$ Btu for uncertainties, the Zircaloy-clad fuel for the VMR would show a fuel-cycle cost between 9 and $16 \%$ higher than the conventional BWR. The stainless-steel-clad fuel for the VMR would have a fuel-cycle cost between 5 and $12 \%$ higher than the conventional reactor。

4. General Discussion of VMR and Conventional BWR Fuel-Cycle-Cost Differences

Table V summarizes the differences in fuel-cycle costs obtained by different methods.

Table V

Summary of VMR and Conventional BWR Fuel-Cycle-Cost Differences

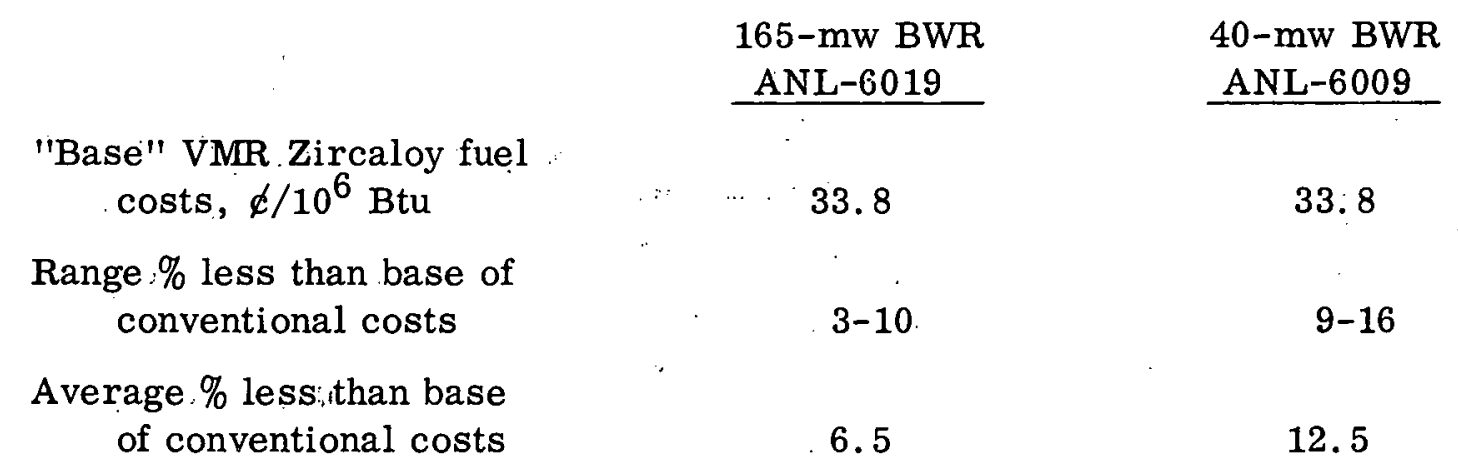

From Table V, it would appear that an optimized.conventional BWR will have fuel-cycle costs between 7 and $12 \%$ less than the VMR. As noted in previous discussionș, however, there is considerable uncertainty in the 7 to $12 \%$ difference between the VMR fuel-cycle.costs and conventional BWR costs. The reason for this uncertainty is that it is difficult to reconstruct the work done by others. To reduce the uncertainty, a conventional BWR is being analyzed by the same hydrodynamic and physics procedures as those used on the VMR.

Those factors which tend to make the VMR fuel costs higher than a.conventional BWR are:

a. Stainless Steel Shrouds

The additional poison introduced by the stainless steel shrouds (compared.with conventional reactors with Zircaloy structural materials) reduces the conversion ratio. 
Zircaloy shrouds may be feasible on the.VMR if the technology in Zircaloy welding advances sufficiently.

b. High Water/UO 2 Ratio

The use of a separate moderator region results in a water $/ \mathrm{UO}_{2}$ ratio which is higher than normally used in a conventional BWR, resulting in slightly lower conversion ratios. However, this effect is not as significant as the costs associated with "a"."

Tending to offset the VMR fuel-cycle cost disadvantages outlined above is the improved peak-to-average power ratio obtained as a result of the elimination of control rods. Although the VMR has a slightly higher fuel-cell peak-to-average power ratio than a conventional BWR, it has a relatively low axial peak-to-average power ratio. This low axial peak-to-average power ratio is possible because the moderator is maintained at a uniform height throughout the fuel life by the addition of a soluble poison. A conventional BWR, on the other hand, may have a relatively high axial peak-to-average power ratio because of the flux distortion introduced by the control rods.

In the initial technical and economic feasibility report on the VMR, the net fuel-cycle advantage or disadvantage will be determined with greater accuracy than in this report. If the fuel costs are significantly higher in the VMR than in a conventional BWR, these increased fuel costs must be offset by the decreased capital and maintenance costs in order for the VMR to be attractive. The capital and maintenance costs for the VMR will be lower than those for a conventional BWR because of the elimination of control rods.

\section{E. Method of Computing Fuel-Cycle Costs}

Table VI includes all of the data used to compute fuel-cycle costs and is largely. self explanatory. A description of the method is outlined below.

\section{Reactivity}

The value of $\mathrm{k}_{\text {effective }}$ is determined at the beginning and end of life (as determined from the MSBU burnup computer code) by means of a VAE PROD IBM-650 calculation. The end-of-life $\mathrm{k}_{\text {eff }, .}$ is adjusted to retain $5.5 \%$ : surplus reactivity, corresponding to $\mathrm{Xe}, \mathrm{Sm}$, and shutdown reactivity, margin. Xe and $\mathrm{Sm}$ reactivities are not included in the MSBU calculations. 
2. Beginning- and End-of-Life Uranium and Plutonium Concentrations

The beginning-of-life concentrations are first estimated, and the end-of-life concentrations are then obtained (for $15,000 \mathrm{mwd} / \mathrm{T}$ burnup) from the MSBU code. The beginningand end-of-life concentrations are then adjusted to result in the desired $5.5 \%$ excess $\mathrm{k}_{\text {eff }}$.

3. Reactor Power Output

Calculations are made to determine whether the specific core design being considered is:limited by hydrodynamic considerations, or by heat flux or center temperature. The limiting power is used.

\section{Fabrication Costs}

The fabrication costs are based upon preliminary data received from fuel fabricators and is subject to change as final quotations are received. Losses are included but use charges are not.

\section{Reprocessing Fuel to Nitrates}

The reprocessing costs are based upon the AEC estimate ${ }^{10}$ of costs for a typical reprocessing plant and are computed at $\$ 15,300$ per $1000 \mathrm{~kg}$ U plus $\$ 15,300$ per cleanup day. The number of days of cleanup time are estimated at one day per $1000 \mathrm{~kg} \mathrm{U}$, with a minimum of 3 days and a maximum of 8 days. Because of the minimum charge of $\$ 45,900$ associated with reprocessing, the fuel is assumed to be held in storage until a minimum of $3000 \mathrm{~kg}$ is available for processing.

\section{Burnup Cost}

The burnup cost is based upon the AEC-published values of uranium as a function of U 235.concentration.

\section{Pu Credit}

Plutonium credit is computed at $\$ 12 / \mathrm{gm}$ of $\mathrm{Pu}$. A separate calculation is made to determine the cost of producing plutonium buttons at the rate of $\$ 1.50 / \mathrm{gm}$ of $\mathrm{Pu}$.

8. Conversion Nitrates to $\mathrm{UF}_{6}$

Conversion costs are computed at the AEC-published value of $\$ 5.60 / \mathrm{kg} \mathrm{U}$.

10: "Notice of AEC Services in Chemical Processing of Spent Reactor Fuels, " 22 FR 1591, March 12, 1957. 


\section{Losses}

Processing losses of $1 \%$ are assumed. Uranium values are calculated at the endof-life enrichments, and plutonium losses are calculated at $\$ 12 / \mathrm{gm}$.

10. Use Charges

All use charges are computed at $4 \%$ per annum of the value at the beginning-of-life enrichment. In addition to the fuel in the reactor, a fabrication time of 7 months and a cooling-off and shipping period of 7.2 months is assumed for each fuel cycle. During the cooling -off period, if less than $3000 \mathrm{~kg}$ of fuel are available, use charges are paid on the discharged fuel until $3000 \mathrm{~kg}$ are accumulated.

11. Shipping

Shipping charges are assumed to be $\$ 3 / \mathrm{kg}$ U。

12. Interest on Fabrication Capital

Interest on the fabrication capital is computed at $6 \%$ per annum for the length of the fuel cycle. 
TABLE VI

VMR FUEL-CYCLE ANALYSIS

\begin{tabular}{|c|c|c|c|c|c|c|c|c|c|c|c|c|c|c|c|c|c|c|c|c|}
\hline \multirow[b]{2}{*}{ “ } & \multicolumn{13}{|c|}{ CORE DESIGN NO. } & & & & \multicolumn{2}{|c|}{$\begin{array}{l}\text { Prototype BWR } \\
\text { ANL-6019 }\end{array}$} & \multirow{2}{*}{$\begin{array}{l}5-40 \\
\text { emw } \\
\text { BWR } \\
\text { TID- } \\
8510 \\
\end{array}$} & \multirow{2}{*}{$\begin{array}{l}\text { BWR } \\
\text { ANL- } \\
6009\end{array}$} \\
\hline & 23 & 26 & $26 \mathrm{~A}$ & 28 & 29 & $29 \mathrm{~A}$ & 30 & 31 & 32 & 33 & 35 & 36 & 37 & 38 & 39 & 40 & \begin{tabular}{|c|}
$825-\mathrm{mw}$ \\
Divided \\
Core
\end{tabular} & $\begin{array}{c}165-\mathrm{mw} \\
\text { Divided } \\
\text { Core }\end{array}$ & & \\
\hline 1) $\mathrm{k}_{\text {eff }}$ at $0 \mathrm{mwd} / \mathrm{T}$ & 1. 1884 & 1. 1967 & 1. 1303 & 1. 1844 & 1. 1559 & 1.1559 & .1. 1883 & 1.1537 & 1. 1954 & 1. 2376 & 1.1782 & 1. 2070 & 1.1507 & 1.2250 & 1. 1362 & 1.2113 & & & & \\
\hline 2) $\mathrm{k}_{\text {eff }}$ at $15,000 \mathrm{mwd} / \mathrm{T}$ & 0.9843 & 1.0379 & 1.0721 & 1.0787 & 1.0704 & 1.0704 & 1.0521 & 1.1012 & 1.0706 & $|1.0784|$ & 1.0092 & 1.0578 & 0.9929 & 1.0772 & 0.9908 & 0020 & & & & \\
\hline 3) $\% \Delta \mathrm{k} \quad 0-15,000 \mathrm{mwd} / \mathrm{T}$ & 17.172 & 13.3 & 5.15 & 8. 93 & 7.39 & 7. 39 & 11.47 & 4.55 & 10.44 & 12.86 & |14. 23 & 12.42 & 13.70 & |12.2. 07 & 12.79 & $|12.268|$ & & & & \\
\hline $\begin{array}{l}\text { 4) (2) }-1.055=\text { surplus (or deficit) } k \\
\text { 5) Natural or forced circulation }\end{array}$ & $\begin{array}{c}-0.0707 \\
\text { Nat. }\end{array}$ & -0.017 & 0.017 & 0.0237 & $|0.0154|$ & 0.0154 & -0.003 & 0.046 & 0.0156 & 0.0234 & -0.0458 & 0.0028 & -0.0621 & 0.0222 & -0.0642 & 0.0076 & & & & \\
\hline 6) Beginning-of-life concentrations $\times 10^{4}$ & & & & & & & & & & & & & & & & & || Forced & Nat. & & \\
\hline a) 235 & 1. 2569 & 1.8041 & 1. 8041 & 2.7655 & 3.4607 & 3.4607 & 2.0008 & 2.4702 & 2.3960 & 1.7335 & \begin{tabular}{|l|}
$\mid 1.6128$ \\
\end{tabular} & 1.8710 & 1.6770 & 1.9805 & $|1.6715|$ & 1.8244 & & & & \\
\hline b) 238 & 40.639 & 45.6730 & 45. 6730 & 63.0791 & 73.4434 & 73.4434 & 50.6525 & 59.2845 & 57.5041 & 38.5799 & $\mid 52.1469$ & 47.3662 & $|46.2410|$ & $|47.5330|$ & 46.0860 & $|43.7844|$ & & & & \\
\hline $\begin{array}{l}\text { c) Total }=(6 \mathrm{a})+(6 \mathrm{~b}) \\
\text { d) } \% 235=100 \times(6 \mathrm{a} /(6 \mathrm{C}\end{array}$ & $\begin{array}{c}41.8959 \\
3.00\end{array}$ & $\begin{array}{l}47.4771 \\
3.80\end{array}$ & $\mid \begin{array}{c}47.4771 \\
3.80\end{array}$ & 65.8446 & $\left|\begin{array}{c}76.9041 \\
4.50\end{array}\right|$ & 76.9041 & 52.6533 & 61.7547 & 59. 9001 & 40.3134 & 53.7597 & 49. 2372 & 47.9180 & 49.5135 & 47.7575 & 45.609 & & & & \\
\hline 7) End-of-life concentrations $\times 10^{4}$ & & & 3.80 & 4,20 & & 4.50 & 3. 80 & 4.00 & 4.00 & 4.30 & & 3.80 & 3. 50 & 4.00 & 3. 50 & 4.00 & & & & \\
\hline a) 235 & 0.5569 & 0.9461 & 0.9580 & 1. 6528 & 2. 1708 & 2. 1708 & 1.1044 & 1.4354 & 1.3714 & 0.9997 & 0.7487 & 1. 0190 & 0.8631 & 1.1144 & $|0.8768|$ & 1.02 & & & & \\
\hline b) 238 & 40.2675 & 45.2728 & 45.2894 & 62.4424 & 72. 5924 & 72.5924 & 50.1905 & 58.6724 & 56.9683 & 38.3172 & 51.6148 & 46.9668 & 45.8184 & 47.1537 & 45.6506 & 43.424 & & & & \\
\hline c) Total Pu & 0.2081 & 0.2379 & 0.2308 & 0.3903 & 0.5341 & 0.5341 & 0.2772 & 0.3728 & 0.3236 & 0.1620 & 0.2988 & 0.2385 & $|0.2473|$ & 0.2283 & 0.2586 & $|0.2188|$ & & & & \\
\hline 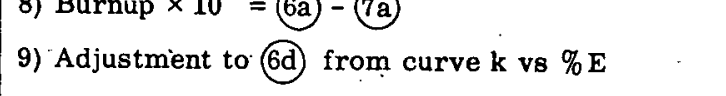 & $\left|\begin{array}{c}0.7001 \\
+0.56\end{array}\right|$ & $\begin{array}{c}0.8580 \\
+0.12\end{array}$ & $\mid \begin{array}{c}0.8461 \\
-0.12\end{array}$ & $\begin{array}{c}1.1127 \\
-0.18\end{array}$ & $\begin{array}{c}1.2899 \\
-0.11\end{array}$ & 1.2899 & 0.8964 & $\begin{array}{c}1.0348 \\
-0.36-\end{array}$ & $\mid \begin{array}{l}1.0246 \\
-0.12\end{array}$ & $\left|\begin{array}{c}0.7338 \\
-0.17\end{array}\right|$ & $\left|\begin{array}{c}0.8641 \\
+0.36\end{array}\right|$ & $\mid \begin{array}{c}0.8520 \\
-0.02\end{array}$ & $\begin{array}{c}0.8139 \\
0.99\end{array}$ & 0.8661 & 0.7947 & 0.8045 & & & & \\
\hline $\begin{array}{l}\text { 10) Adjusted } \% 235 \text { at } 0 \mathrm{mwd} / \mathrm{T} \\
\text { 11) Adjusted beginning-of-life concentration } \times 10^{4}\end{array}$ & 3.56 & 3.92 & 3.68 & 4.02 & $\begin{array}{r}-0.11 \\
4.39\end{array}$ & $\begin{array}{l}-0.11 \\
4.39\end{array}$ & $\begin{array}{l}+0.02 \\
3.82\end{array}$ & $\begin{array}{r}-0.36 \\
3.64\end{array}$ & $\begin{array}{r}-0.12 \\
3.88\end{array}$ & $\begin{array}{r}-0.17 \\
4.13\end{array}$ & $\begin{array}{c}+0.36 \\
3.36\end{array}$ & $\begin{array}{r}-0.02 \\
3.78\end{array}$ & $\begin{array}{r}+0.49 \\
3.99\end{array}$ & $\begin{array}{r}-0.16 \\
3.84\end{array}$ & $\begin{array}{r}+0.50 \\
4.00\end{array}$ & $\begin{array}{r}-0.06 \\
3.94\end{array}$ & 2.50 & 2. 65 & 2.00 & 1.50 \\
\hline a) $235=$ (60 $\times(10) / 100$ & 1.492 & 1.861 & 1.746 & 2. 648 & 3.375 & 3.375 & 2.011 & 2.248 & 2.324 & 1.664 & 1.806 & 1.860 & 1.912 & 1.902 & 1.910 & 1.797 & & & & \\
\hline $\begin{array}{l}\text { b) } 238=(6 c)-(112) \\
\text { 12) Adjusted end-of-life concentration } \times 10^{4}\end{array}$ & 40.404 & 45.616 & 45.731 & 63.197 & 73.529 & 73.529 & 50.642 & 59.507 & 57.576 & 38.649 & 51.954 & 47.377 & 46. 006 & 47.612 & 45. 848 & 44.812 & & & & \\
\hline a) $235=112-8$ & 0.7915 & 1.003 & 0.900 & 1.535 & 2.085 & 2.085 & 1.115 & 1.135 & 1. 299 & 0.930 & 0.942 & 1.008 & 1.098 & 1.036 & 1.115 & 0.9925 & & & & \\
\hline $\begin{array}{l}\text { b) } 238=(10)-[(6 b)-(7 b)] \\
\text { c) Total } p u=\text { ?c }\end{array}$ & 40.033 & 45. 216 & 45.347 & 62.560 & 72.678 & 72. 678 & 50.180 & 58.895 & 57.040 & $38.386^{\circ}$ & 51.422 & 46. 978 & 45. 583 & 47.233 & 45.413 & 44.452 & & & & \\
\hline c) Total $\mathrm{Pu}=(7 \mathrm{c})$ & 0.2081 & 0.238 & 0.231 & 0.390 & 0.534 & 0.534 & 0.277 & 0.373 & 0.324 & 0.162 & 0.299 & 0.239 & 0.247 & 0.228 & 0.259 & 0.2188 & & & & \\
\hline $\begin{array}{l}\text { d) Total }=(12 a)+(12 b)+(12 a) \\
\text { e) Total } U=(12 a)+(12 b)\end{array}$ & $\mid \begin{array}{l}41.032 \\
40.824\end{array}$ & $\mid \begin{array}{l}46.457 \\
46.219\end{array}$ & $\begin{array}{l}46.478 \\
46.247\end{array}$ & $\mid \begin{array}{l}64.485 \\
64.095\end{array}$ & $\mid \begin{array}{l}75.297 \\
74.763\end{array}$ & $\begin{array}{l}75.297 \\
74.763\end{array}$ & $\left|\begin{array}{l}51.572 \\
51.295\end{array}\right|$ & $\begin{array}{l}60.403 \\
60.030\end{array}$ & $\begin{array}{l}58.663 \\
58.339\end{array}$ & $\mid \begin{array}{l}39.478 \\
39.316\end{array}$ & $\begin{array}{l}52.663 \\
52.364\end{array}$ & $\begin{array}{l}48.225 \\
47.986\end{array}$ & 46.928 & 48. 497 & $\begin{array}{l}46.787 \\
46.528\end{array}$ & 45.663 & & & & \\
\hline f) $\% \mathrm{U} 235=100 \times 122$ & 1.939 & 2.17 & 1.95 & 2.40 & 2.79 & 2.79 & 2.18 & 1. 89 & 2.23 & 2.37 & 1.80 & $\begin{array}{l}47.986 \\
2.10\end{array}$ & $\begin{array}{l}46.681 \\
2.36\end{array}$ & $\int_{2.15}^{48.269}$ & $\begin{array}{c}46.528 \\
2.40\end{array}$ & $\begin{array}{r}45.444 \\
2.184\end{array}$ & 0.96 & $1: 60$ & 0.578 & 0.495 \\
\hline g) $\% \mathrm{Pu}=100 \times(120)$ & 0.507 & 0.512 & 0.497 & 0.605 & 0.710 & 0.710 & 0.537 & 0.617 & 0.552 & 0.410 & 0.567 & 0.496 & 0.527 & 0.470 & 0.557 & 0.479 & 0.82 & 0.64 & 0.894 & 0.573 \\
\hline 13) Mwd/short ton U & 15,250 & 15,399 & 15,067 & 15,115 & 15,202 & 15,202 & 15,033 & 15,064 & 15,105 & 15,081 & 15,111 & 15,131 & 15,207 & 15,108 & 15,015 & 15,228 & $\mid 16,360$ & 10,940 & 15,000 & 11,180 \\
\hline 14) $\mathrm{Kg} \mathrm{UO}_{2} /$ core & 4,980 & 4,620 & 4,620 & 4,590 & 4,660 & 4,660 & 4,620 & 4,620 & 4,630 . & 4,620 & 4,980 & 4,620 & 4,620 & 4,650 & 4,600 & 4,600 & $\| 67,050$ & 13,410 & & \\
\hline $\begin{array}{l}\text { 15) } \mathrm{Kg} \mathrm{UO}_{2} / \text { cycle } \\
\text { 16) } \mathrm{Kg} \mathrm{U} / \text { core }\end{array}$ & $\begin{array}{l}4,980 \\
4,383\end{array}$ & $\begin{array}{l}4,620 \\
4,070\end{array}$ & 1,540 & 4,590 & 4,660 & 4,660 & 4,620 & 4,620 & 4,630 & 4.620 & 4,980 & 4,620 & 4,620 & 4,650 & 4,600 & 4,600 & 13,410 & 2,680 & & \\
\hline 17.) $\mathrm{Kg} \mathrm{U} / \mathrm{cycle}$ & $\begin{array}{l}4,383 \\
4,383\end{array}$ & $\begin{array}{l}4,070 \\
4,070\end{array}$ & $\begin{array}{l}4,070 \\
1,356\end{array}$ & $\begin{array}{l}4,040 \\
4,040\end{array}$ & $\begin{array}{l}4,100 \\
4,100\end{array}$ & $\begin{array}{l}4,100 \\
4,100\end{array}$ & $\begin{array}{l}4,070 \\
4,070\end{array}$ & $\begin{array}{l}4,070 \\
4,070\end{array}$ & $\begin{array}{l}4,080 \\
4,080\end{array}$ & $\begin{array}{l}4,070 \\
4,070\end{array}$ & $\begin{array}{l}4,380 \\
4,380\end{array}$ & $\begin{array}{l}4,070 \\
4,070\end{array}$ & $\begin{array}{l}4,070 \\
4,070\end{array}$ & 4,090 & 4,050 & 4,048 & 58,500 & 11,700 & 3,796 & 10,300 \\
\hline 3) Short tons $0 /$ cycle & 4.821 & 4.48 & 1.49 & 4.44 & 4.51 & 4.51 & 4.48 & 4.48 & 4.49 & 4.48 & $\begin{array}{l}4,000 \\
4.82\end{array}$ & 4.48 & $\begin{array}{l}4,40 \\
4.48\end{array}$ & $\begin{array}{l}4,090 \\
4.50\end{array}$ & $\begin{array}{l}4,050 \\
4.50\end{array}$ & $\begin{array}{l}4,048 \\
4.454\end{array}$ & $\|_{12,86}^{11,700}$ & $\begin{array}{l}2,340 \\
2.57\end{array}$ & $\begin{array}{l}3,796 \\
4.18\end{array}$ & $\begin{array}{l}1,030 \\
1.134\end{array}$ \\
\hline 19) Peak power/foot pin $(\underset{\gamma}{\mathrm{k} w} / \mathrm{ft})$ & 10 & 9.82 & 9.82 & 5.33 & 2.93 & 9.03 & 9.86 & 9. 86 . & 6. 28 & 9.82 & 5.15 & 9.86 & 9.58 & 10 & 1.69 & 10 & & & & \\
\hline
\end{tabular}

Power per foot values less than $10 \mathrm{kw}$ are pressure-drop-limited with natural circulation, rather than centerline-temperature- or heat-flux-limited. 


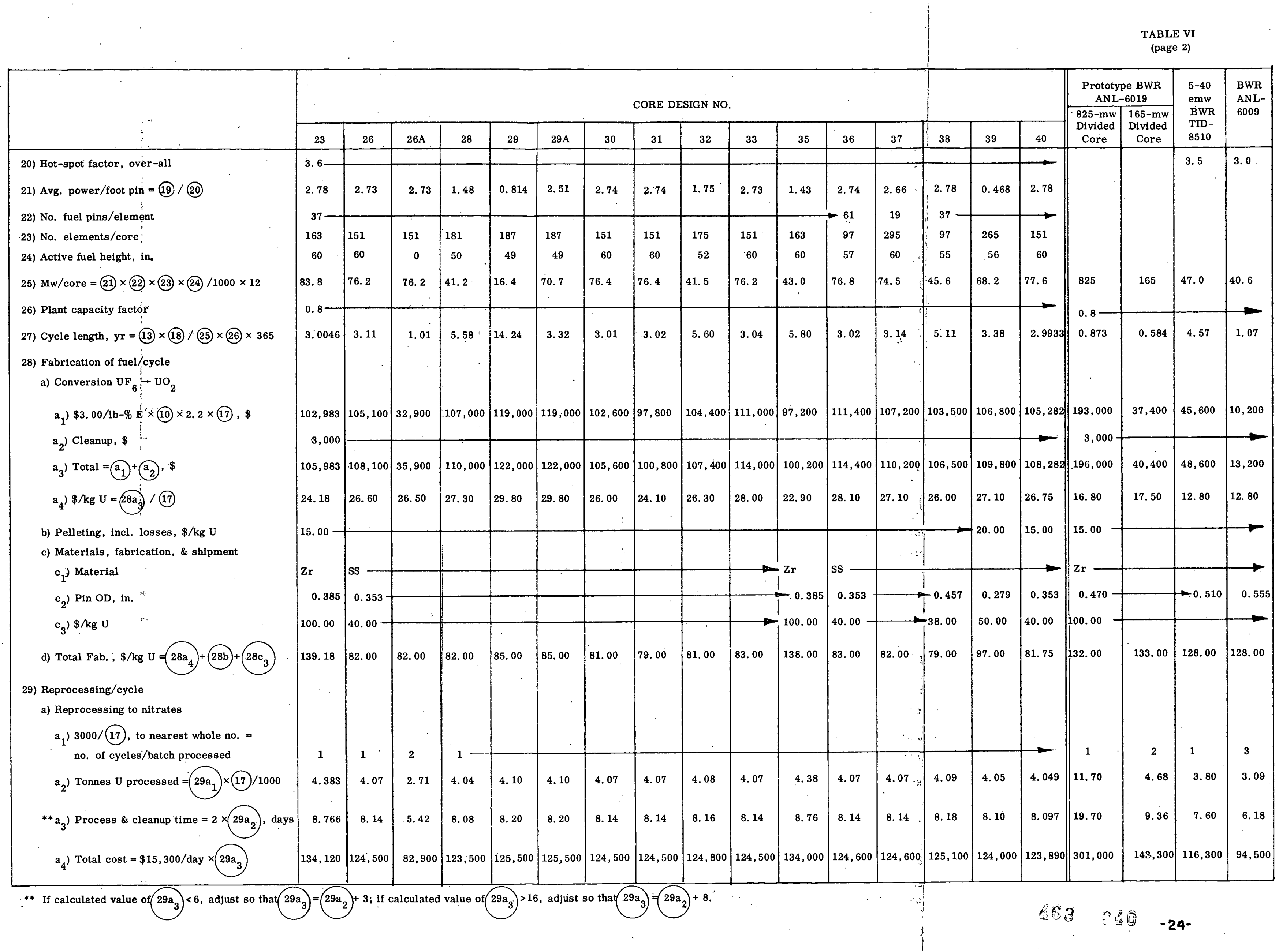




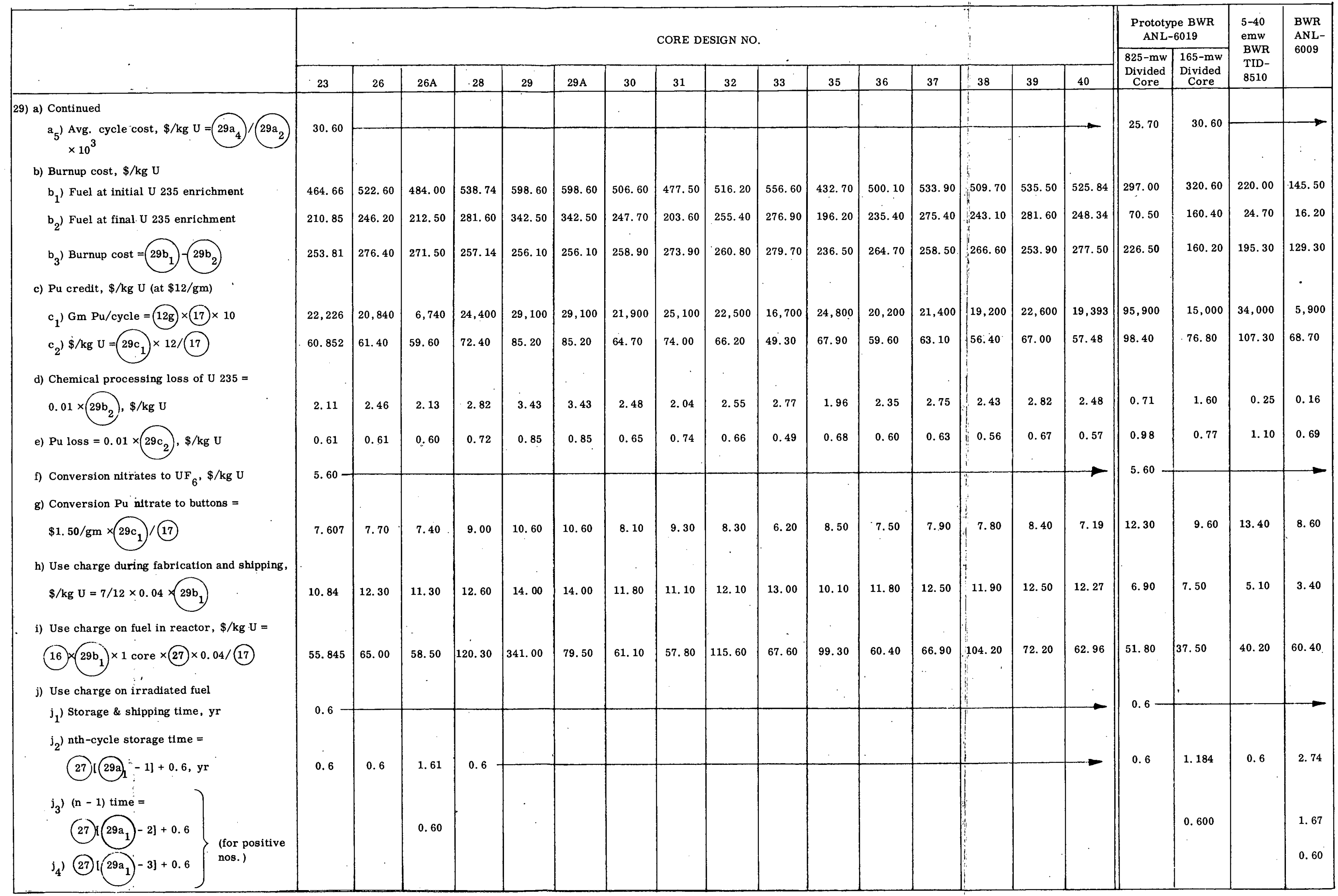




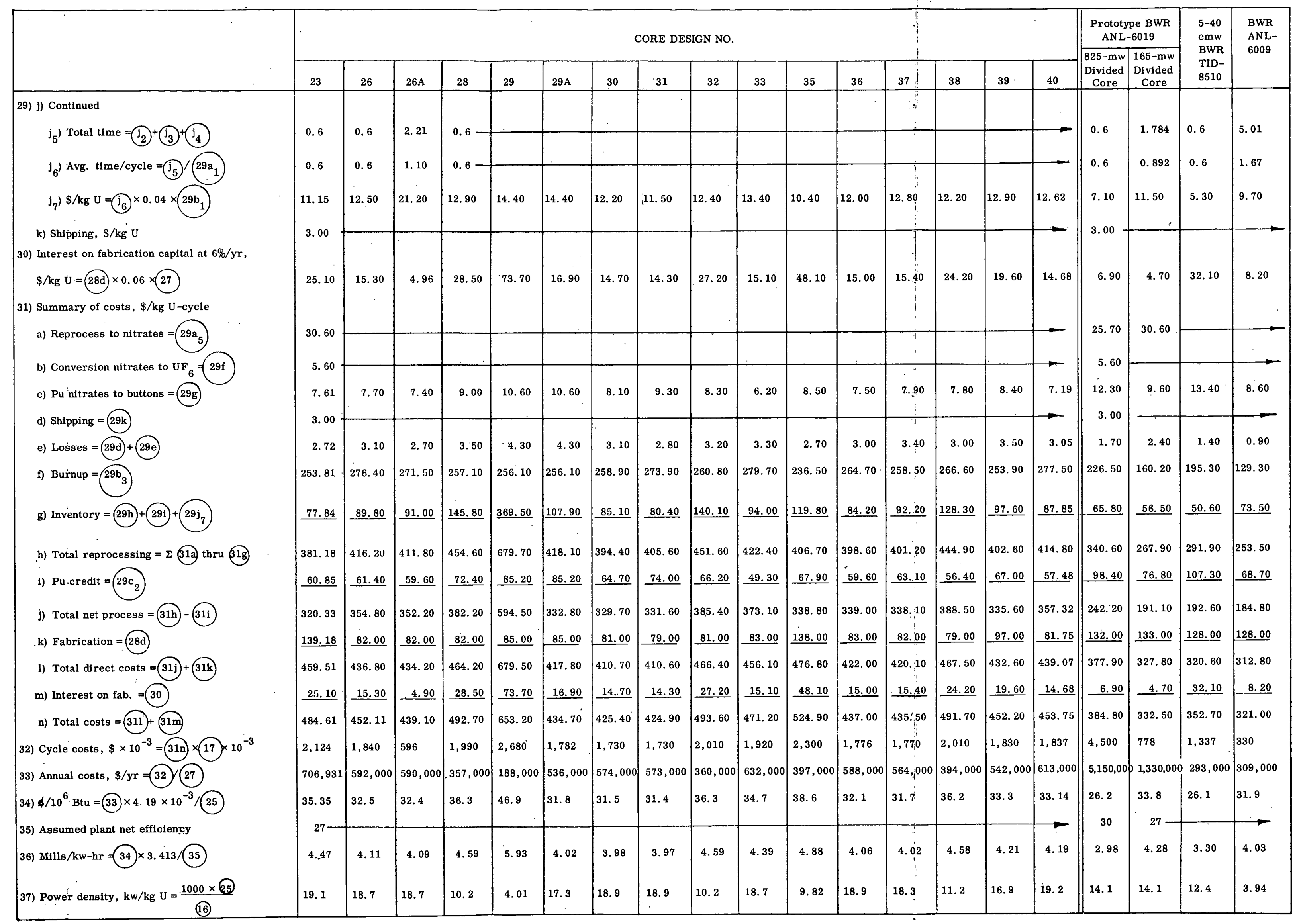




\section{MSBU FUE L-BURNUP CODE}

\section{A. General Description of Code}

The method used for computing isotopic concentrations and effective multiplication as a function of specific exposure is an IBM-650 computer code, MSBU, which has been designed to provide convenient treatment of non-uniform burnup and fuel and control poison'ing, and to have general validity over a wide range of conversion ratios and specific exposures. Although the burnup calculation itself is essentially a zero-space-dimensional computation, it provides direct fàcilities for. inserting local energy-dependent leakages and control poisons in the input, and it yields output directly usable in four-group diffusion calculations of flux and power distribution and effective multiplication. The computation is performed in four energy groups, using, for each group $i$, the following cross.section data:

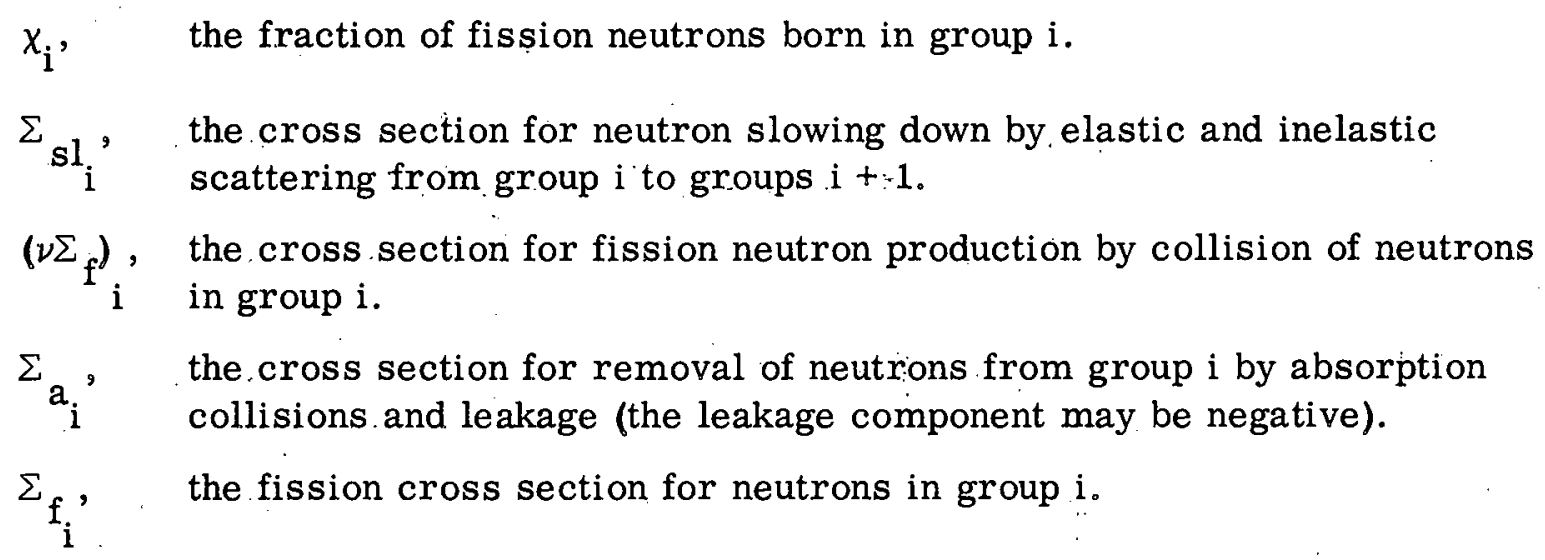

The first two quantities are specified as input. The others are computed at each time step from the concentration of $\mathrm{U} 235, \mathrm{U} 238, \mathrm{Pu} 239, \mathrm{Pu} 240, \mathrm{Pu} 241$, fission products, and from the input values of the microscopic cross section and $\Sigma_{\text {as }}$, the macroscopic component of $\Sigma_{a_{i}}$ due to other materials present and to leakage. From these.cross.sections, the four group fluxes. are computed at each time step from the equation

$$
\phi_{i}=\frac{F \chi_{i}+\Sigma_{s l_{i-1}} \phi_{i-1}}{\Sigma_{a_{i}}+\sum_{s l_{i}}}
$$

where $F$ is an input constant equal to the approximate number of fission neutrons produced per second per $\mathrm{cm}^{3}$.

$$
-27-\quad 03 \quad 093
$$


The $\phi_{i}$ are then used to obtain the effective multiplication, the change in concentration of each isotope, and the increase in specific exposure during the time step, from the following $\because$ differential equations. These equations are solved by means of an iterative predictorcorrection technique.

$$
\begin{aligned}
& k=1+\sum_{i}\left[\left(\nu \Sigma_{f}\right)_{i}-\Sigma_{a_{i}}\right] \phi_{i} . \\
& \frac{\mathrm{dN}^{25}}{\mathrm{dt}}=-\mathrm{N}^{25} \sum_{\mathrm{i}} \phi_{\mathrm{i}}{\stackrel{\sigma}{\mathrm{a}_{\mathrm{i}}}}^{25} \\
& \frac{\mathrm{dN}^{28}}{\mathrm{dt}}=-\mathrm{N}^{28} \sum_{\mathrm{i}} \dot{\phi}_{\mathrm{i}} \sigma_{\mathrm{a}_{\mathrm{i}}}^{28} \\
& \frac{\mathrm{dN}^{49}}{\mathrm{dt}}=\mathrm{N}^{28} \sum_{\mathrm{i}} \phi_{\mathrm{i}}\left(\sigma_{a_{i}}^{28}-\sigma_{f_{i}}^{28}\right)-\mathrm{N}^{49} \sum_{\mathrm{i}} \phi_{\mathrm{i}} \sigma_{\mathrm{a}_{\mathrm{i}}}^{49} \\
& \frac{\mathrm{dN}^{40}}{\mathrm{dt}}=\mathrm{N}^{49} \sum_{\mathrm{i}} \phi_{i}\left(\sigma_{a_{i}}^{49}-\sigma_{\mathrm{f}_{i}}^{49}\right)-\mathrm{N}^{40} \sum_{\mathrm{i}} \phi_{\mathrm{i}} \sigma_{a_{i}}^{40} \\
& \frac{d N^{41}}{d t}=N^{40} \quad \sum_{i} \phi_{i}\left(\sigma_{a_{i}}^{40}-\sigma_{f_{i}}^{40}\right)-N^{41} \sum_{i} \phi_{i} \sigma_{a_{i}}^{41} \\
& \frac{d E}{d t}=C^{\prime} \sum_{i} \Sigma_{f_{i}} \text {. } \\
& \frac{d N^{F P}}{d t}=\sum_{i} \Sigma_{f_{i}} \phi_{i}-N^{F P} \cdot \sum_{i} \phi_{i} \sigma_{i}^{F P}
\end{aligned}
$$

$\mathrm{C}$ is an input constant equal to the number of $\mathrm{mwd} / \mathrm{T}$ per fission per $\mathrm{cm}^{3}$. At each time step, the information printed out by the program consists of the exposure and each of the concentrations computed above. In addition, at each time step, the macroscopic cross sections, including input values of the diffusion coefficients, are punched out in a form directly usable in the multigroup diffusion code. Since the input values of the $\Sigma_{a s_{i}}{ }^{3}$ the $\Sigma_{s l_{i}}$, and the $D_{i}$ may be changed at any, time step, MSBU can include the effects of changes in the local leakage and poison cross sections and coolant and power densities during operation. Since, further, the output cross sections are directly usable for each region of a multigroup diffusion calculation, the values of these changes may conveniently be computed, and similarly, control-rod programming calculations may be performed. 
Some detailed calculations on Core Design No. 26 are described in sections C and D below. As the description shows, the inclusion of control poisons and leakage variation has only a slight effect on fuel-cycle costs for a well thermalized low-conversion reactor like the VMR. It is possible, however, that this effect, which is the sum of several opposing: factors, is significant for some VMR design cases. In Table VII, the magnitude of some other effects is illustrated by calculations on Core Design No. 36. Case A was computed at zero exposure. with no control poisons inserted to hold down the burnup reactivity change. In case $B_{9}$ sufficient $1 / v$ poișon was inserted to hold down half the burnup reactivity change. Cases $\mathrm{C}$ and $\mathrm{D}$ were computed at $15,000 \mathrm{mwd} / \mathrm{T}$, but in $\mathrm{C}$ the thermal microscopic cross sections were recomputed for a Wigner-Wilkins, spectrum corresponding to the isotopic composition at that exposure.

Examination of the table shows that, although the thermal and non-thermal conversion ratios are somewhat different in each case, the maximum difference between the total conversion ratio of any two cases is $4 \%$. Further, the values of $\mathrm{k}$ obtained for cases $\mathrm{C}$ and $\mathrm{D}$ are only $1 \%$ different. Since the core designs that appear attractive for the VMR are Nos. 26 and 36, and since.consideration of various effects does not appear to change significantly the results of the fuel-cycle.cost analysis obtained by the "batch" loading calculational procedure described in section B below, this simplified burnup code is.considered to represent adequately the.VMR fuel-cycle analysis. If other attractive core designs are considered besides 26 and 36 , further review will be made of the nuclear effects on the simplified burnup code as applied to these cases. 
TABLE VH

SPECIAL NUCLEAR EFFECTS IN VMR CORE DESIGN NO. 36

\begin{tabular}{|c|c|c|c|c|}
\hline Case & A & B & $\mathbf{C}$ & $\mathrm{D}$ \\
\hline $\begin{array}{l}\text { Fraction of thermal neutrons absorbed } \\
\quad \text { in U } 238\end{array}$ & 0.07916 & 0.06566 & & 0.08562 \\
\hline $\begin{array}{l}\text { Fraction of thermal neutrons absorbed } \\
\text { in U } 235\end{array}$ & 0.7242 & 0.6698 & 0.4312 & 0.4302 \\
\hline $\begin{array}{l}\text { Fraction of thermal neutrons absorbed } \\
\text { in FP }\end{array}$ & 0 & $\dot{0}$ & 0.03401 & 0.03378 \\
\hline $\begin{array}{l}\text { Fraction of thermal neutrons absorbed } \\
\text { in } \mathrm{Pu}\end{array}$ & 0 & 0 & 0.2308 & 0.2356 \\
\hline $\begin{array}{l}\text { Fraction of thermal neutrons absorbed } \\
\text { in others }\end{array}$ & 0.1968 & 0.2645 & & 0.2147 \\
\hline $\begin{array}{l}\text { Number of Pu } 239 \text { atoms formed by } \\
\text { thermal capture in U: } 238 \text { per U } 235 \\
\text { atoms destroyed }\end{array}$ & 0.09465 & 0.09362 & $\begin{array}{c}0.1764 \\
\vdots\end{array}$ & 0.1744 \\
\hline $\begin{array}{l}\text { Number of Pu } 239 \text { atoms formed by } \\
\text { capture in U } 238 \text { per U } 235 \text { atoms } \\
\text { destroyed }\end{array}$ & 0.3257 & 0.3411 & 0.5619 & 0.5608 \\
\hline${ }^{*} \mathrm{C}$ thermal & 0.09465 & 0.09362 & 0.1032 & 0.1023 \\
\hline C non-thermal & 0.2311 & 0.2475 & 0.2257 & 0.2266 \\
\hline Fraction of neutrons reaching thermal & 0.7203 & 0.7171 & 0.7441 & 0.7441 \\
\hline Reactivity, $\mathrm{k}$ & 1.: 298 & 1.211 & 1.129 & 1. 137 \\
\hline
\end{tabular}




\section{B. "Batch" Loading Calculational Procedure}

The MSBU code described above was used in conjunction with a four-group diffusiontheory calculation, using VAL PROD, to evaluate the changes in flux, power density, and reactivity for a uniformly burned core. This batch-loaded corewas evaluated at $0 \mathrm{mwd} / \mathrm{T}$ and 15,000 $\mathrm{mwd} / \mathrm{T}$ to simulate a beginning-and end-of-life condition for the uniform core. The changes in flux and power density are shown in.Figures 14 and.15. The reduction in reactivity for Core Design No. 26 was found to be $13.2 \%$.

The microscopic parameters for the MSBU code were determined from the particular specifications of this design and from information obtained from the PUREE' code and a $P_{3}$ approximation for the thermal group, using the Wigner-Wilkins spectrum via Amster's Table. ${ }^{11}$ This same procedure was followed for all the water lattices under consideration and the resulting macroscopic parameters used in the beginning- and end-of-life four-group diffusion-theory calculations.

As seen from the description of MSBU (section A above), the concentrations and macroscopic diffusion-theory parameters are produced as functions of $\mathrm{mwd} / \mathrm{T}$. The output at $15,000 \mathrm{mwd} / \mathrm{T}$ was used to perform the end-of-life diffusion calculation and produced the results mentioned above.

C. "Three Region" Loading Calculational Procedure

To gain a more realistic picture of the operational reactor, a three-region core was evaluated, each region having an average burnup of $5000 \mathrm{mwd} / \mathrm{T}$.

The cylindrical core was divided into three equal-volume regions, and the burnup in each region was treated as follows:

$$
\begin{array}{lc}
\mathrm{R}_{\mathrm{I}} & 10,000-15,000 \mathrm{mwd} / \mathrm{T} \\
\mathrm{R}_{\text {II }} & 5,000-10,000 \mathrm{mwd} / \mathrm{T} \\
\mathrm{R}_{\text {III }} & 0-5,000 \mathrm{mwd} / \mathrm{T}
\end{array}
$$

Three separate calculations using the MSBU code were performed. From a set of similar three-region core calculations, the leakage cross sections for the three regions and four groups were evaluated and used in conjunction with four-group flux-weighted cross sections

11. Harvey J. Amster, "A Compendium of Thermal Neutron Cross Sections Averaged Over the Spectra of Wigner and Wilkins," WAPD-185, January 1958. 


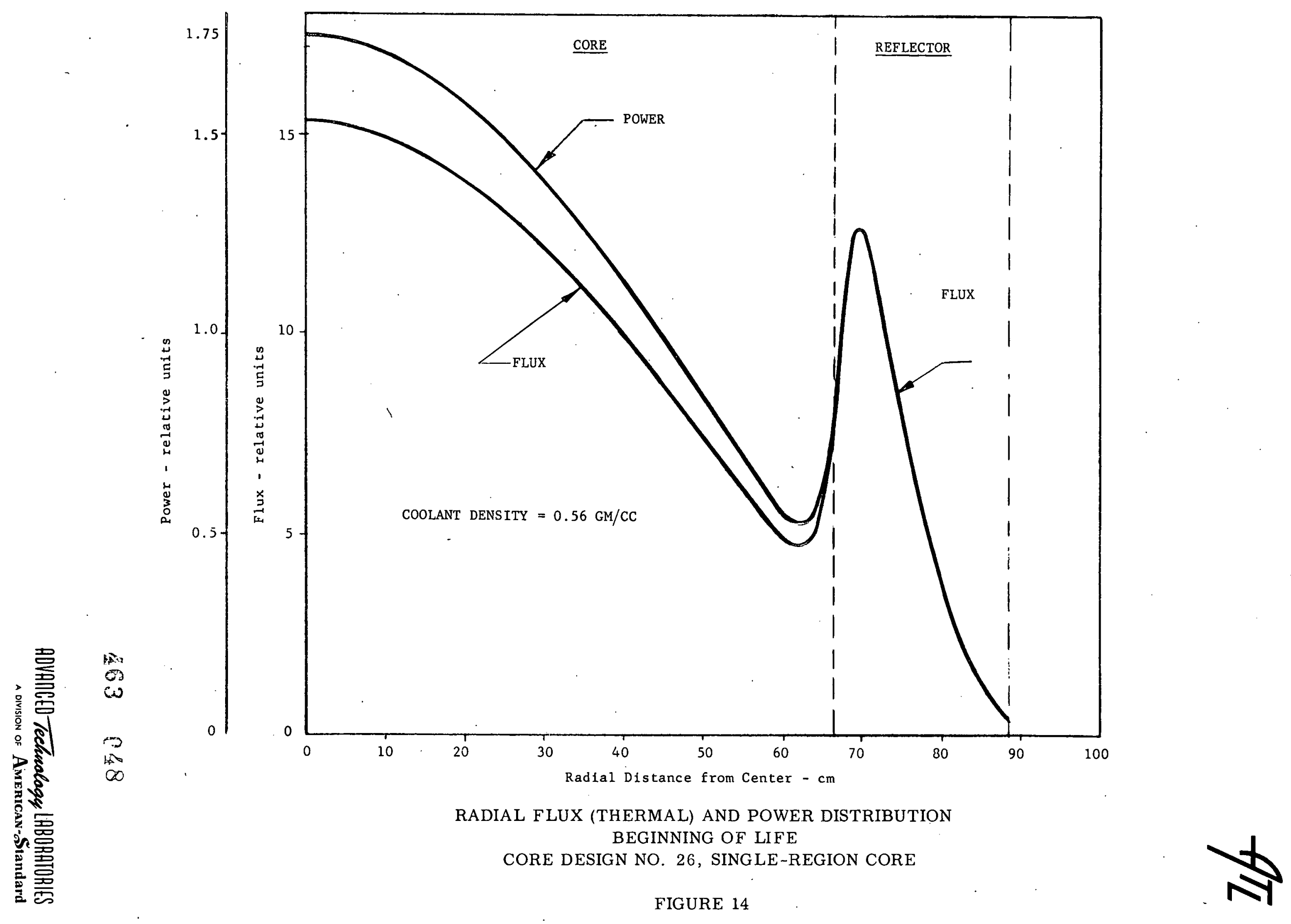




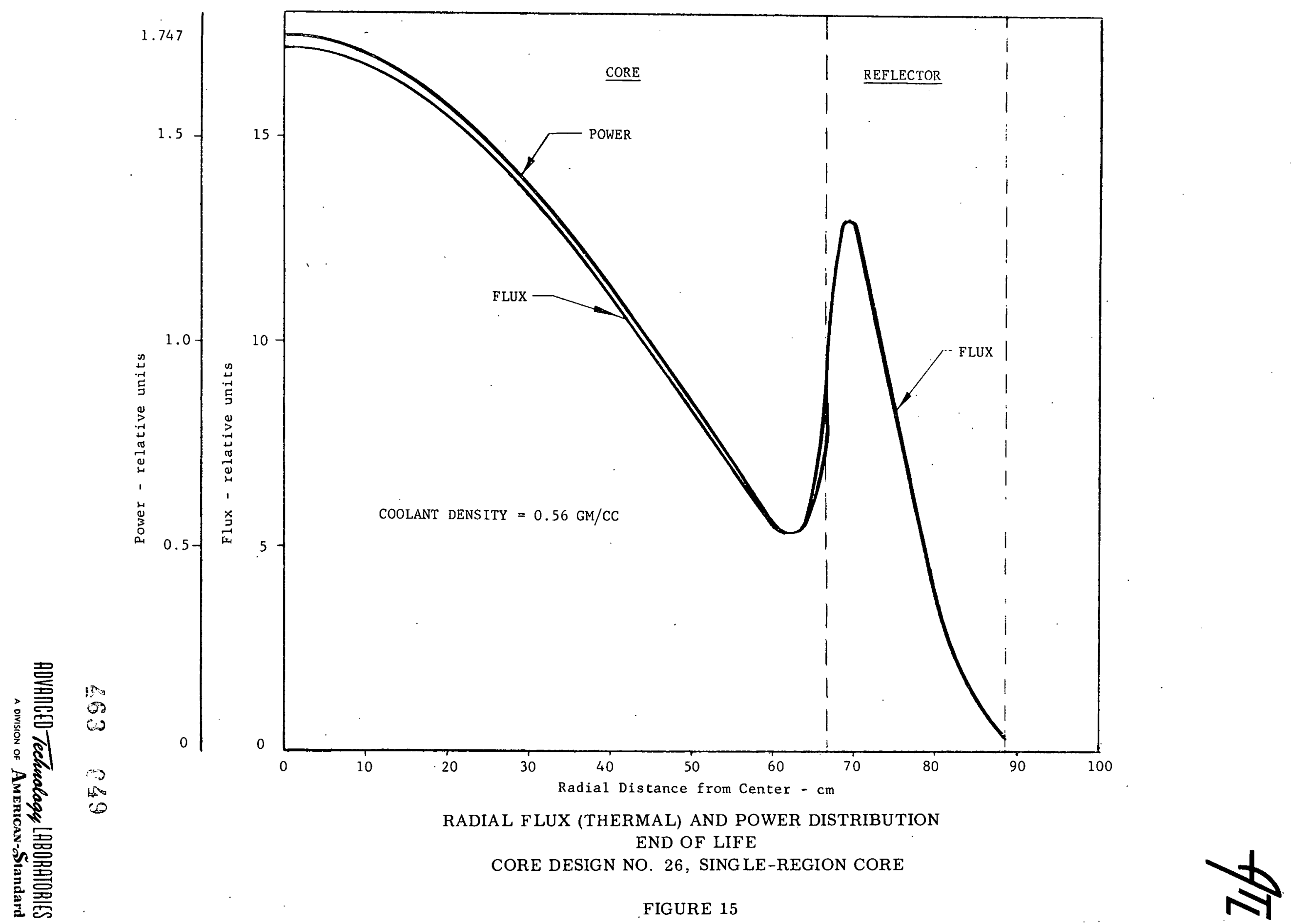


for a $1 / v$ absorber (Boron), and these two quantities were included in the structure cross sections in the MSBU input. The burnup code (MSBU) was then run for $\mathrm{R}_{\text {III }}$ from 0 to $5000 \mathrm{mwd} / \mathrm{T}$, with the initial concentrations of $U 235$ and $U 238$ and the appropriate structure cross sections. The concentrations given at $5000 \mathrm{mwd} / \mathrm{T}$ were then used in a burnup calculation for $\mathrm{R}_{\mathrm{II}}(5,000-10,000 \mathrm{mwd} / \mathrm{T})$, with the appropriate structure cross sections. A similar procedure was used for $R_{I}(10,000-15,000 \mathrm{mwd} / \mathrm{T})$.

The macroscopic parameters generated by the MSSBU code were used in performing the two four-group diffusion-theory calculations for the beginning- and end-of-cycle configurations. The change in power-density distribution is shown in Figure 16, and the reduction in peakto-average power ratio in going from a batch-loaded to a three-region core can be seen by comparing Figures 14, 15, and 16. The reduction in reactivity from beginning to end of cycle was found to be $5.15 \%$. Figure 17 shows radial-flux distribution at the beginning and end of cycle for the three-region core.

Figure 18 shows the thermal-flux distribution in the large cell (a complete fuel assembly with its associated fuel, cladding, coolant, shroud, and moderator). It is noted that the peak-to-average of importance with regard to fuel-center-temperature calculations is that within the fuel region and is less than the 1.27 shown for the complete cell. This peak-toaverage across the large cell is lower than was anticipated and will result in lower fuel-cycle costs than those shown elsewhere in the report for center-temperature-limited cores.

Figure 19 shows the thermal-flux distribution for the small cell (pellet, clad, and coolant).

\section{Discussion of "Batch" Loading Versus "Three Region" Fuel Loading}

It is recognized that a multizone fuel-loading scheme is required in order to reduce the radial-power peaking factors in the core.and thus obtain an attractive fuel cycle. It is also recognized that it is desirable to obtain a fuel cycle which requires plant shutdown in integral increments of years. Therefore; for an average burnup of 15,000 mwd/short ton $U$ (selected because it appears to be an achievable maximum based on present day technology), a fuel cycle is selected which results in the discharge of one-third of the core per year for an 0.8 plant capacity factor.

In order to simplify the calculations for the parametric study, the "batch" loading calcu- . lational technique described in section $B$ is used, together with the expected three-region 

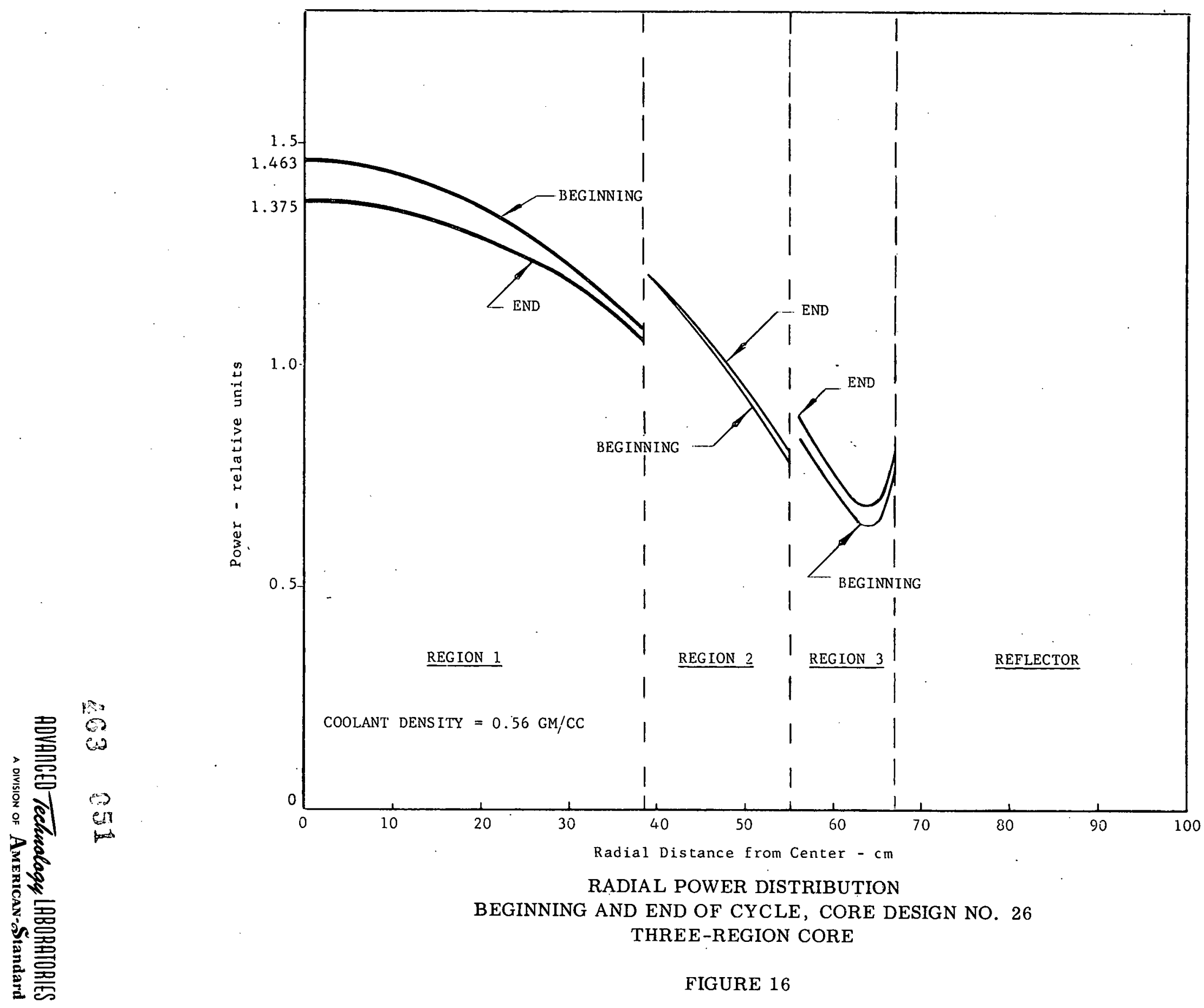

RADIAL POWER DISTRIBUTION

BEGINNING AND END OF CYCLE, CORE DESIGN NO. 26 THREE-REGION CORE 


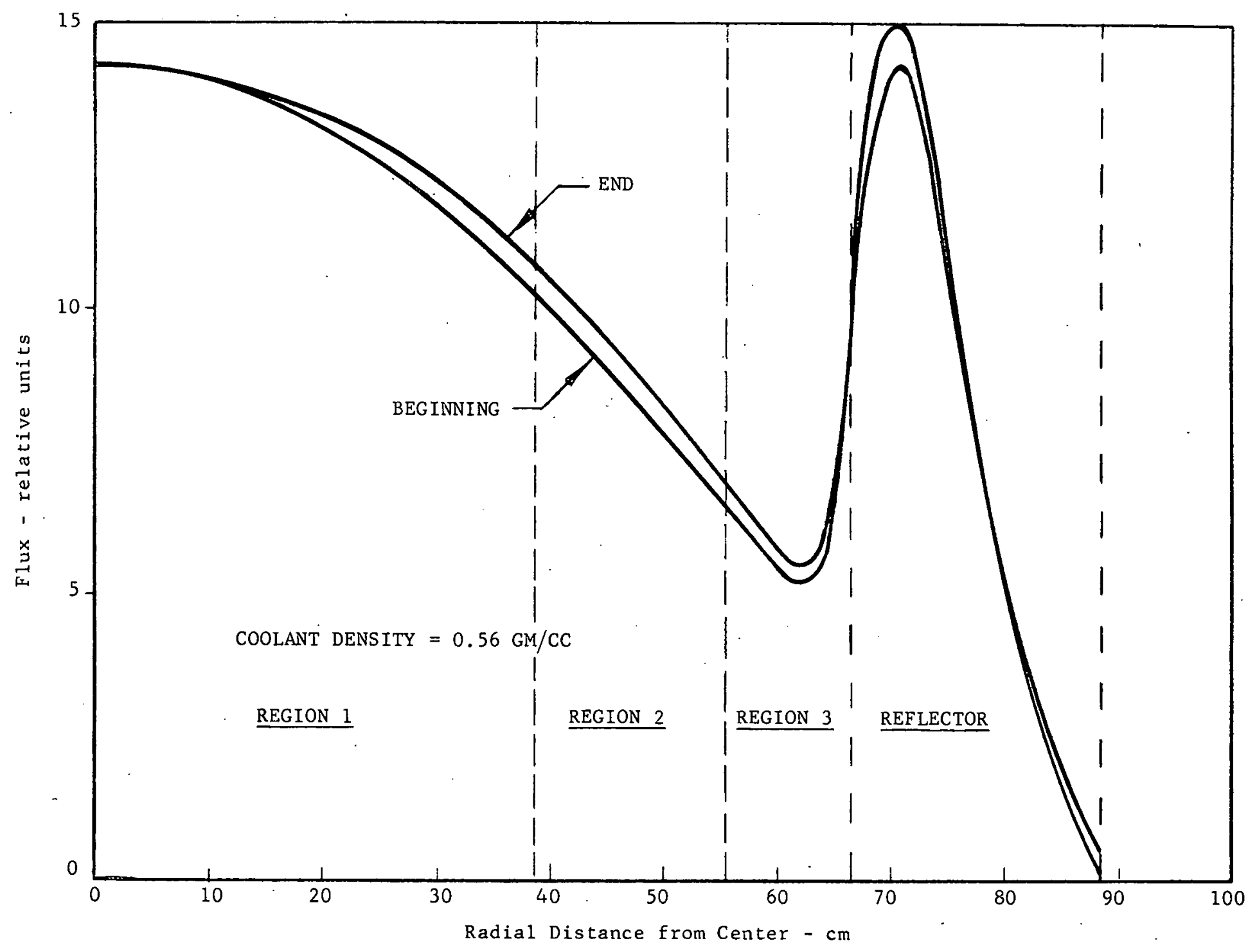

RADIAL FLUX (THERMAL) DISTRIBUTION BEGINNING AND END OF CYCLE, CORE DESIGN NO. 26 THREE-REGION CORE

FIGURE 17 


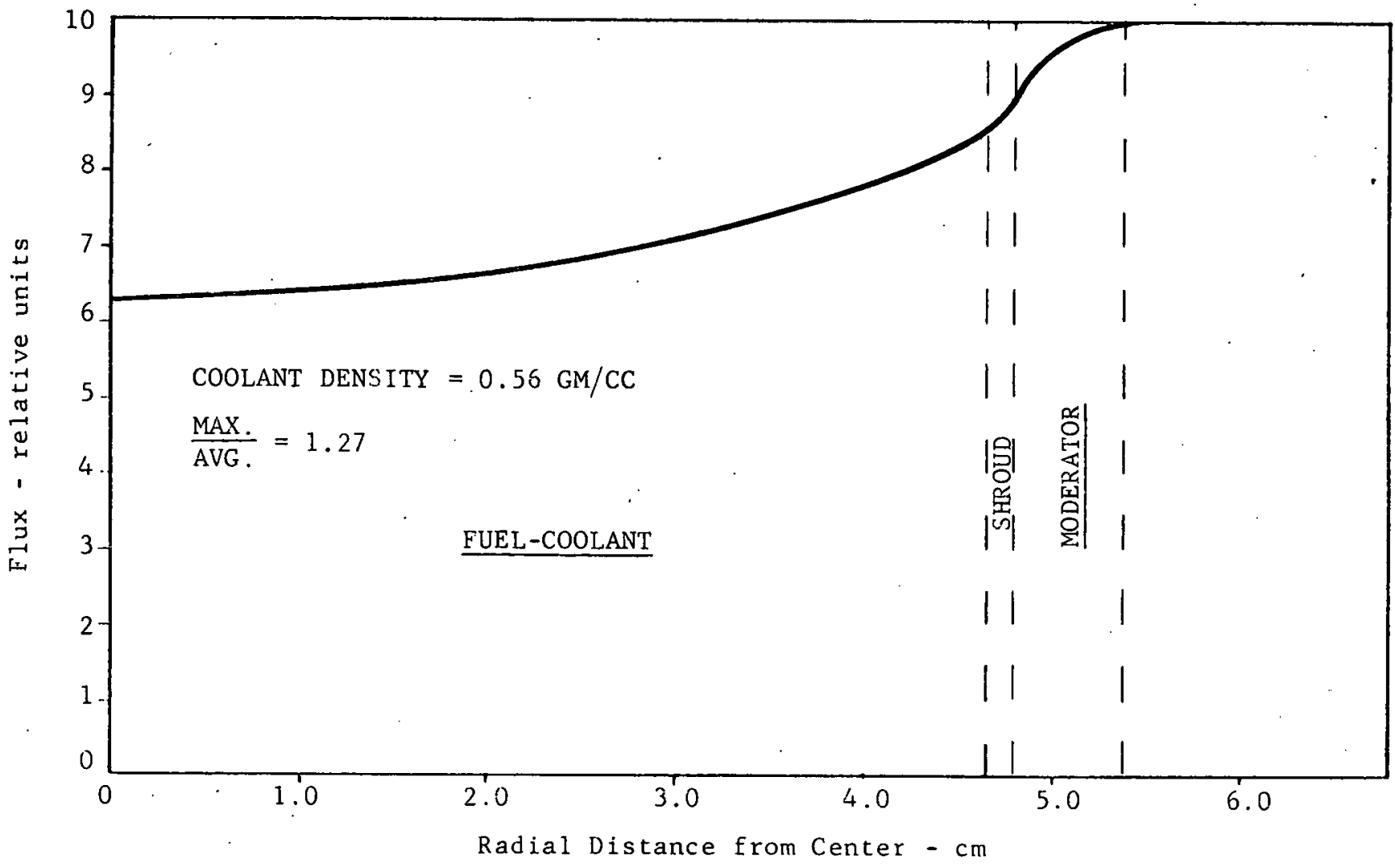

THERMAL FLUX IN THE LARGE CELL CORE DESIGN NO. 26

FIGURE 18 

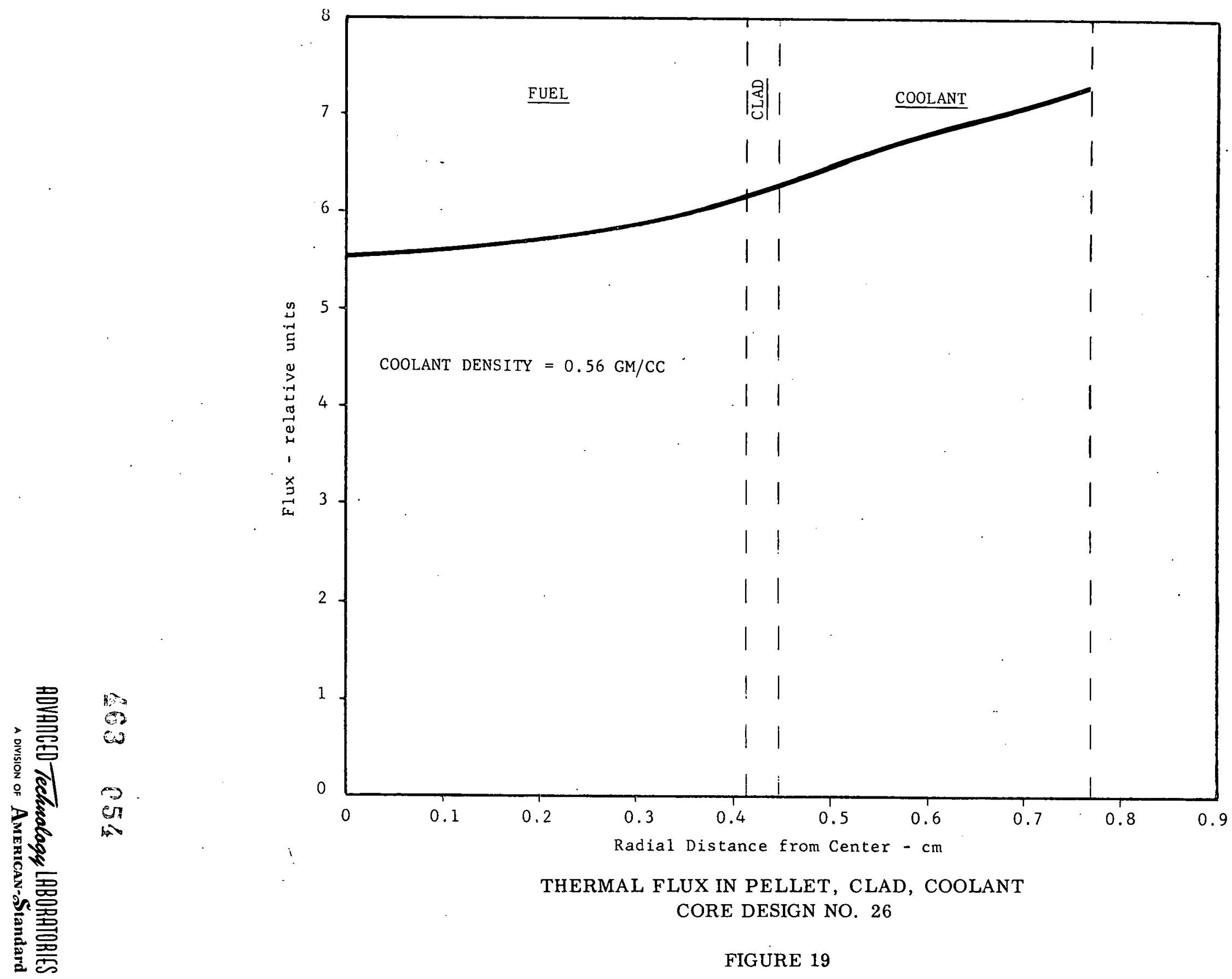

THERMAL FLUX IN PELLET, CLAD, COOLANT CORE DESIGN NO. 26 
peak-to-average power ratios for total-core power determination. For Core-Design No. 26, the more detailed: "three region" calculational technique described in section $\mathbf{C}$ is also used. : From Table.VI in section I. E, the "batch" loading technique results in a fuel-cycle cost of 32.5 cents $/ 10^{6} \mathrm{Btu}$, while the "three region" technique results in a cycle cost of 32.4 cents $/ 10^{6}$ Btu for Core. Deșign No. 26. 


\section{KINETICS}

The reactor kinetics model presented in the last quarterly report ${ }^{12}$ has been represented on an analog computer for both positive and negative void coefficients of reactivity. The results of the analog investigations are shown in Figures 21 through 31 . The reference values of the model parameters are listed in Table VIII, and the flow diagram for the model is shown in Figure 20.

The purpose of this preliminary analog work was to evaluate the relative importance and effect of various system parameters and to determine a control system for stable, loadfollowing reactor operation. Consequently, the general procedure in the analog work was to set all parameters at their reference values and vary, from run to run, only one parameter. Thus, it is to be understood that all parameters have reference values except those specifically mentioned:

Inspection of Figures 29, 30 and 31 reveals that a control system using reactor pressure as the input signal appears to provide stable operation of the model with positive, negative, or zero void coefficients of reactivity.

Kinetics work presently being done is directed toward demonstrating that the kinetics model can be used to predict the measured reactivity feedback transfer function of the EBWR. Preliminary calculations are encouraging in this respect. Subsequent work will be restricted to application of the kinetics model to the VMR reactor design selected for. its economic potential.

12. "Kinetics Model for Boiling,Water Reactors," ATL-226 Preliminary, 29 February 1960 9. Attachment I to Quarterly Progress Report No. 3, ATL-A-107. 
PAGES 35 THROUGH 38 WERE ELIMINATED. 


\section{Nomenclature}

$\mathrm{c}_{\mathrm{p}}$

$\Delta \cdot D$

$\Delta^{n} \mathrm{G}$

$G_{0}$

$\Delta \mathrm{h}$

L

$\mathrm{L}_{\mathrm{p}}$

$\mathrm{m}_{\mathrm{o}}$

$\mathrm{N}$

$P$

$\Delta^{\prime} Q_{c}$

$\Delta^{\prime} Q_{g}$

Q

$\mathbf{R}$

$\Delta \mathrm{R}_{\mathrm{T}}$

$\Delta \mathbf{R}$

$\Delta \mathrm{R}_{\mathrm{L}}$

ro

$\mathbf{s}$

$\mathrm{T}_{\mathrm{f}}$

$\mathrm{T}_{\text {in }}$

$\mathrm{T}_{\text {sat }}$

$\mathrm{T}_{\text {feed }}$

W

$\rho$

$\rho c$

Unit heat capacity of liquid water

Fractional change in steam demand

Fractional change in steam-generation rate

Reference steam-generation rate

Heat of vaporization of water

Moderator level

Length of fuel pin

Mass rate of water entering core

Number of fuel pins in core

Reactor pressure

Fractional change in heat rate to coolant

Fractional change in core heat-generation rate

Steady-state heat-generation rate

Excess multiplication

Change in excess multiplication due to change in fuel temperature

Change in excess multiplication due to change in coolant density

Change in excess multiplication due to change in moderator level

Radius of $\mathrm{UO}_{2}$ fuel pellet

Laplace transform variable

Fuel temperature

Temperature of water entering core

Saturation temperature of water

Temperature of feedwater delivered to reactor.

Mass of water in two-phase region above core

Density of coolant

Heat capacity per unit volume of fụel

$93 \bigcirc 58$ 


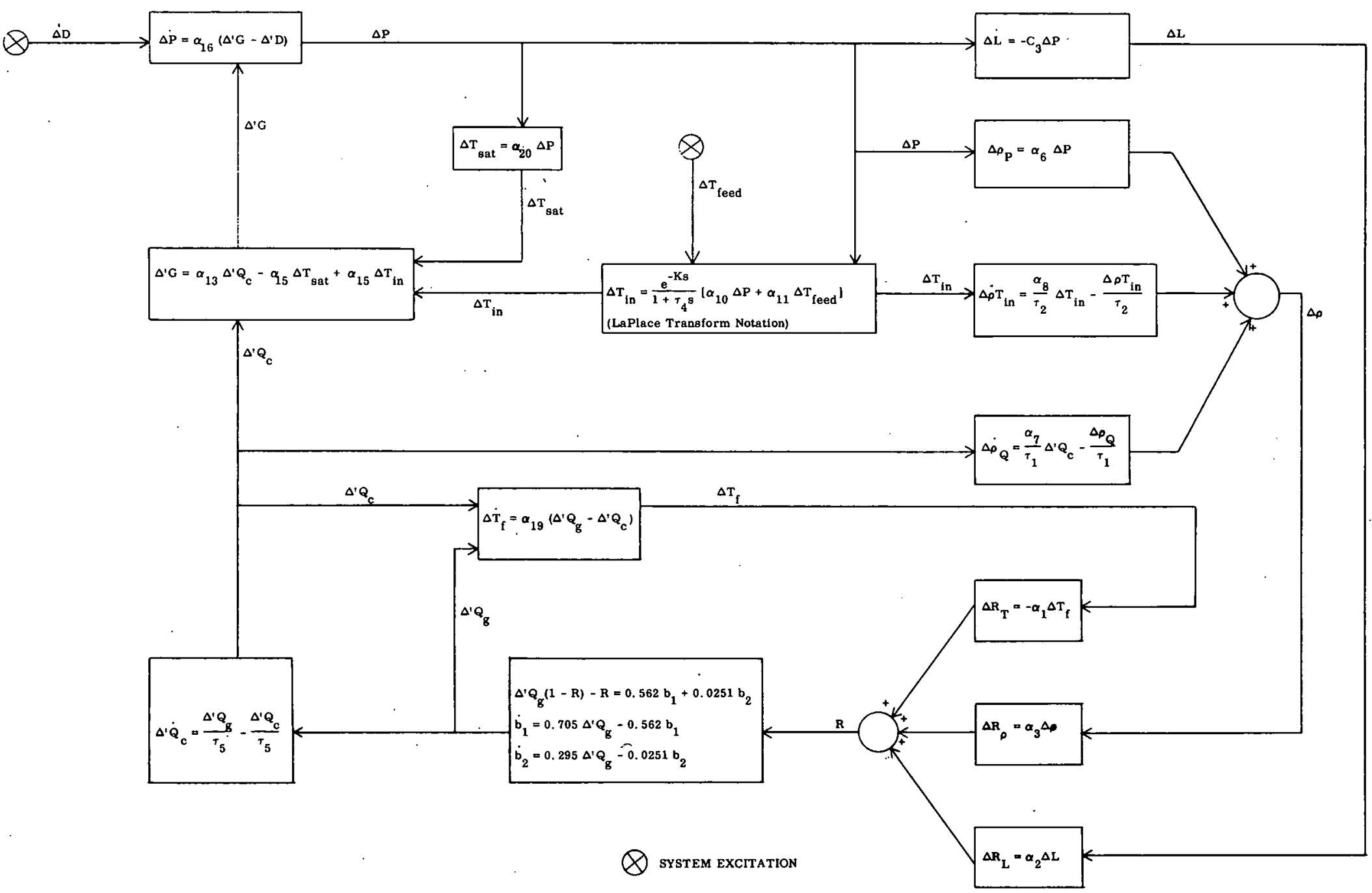

REACTOR KINETICS SYSTEM FLOW DIAGRAM 


\section{TABLE VIII}

DE FINITIONS OF CONSTANTS, FOR FIGURE 20
Constant

$\alpha_{1}$

$\alpha_{2}$

$\alpha_{3}$

$\alpha_{6}$

$\alpha_{7}$

$\alpha_{8}$

$\alpha_{10} \quad\left[1-\frac{\mathrm{G}_{\mathrm{o}}}{\mathrm{m}_{\mathrm{o}}}\right] \frac{\mathrm{dT}_{\text {sat }}}{\mathrm{dP}}$

$\alpha_{11}$

${ }_{13}$

${ }_{15} \frac{c_{p} m_{o}}{\Delta h_{o}}$

$\alpha_{16}=\frac{\Delta \mathrm{hG}_{\mathrm{o}}}{3600 \mathrm{c}_{\mathrm{p}} \mathrm{W}_{\mathrm{o}}\left(\mathrm{dT} \mathrm{dat}_{\mathrm{sat}} / \mathrm{dP}\right)}$

$\alpha$

$\dot{\alpha}_{20} \frac{\mathrm{dT}_{\text {sat }}}{\mathrm{dP}}$

$\tau_{1}^{\prime}$

$\tau_{2}$

$T^{T} 4$

\section{Definition}

$-\partial \mathrm{R} / \partial \mathrm{T}_{\mathrm{f}}$

$\partial \mathrm{R} / \partial \mathrm{L}$

$\partial \mathrm{R} / \partial \rho$

$\partial \rho / \partial \mathrm{P}$

$\partial \rho / \partial \Delta^{r} \cdot Q_{c}$

$\partial \rho / \partial \mathrm{T}_{\text {in }}$

$\mathrm{G}_{\mathrm{O}} / \mathrm{m}_{\mathrm{O}}$

$1+\frac{\mathrm{m}_{\mathrm{o}}}{\mathrm{G}_{\mathrm{o}}} \cdot \frac{\mathrm{c}_{\mathrm{p}}}{\Delta \mathrm{h}}\left(\mathrm{T}_{\mathrm{sat}}-\mathrm{T}_{\mathrm{in}}\right)_{\mathrm{o}}$

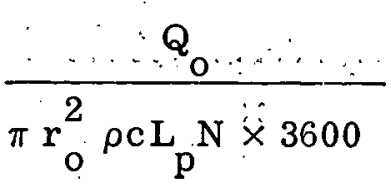

(see eq: 20$)^{*}$

(see eq. 20)*

(see eq. . 43)*
Units

$\$ /{ }^{\circ} \mathrm{F}$

$\$ / \mathrm{ft}$

$\$ / \mathrm{lb} / \mathrm{ft}^{3}$

$\left(1 \mathrm{~b} / \mathrm{ft}^{3}\right) / \mathrm{psi}$

$\mathrm{lb} / \mathrm{ft}^{3}$

$\left(\mathrm{lb} / \mathrm{ft}^{3}\right) /{ }^{\circ} \mathrm{F}$

${ }^{\circ} \mathrm{F} / \mathrm{psi}$

$-$

$--$

$1 /{ }^{\circ} \mathrm{F}$

$\mathrm{psi} / \mathrm{sec}$

${ }^{\circ} \mathrm{F} / \mathrm{sec}$

${ }^{\circ} \mathrm{F} / \mathrm{psi}$

0.1215

$\sec$

$\mathrm{sec}$

sec

31.2

0.4

0.4

3. 0

\section{$\underline{\text { Reference Value }}$}

0.00133

7. 42

$-0.0553$

0.06

$-10$

$-0.45$

0.113

0.07

1. 171

0.0284 
TABLE VIII (concl.)

\begin{tabular}{|c|c|c|c|}
\hline Constant & Definition & $\underline{\text { Units }}$ & Reference Value \\
\hline$\tau_{5}$ & $\zeta_{1}(\text { eq. } 30)^{*}$ & $\mathrm{sec}$ & .9 .5 \\
\hline$\tau_{6}$ & $\zeta_{2}(\text { eq. } 30)^{*}$ & sec & 1.52 \\
\hline $\mathrm{C}_{3}$ & $-(d L / d t) /\left(P-P_{o}\right)$ & $\mathrm{ft} / \mathrm{sec}-\mathrm{psi}$ & $1 \times 10^{-6}$ \\
\hline $\mathrm{K}$ & Downcomer transport delay & $\mathrm{sec}$ & 8 \\
\hline
\end{tabular}

* Reference 12 . 


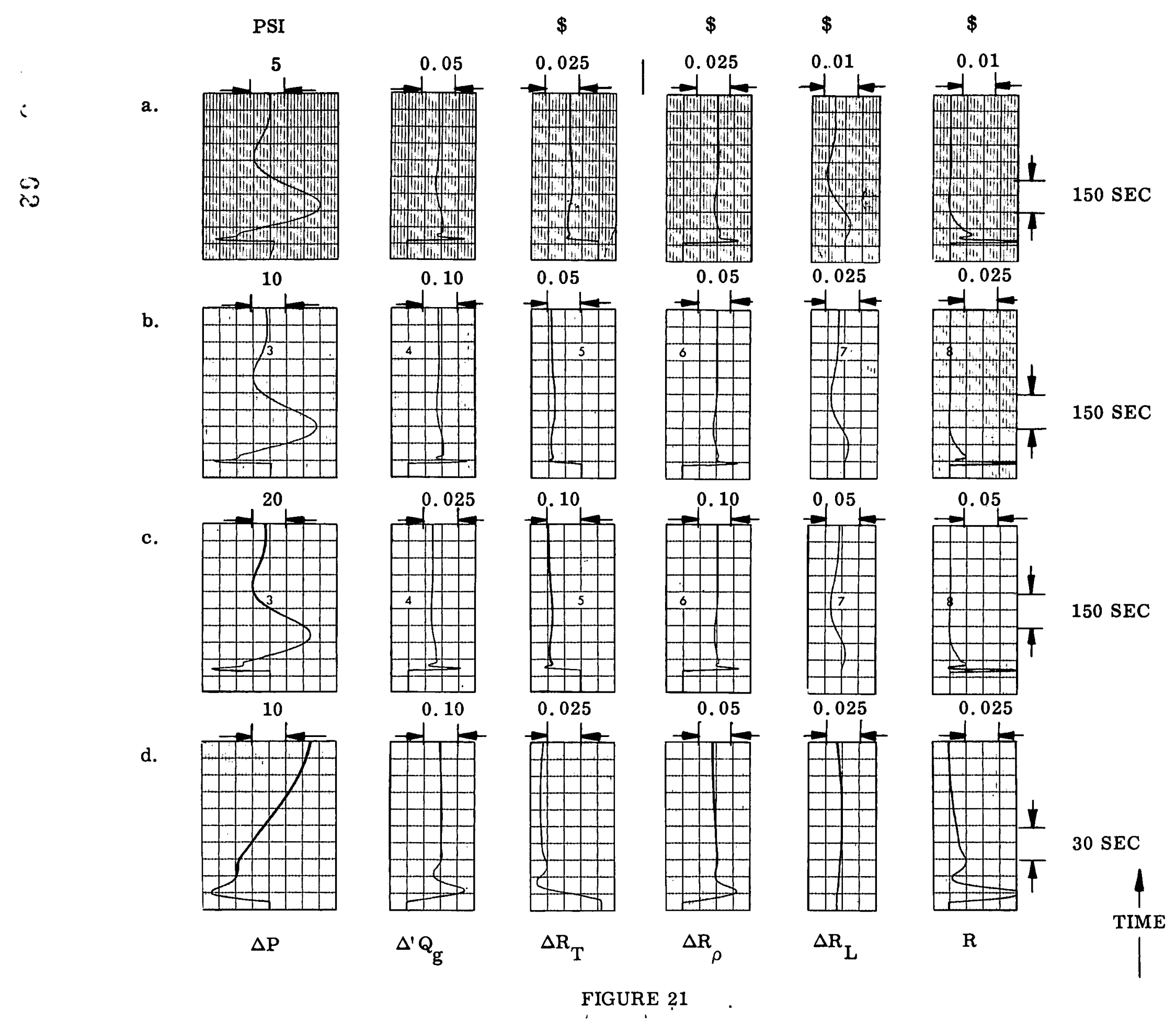


FIGURE 21

(Positive Void Coefficient)

The traces show the response of the system with positive void coefficient to step changes in steam demand. Response to step increases of 5, 10, and 20\% are shown in Figures 21a, $21 \mathrm{~b}$,. and 21c, respectively. . Figures $21 \mathrm{~d}$ and $21 \mathrm{~b}$ are identical except that Figure 21d was obtained using a higher tape speed in order to show the initial response with greater resolution. Figure $21 \mathrm{~b}$ is regarded in the following as a reference curve for the case of a positive void coefficient, because all parameters have their reference values (Table VIII) and because $10 \%$ step increase in steam demand is the excitation used in most of the system investigations.

Examination of Figures 21a, 21b, and 21c shows that the system behaves in an essentially linear manner, inasmuch as the magnitude of the response is proportional to the magnitude of the excitation. This linearity is consistent with the fact that, even with a $20 \%$ step increase in steam demand, the maximum resultant excess multiplication is only: $\$ 0.10$. It is therefore probable that elimination of the product term, $R Q_{g}$, in the nuclear kinetics equations would have little effect on system behavior. Stability and transient behavior.can thus be analytically investigated by linear constant-coefficient methods over the range of system parameters covered in this study. 
$\left.\because \therefore \quad \rightarrow\right|^{20}$

.

is

(iilin 19 in

inititi:

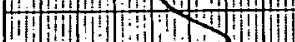

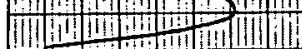

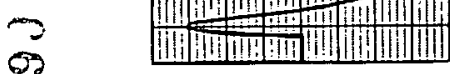

के

b.
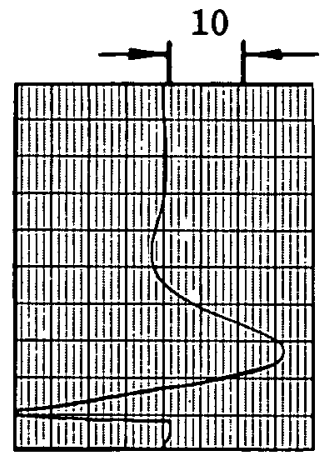

c.

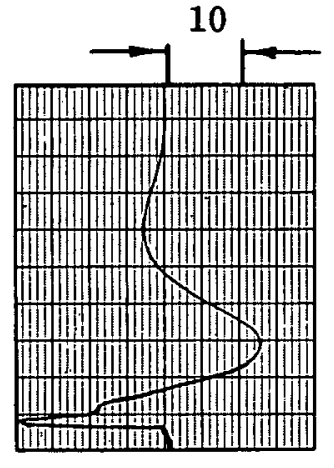

d.

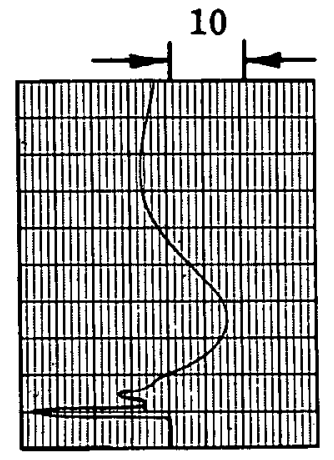

0.10

0.025
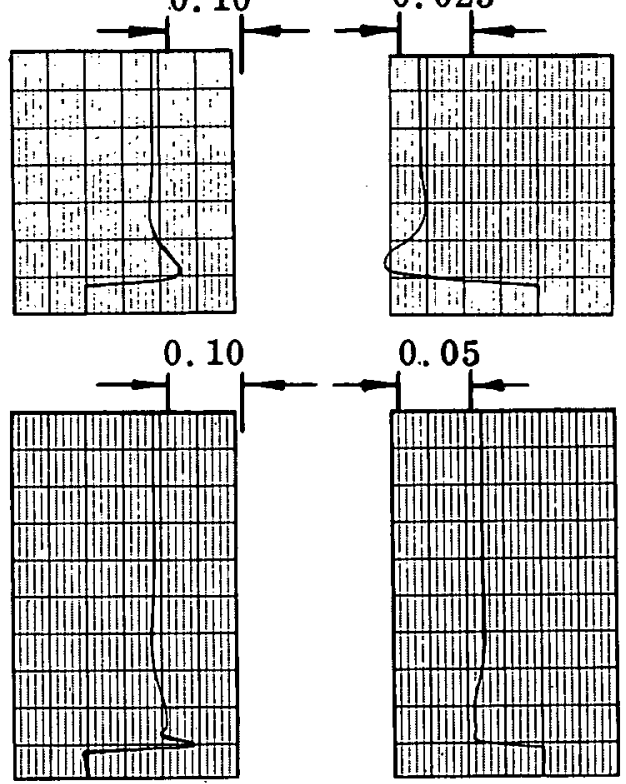

0.10

0.05

$-$

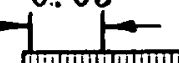

m.

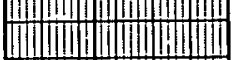

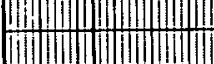

i...... - -

Iili

-

0.05
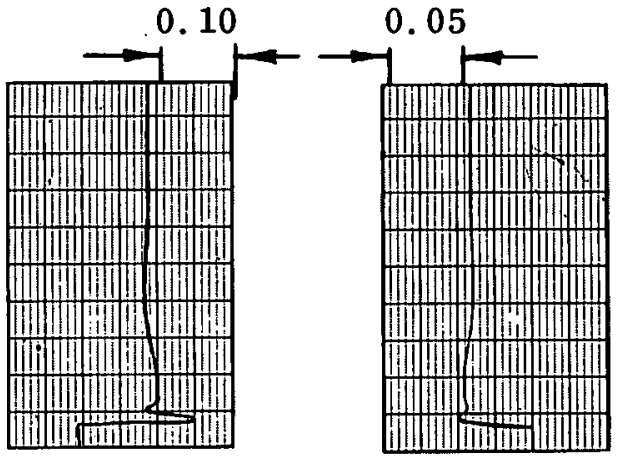

0.10

0.05

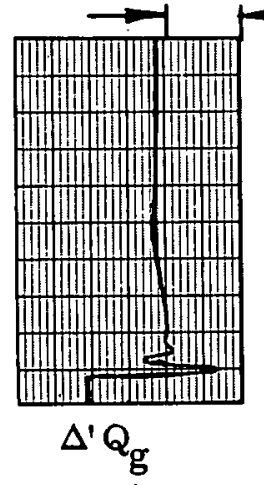

0.05

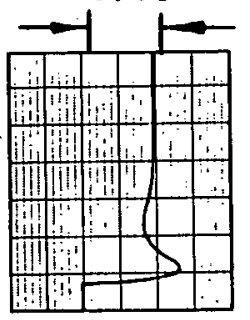

0.05

$\rightarrow-1$ -

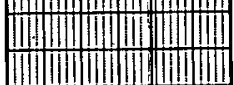

(Ii)

-.

-.......

minumin

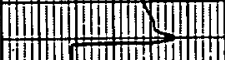

0.05

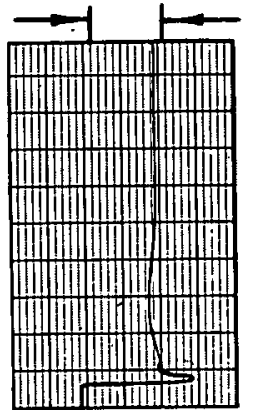

0.05

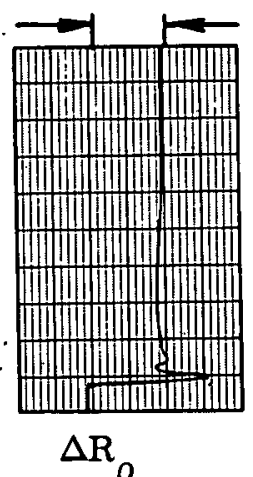

0.01

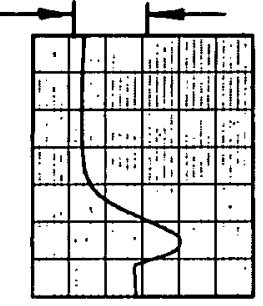

0.025

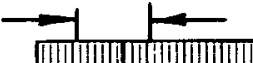

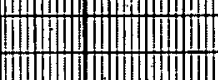

..m.

-1|III

In,

.

-

0.025

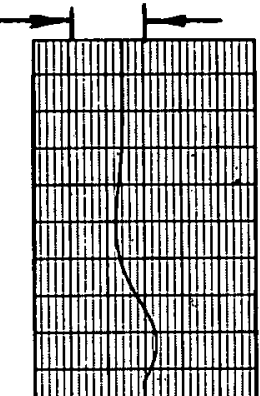

0.025

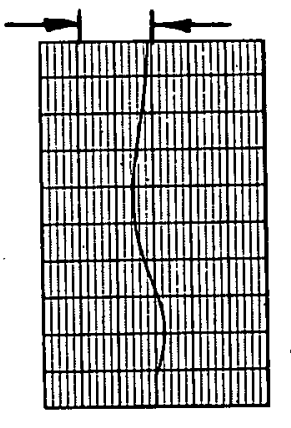

$\Delta \mathrm{R}_{\mathrm{L}}$
0.025

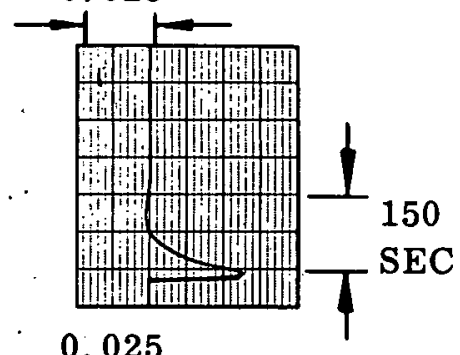

0.025

$\rightarrow$.

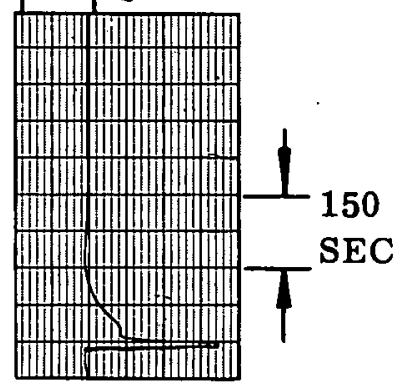

0.025

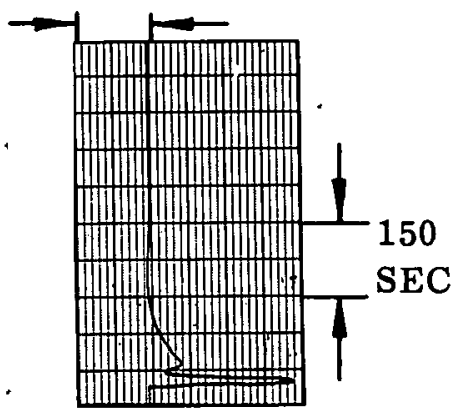

0.025

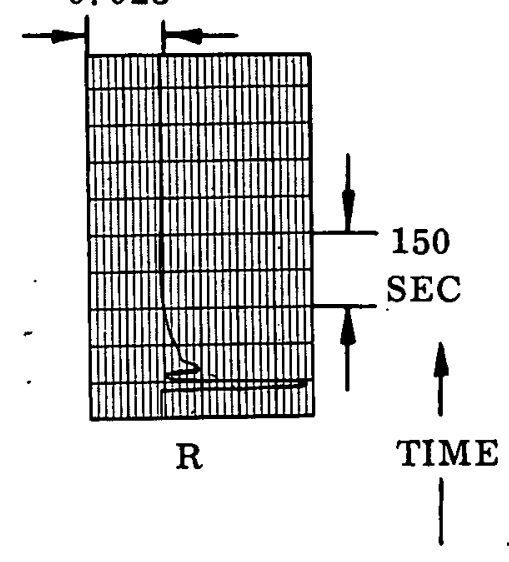

FIGURF 22 
FIGURE 22

(Positive Void Coefficient)

Changes in feedwater temperature, flow rate, reactor pressure, and recirculation ratio produce changes $\left(\mathrm{dT}_{\mathrm{d}}\right)$ in the temperature of the water entering the downcomer (after mixing with the feedwater). The subsequent change, $\mathrm{dT}_{\text {in }}$, in the core inlet-water temperature is equal to $\mathrm{dT}_{\mathrm{d}}$ but is delayed by the transport time associated with flow from the top of the downcomer to the core inlet. The relation between $\mathrm{dT}_{\text {in }}$ and $\mathrm{dT}_{\mathrm{d}}$ has, for the reference model, the form

$$
d T_{\text {in }}=\frac{e^{-K s}}{1+\tau_{4} s} d T_{d}
$$

in which, for the reference case, $\mathrm{K}$ and $\tau_{4}$ are, respectively, 8 and 3 seconds. Figure 22 shows, by comparison with Figure. 21b, the effect of replacing the time delay, $K$, by a simple time constant $\tau_{\mathrm{d}}$. With this substitution, the above equation is altered to the form

$$
\mathrm{dT}_{\text {in }}=\frac{\mathrm{dT}}{\mathrm{d}} \frac{\left.\tau_{4} \mathrm{~s}\right)\left(1+\mathrm{T}_{\mathrm{d}} \mathrm{s}\right)}{(1+\tau}
$$

In Figure $22, \tau_{4}$ has the reference value of 3 seconds, : and $\tau_{d}$ the value of $0,4,8$ and 16 seconds in Figures 22a, 22b, 22c, and 22d, respectively. Comparison of Figures $21 \mathrm{~b}$ and $22 \mathrm{c}$ shows that replacing the 8-second time delay by an 8 -second time constant has little effect on the transient response of the model. 


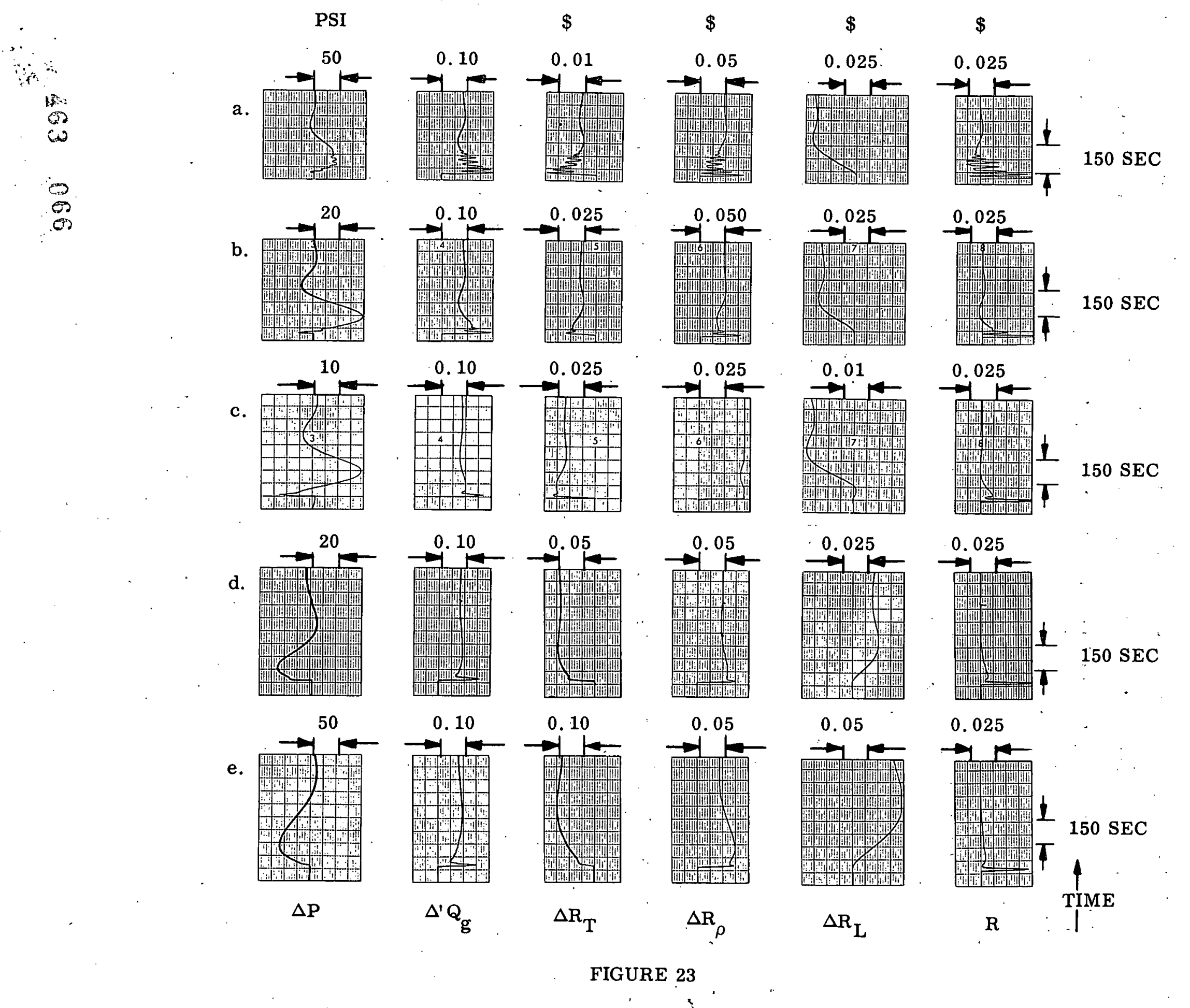


FIGURE 23

(Positive Void Coefficient)

For the reference.case, the fuel-element time response is represented by the relation

$$
\frac{\Delta^{r} Q_{c}}{\Delta^{r} Q_{g}}=\frac{0.922}{1+\tau_{5} s}+\frac{0.078}{1+\tau_{6} s}
$$

in which $\tau_{5}$ and $\tau_{6}$ are, respectively, 9.5 and 1.52 seconds: The effect of replacing this second-order representation of the fuel-element time response by a first-order approximation:

$$
\frac{\Delta^{1} \cdot Q_{C}}{\Delta^{\prime} \cdot Q_{g}}=\frac{1}{1+9.5 s}
$$

can be obtained by comparing Figures $21 \mathrm{~b}$ and $23 \mathrm{c}$. The difference between the two sets of traces is detectable but not large. Figures 23a through $23 e$ show the effect of different (first-order) fuel-element time constants of $2.4,4.8,9.5,19$, and 38 seconds. The fuelelement time constant has a large effect on the temperature change of the fuel in response to a change in steam demand (and thus thermal output of the core). The relation, for a first-order time-constant representation, is given by the equation

$$
\frac{\overline{\mathrm{T}}(\mathrm{s})}{\mathrm{Q}_{\mathrm{g}}(\mathrm{s})}=\frac{1}{\pi \mathrm{r}_{j}^{2} \rho \mathrm{c}}\left(\frac{:^{\tau} 5}{1+\tau_{5} \mathrm{~s}}\right)
$$

(The product $\pi \mathrm{r}_{0}^{2} \rho \mathrm{c}$ is a constant in Figure 23.) Thus; the temperature change, $\overline{\mathrm{T}}$, of the fuel (and therefore the reactivity change) is directly proportional to the time constant. 


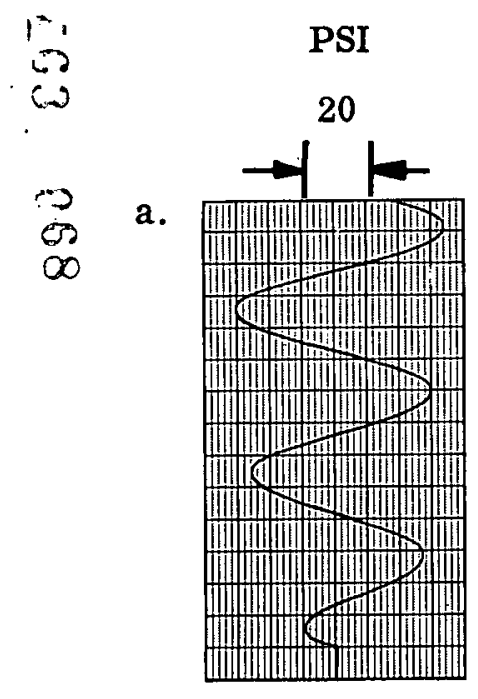

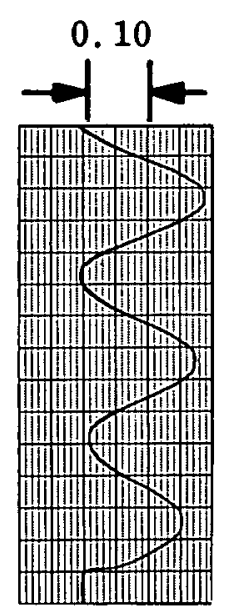

b.

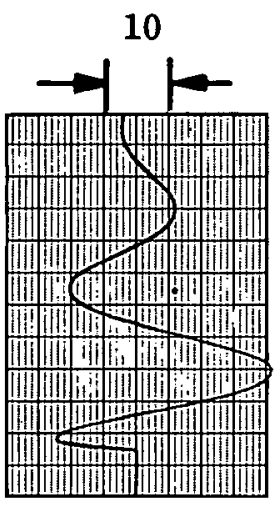

c.

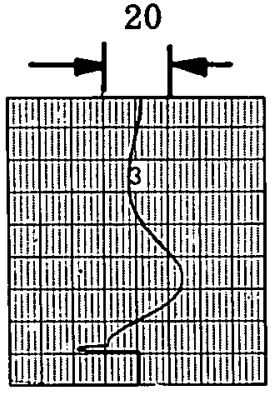

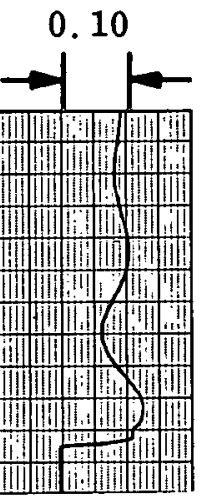

0.10

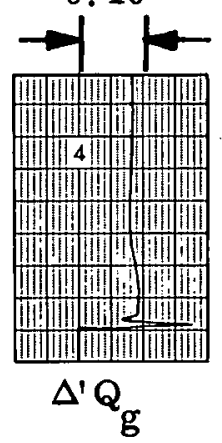

\section{$\$$}

$\$$
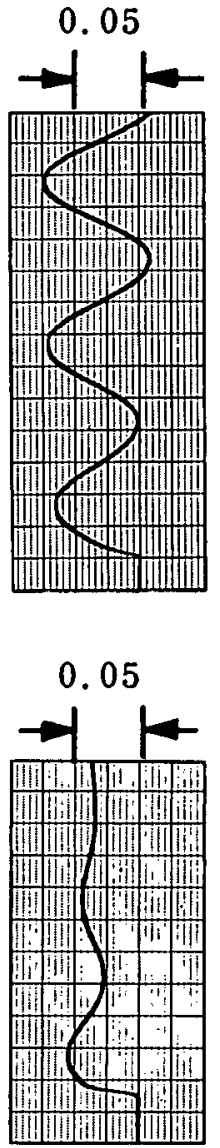

0.05

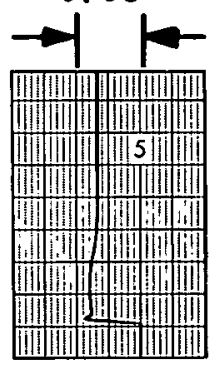

$\Delta \mathbf{R}_{\mathrm{T}}$

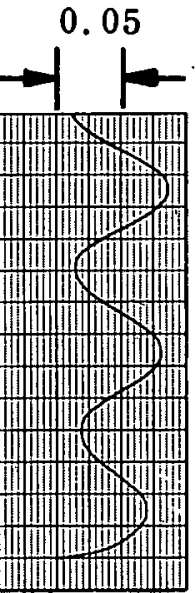

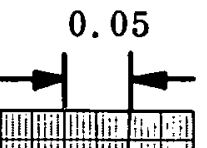

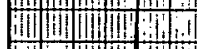

$\rightarrow$

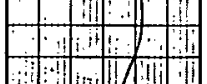

10

(1)

II:IiI III I III

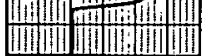

0.05

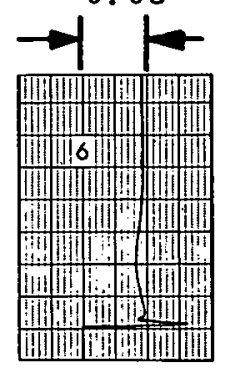

$\Delta \mathrm{R}_{\rho}$
$\$$

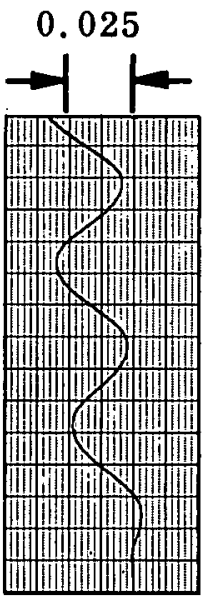

0.025

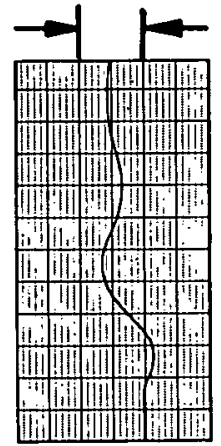

0.025

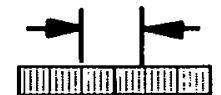

minn.

-nnm

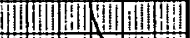

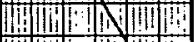

1ii. (1) in. .1.

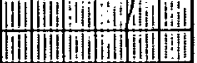

$\Delta \mathrm{R}_{\mathrm{L}}$
$\$$

0.025

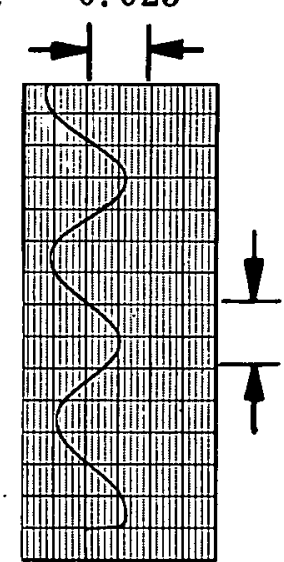

$150 \mathrm{SEC}$

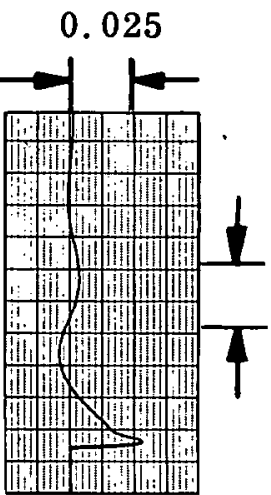

150 SEC

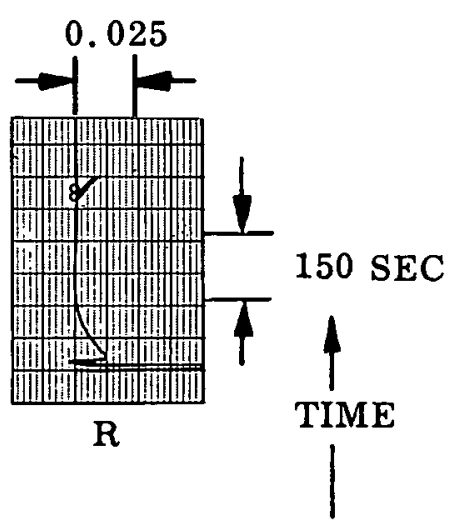

FIGURE 24 
FIGURE 24

(Positive.Void Coefficient)

The rate of change of reactor pressure is related to steam demand and steam generation by the equation

$$
\frac{\mathrm{dP}}{\mathrm{dt}}=\alpha_{16}\left(\Delta^{r} \mathrm{G}-\Delta^{r} \mathrm{D}\right)
$$

For the reference case, $\alpha_{16}$ has the value $46 \mathrm{psi} / \mathrm{sec}$. Figures $24 \mathrm{a}, 24 \mathrm{~b}$, and $24 \mathrm{c}$ show the reactor response to a $10 \%$ step increase in steam demand for values of $\alpha_{16}$ of $5.75,11.5$, and $.92 \mathrm{psi} / \mathrm{sec}$, respectively. It will be observed that a value of $5.75 \mathrm{psi} / \mathrm{sec}$ (Figure 24a) produces unstable operation with the reference control system defined by Figure 20 and Table VIII. No attempt was made to alter control-system gain to produce stable operation with $\alpha_{16}=5.75 \mathrm{psi} / \mathrm{sec}$, since the objective of this analysis is to study the effects of varying parameters on reactor stability, and not to provide stable systems for all possible reactor: designs. The specific reactor designs considered attractive will of course be designed so as to be stable systems. 
$\$$

0.05

b.
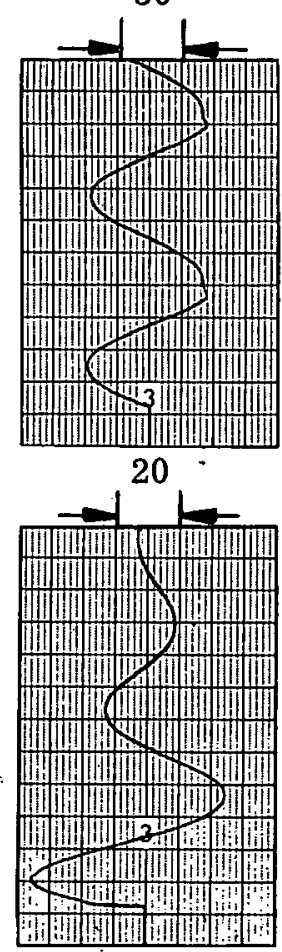

20

c.

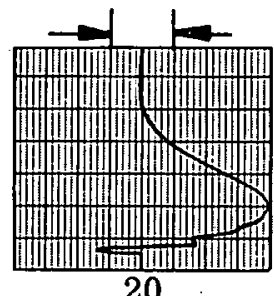

d.

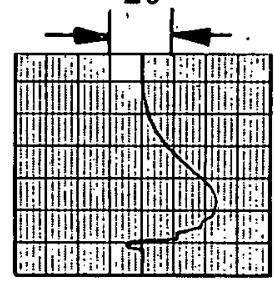

$\Delta \mathrm{P}$

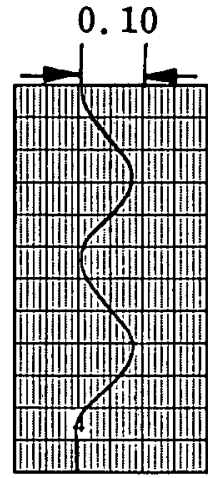

0.1

0.05

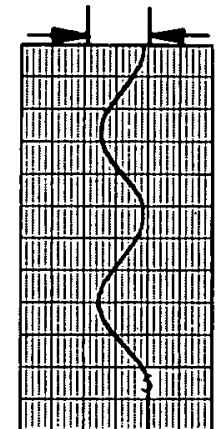

0.05

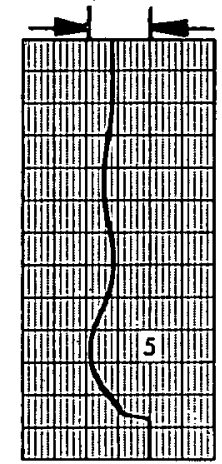

$\Delta^{\prime} \mathrm{Q}_{\mathrm{g}}$
0.05

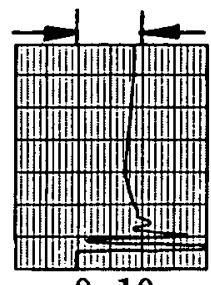

0.10
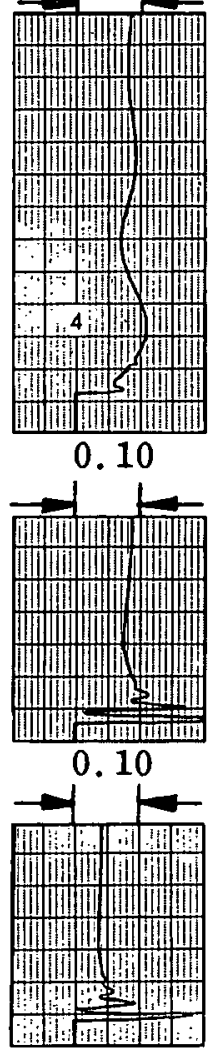

0.10

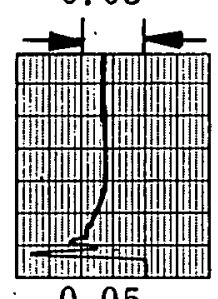

0.05

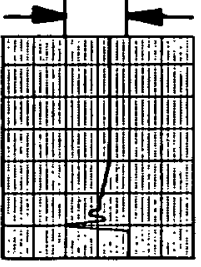

$\Delta \mathrm{R}_{\mathrm{T}}$

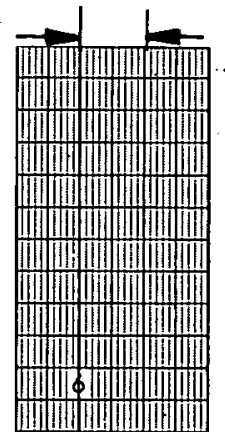

0.05

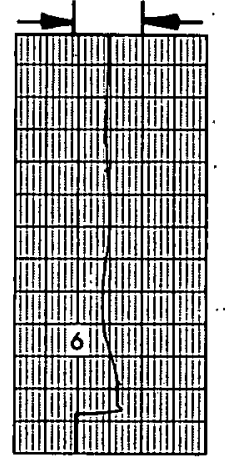

0.05 .

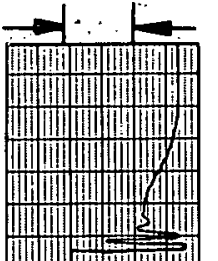

0.05

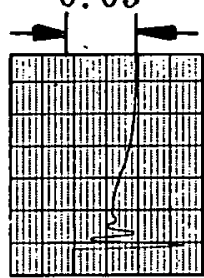

$\Delta \mathrm{R}_{\rho}$
$\$$

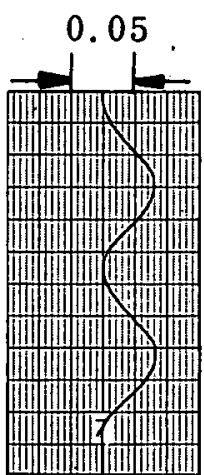

0.025

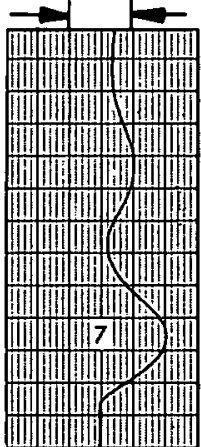

0.05

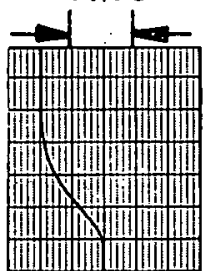

0.05 .

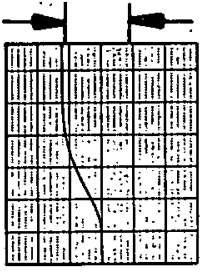

$\dot{\Delta}_{\mathrm{L}}$
$\$$

0.025

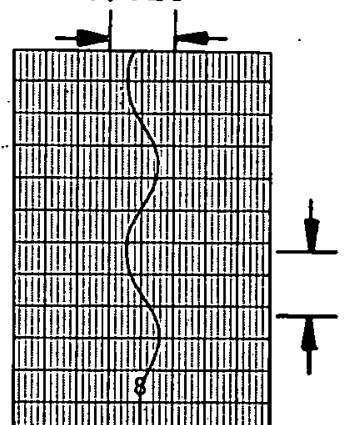

150 SEC

0.025

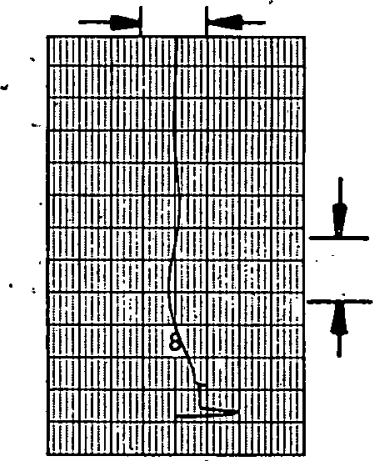

0.025

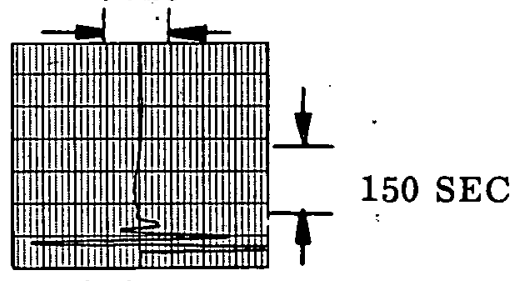

\begin{tabular}{l}
$0 \quad 025$ \\
\hline
\end{tabular}

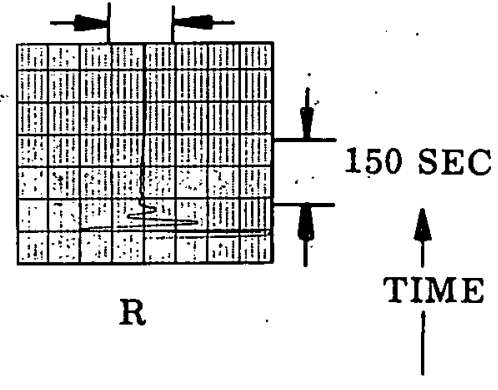

FIGURE 25 
FIGURE 25

(Positive Void Cọfficient)

Figure 25 shows the effect of different values for the positive void coefficient of reactivity. The reference value (cf. Figure $21 \mathrm{~b}$ ) is $-0.0553 . \$ /\left(1 \mathrm{~b} / \mathrm{ft}^{3}\right.$ ). Equivalent values, expressed in different units are, $+0.0244 . \$ /(\%$ voids $)$ and $+0.000156 \Delta \mathrm{k} /(\%$ voids $)$. It will be noted that the absolute magnitude of the positive void coefficient is considerably less than is characteristic for a negative void coefficient, a fact which is believed consistent with the physical limitations encountered in achieving a positive coefficient.

Figures 25a, 25b, 25c, and 25d show system response when the positive void coefficient is $0,1 / 2,1-3 / 4$, and 2 times the reference value. In Figures 25a and 25d, the system excitation is a $5 \%$ step increase in steam demand rather than the "reference" value of $10 \%$. For the case of a zero void coefficient (Figure 25a), the system is neutrally stable. For a negative void coefficient the model, with the reference control system, is unstable. Again, for the same reasons outlined in. Figure 24 , no attempt was made to obtain a stable model with the reference control system and the negative void curve. 

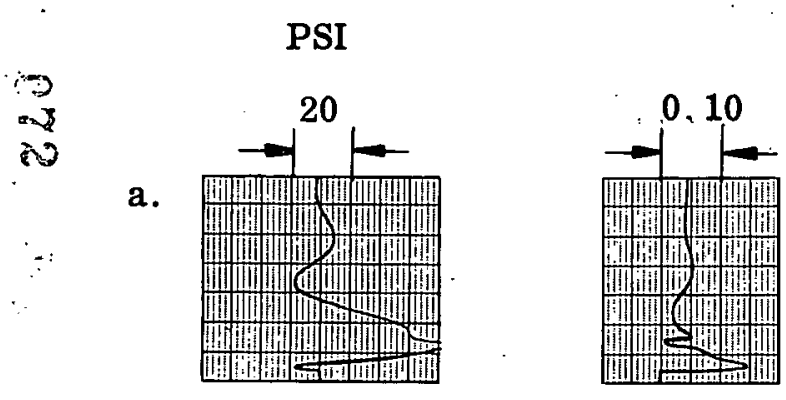

0.10

b.
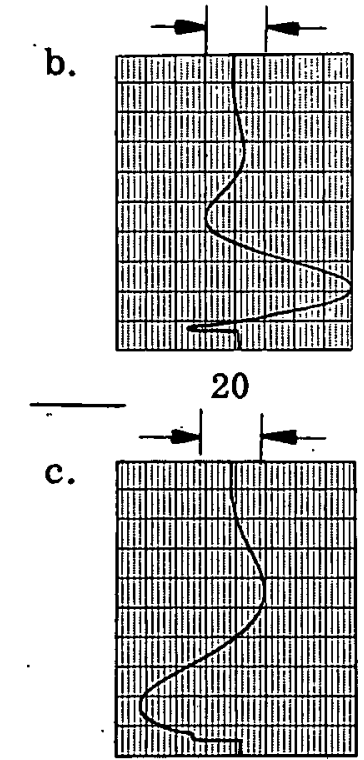

d.
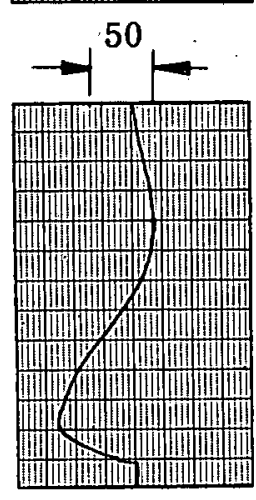

$\Delta \mathrm{P}$

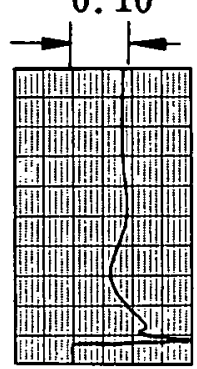

0.1

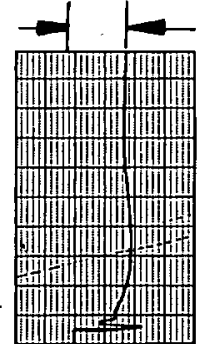

0.10

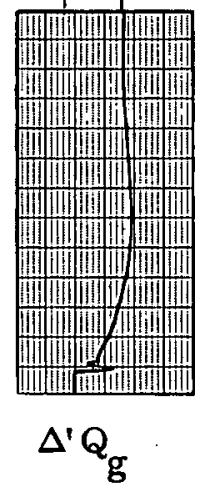

$\$$

$\$$

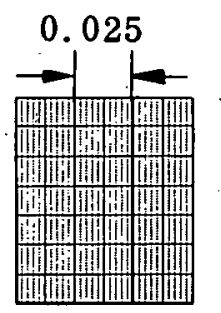

0.025

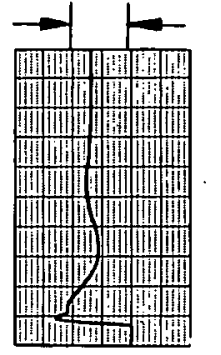

0.05

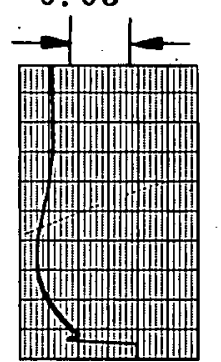

0.10

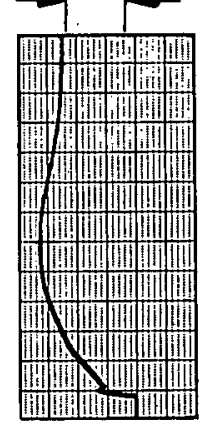

$\Delta \mathrm{R}_{\mathrm{T}}$

0.05

$\Delta \mathrm{R}_{\rho}$
$0.025 \quad 0.025$
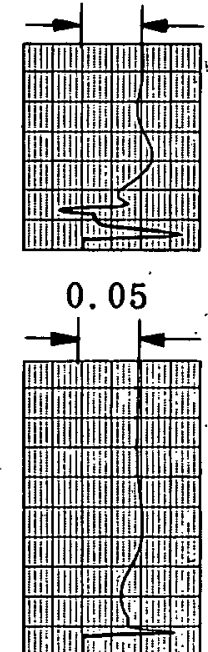

0.05 .
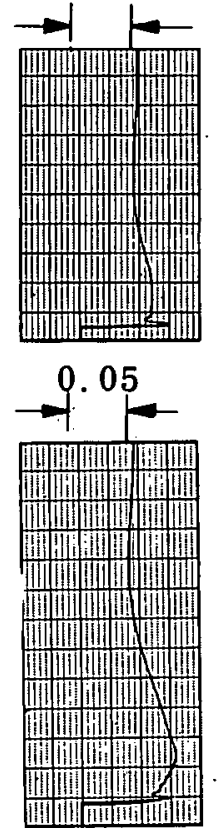

$\rightarrow-0$

(1)

(1)

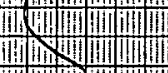

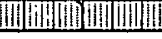

0.05

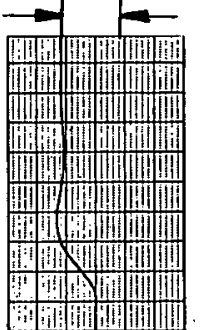

0.05

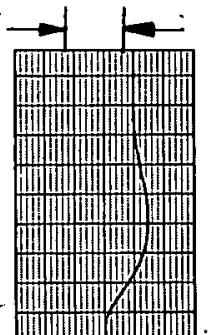

0.10

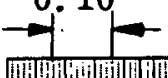

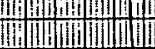

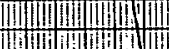

II.

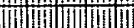

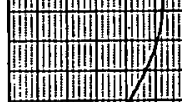

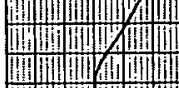

$\Delta R$
0.025

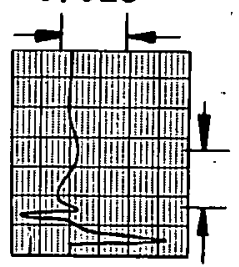

150 SEC 0.025

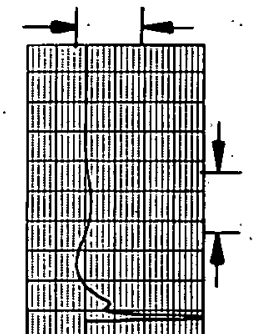

$150 \mathrm{SEC}$

$$
0.025
$$

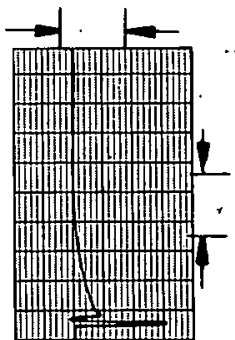

$150 \mathrm{SEC}$
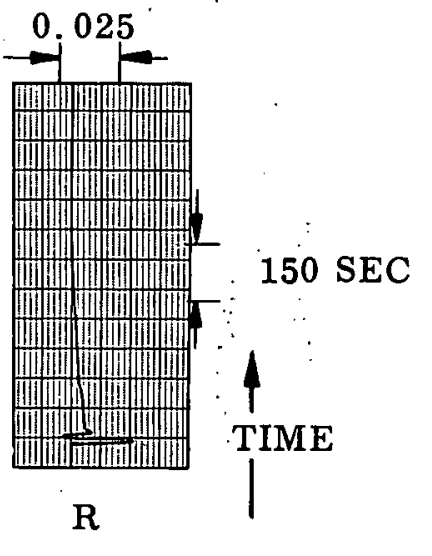
FIGURE 26

(Positive Void Coefficient)

The reference.value of the fuel temperature coefficient of reactivity $\left(\alpha_{1}\right)$ is -0.00133 $\$ /^{\circ} \mathrm{F}$ or $-0.85 \times 10^{-5} \Delta \mathrm{k} /{ }^{\circ} \mathrm{F}\left(-1.5 \times 10^{-5} \Delta \mathrm{k} /{ }^{\circ} \mathrm{C}\right)$. Figures $26 \mathrm{a}, 26 \mathrm{~b}, 26 \mathrm{c}$, and $26 \mathrm{~d}$ show the system response when the coefficient is $0,1 / 2,2$, and 4 times the reference value. It will be noted that Figure $26 \mathrm{a}\left(\alpha_{1}=0\right)$ shows the response to a $5 \%$ step increase in steam demand. For the higher values of the coefficient, the reactivity decrease due to the increase in fuel temperature is larger than the reactivity increase due to the increased voids. The moderator level consequently increases with an increase in steam demand. 

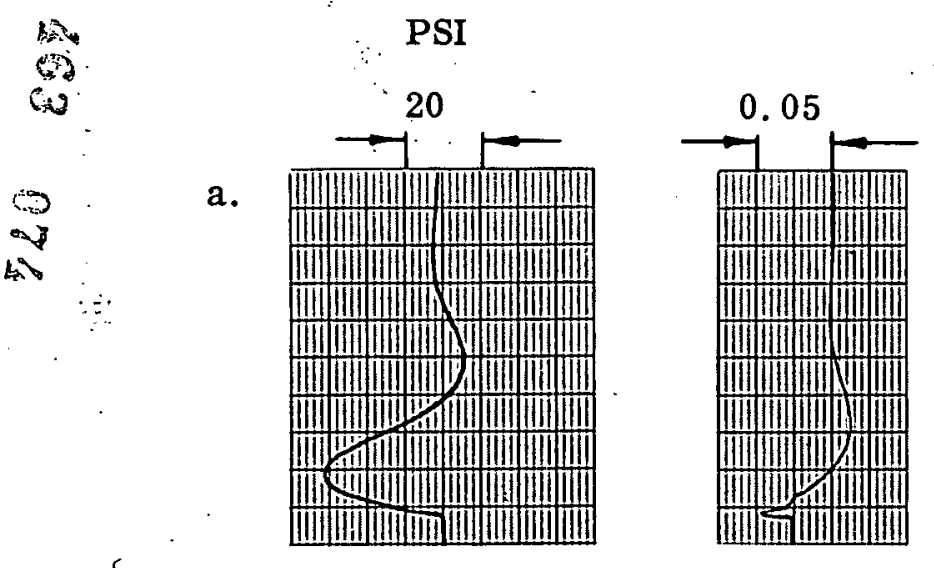

$\$$

$\$$

$\$$

$\$$

0.01

0.01
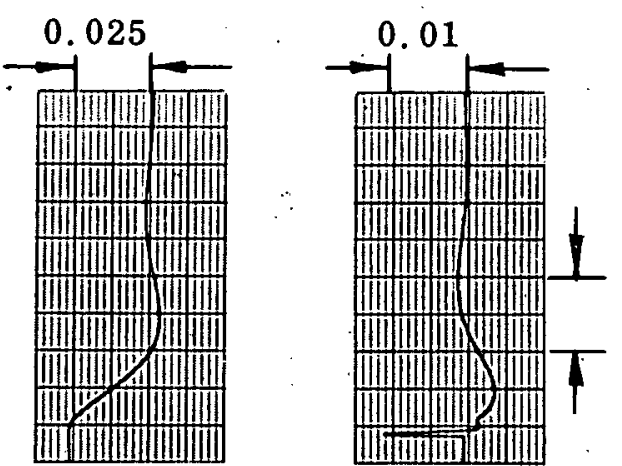

$150 \mathrm{SEC}$

b.
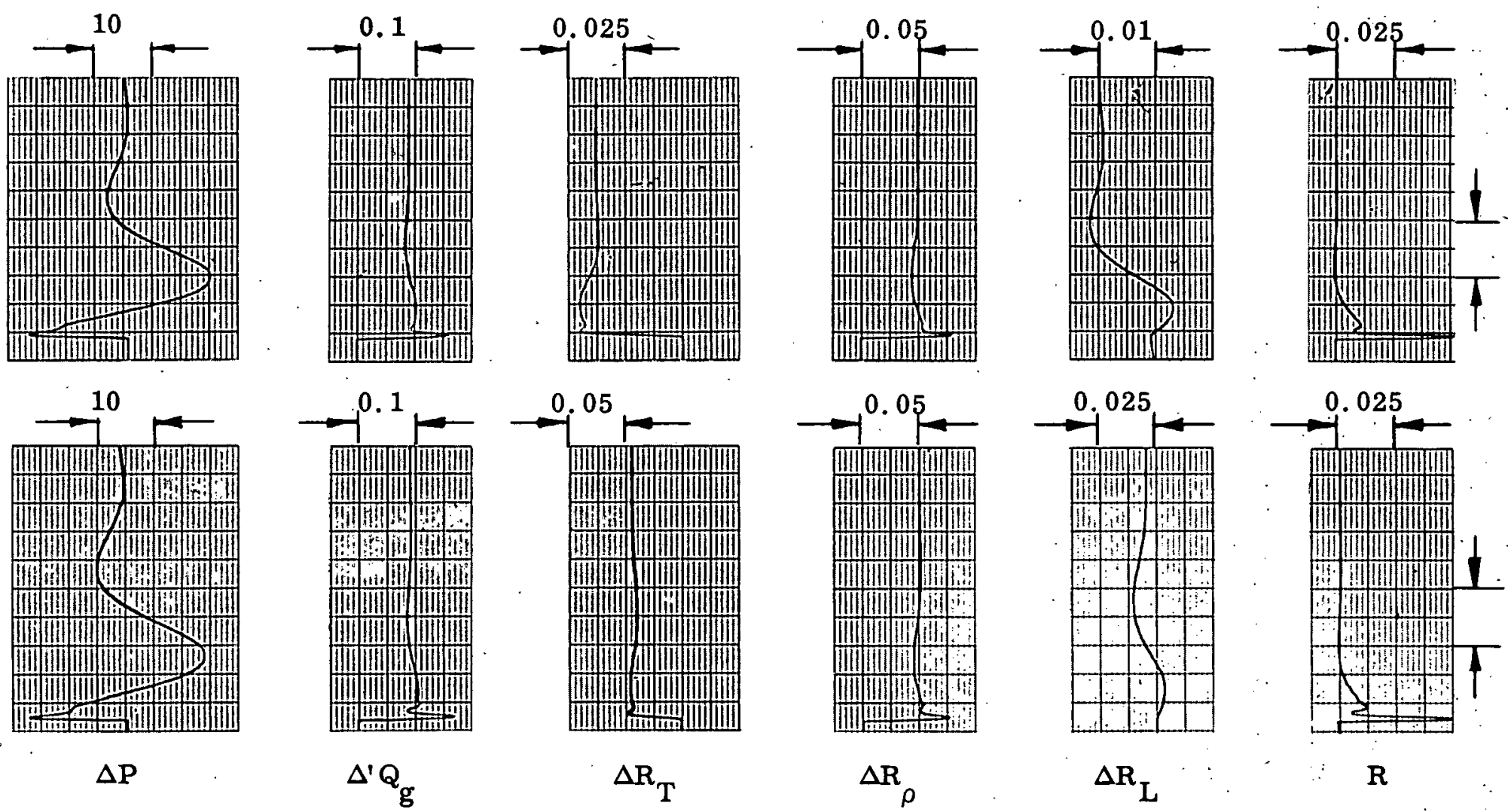

$\Delta^{\prime} Q_{g}$

$\Delta \mathbf{R}_{\rho}$

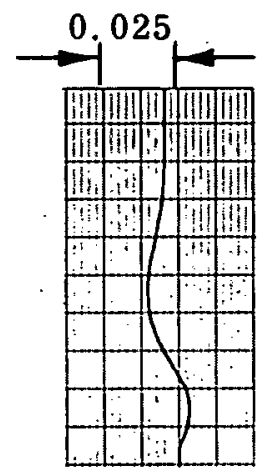

$\Delta \mathrm{R}_{\mathrm{L}}$

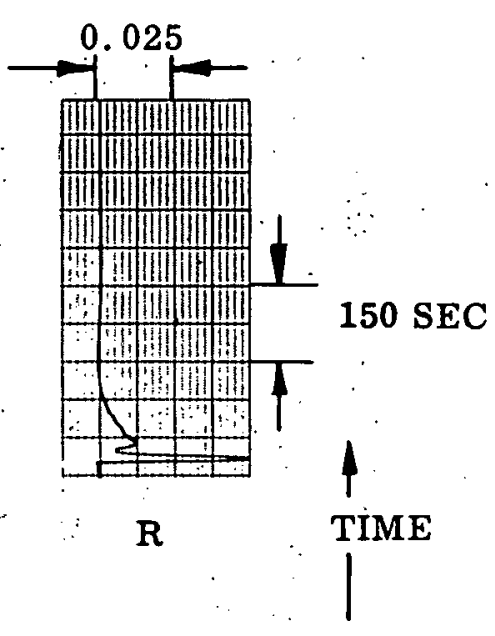

FIGURE 27 


\section{FIGURE 27}

(Positive Void Coefficient)

Figure 27a shows the transient response of the model to a step decrease in reactor feedwater temperature of $15^{\circ} \mathrm{F}$. Steam demand is constant.

As. shown in the discussion of Figure 22 , the relation between a change, $\mathrm{dT}_{\mathrm{d}}$, in downcomer water temperature and the subsequent change in core inlet temperature is given by the relation

$$
\mathrm{dT}_{\text {in }}=\frac{\mathrm{e}^{-\mathrm{Ks}}}{1+\tau_{4} \mathrm{~s}} \cdot \mathrm{dT} \mathrm{d}
$$

in which, for the reference.case, $\mathrm{K}=8 \mathrm{sec}$ and $\tau_{4}=3 \mathrm{sec}$. Figure $27 \mathrm{~b}$ shows the system response to a $10 \%$ step increase in steam demand when $\tau_{4}$ is $1-1 / 2$ seconds. Comparison with Figure $21 \mathrm{~b}$ shows that there is little effect due to this change in the time constant.

Following step changes in heat input rate to the coolant and in coolant inlet temperature to the core, the subsequent changes in coolant density follow with time constants $\tau_{1}$ and $\tau_{2}$. For the reference case, $\tau_{1}$ and $\tau_{2}$ are equal and have the value 0.4 second. Figure $27 \mathrm{c}$ shows the system response when $\tau_{1}=\tau_{2}=1.6 \mathrm{sec}$. Comparison of Figures $27 \mathrm{c}$ and $21 \mathrm{~b}$ reveals no detectable effect due to this change in the two time constants. 

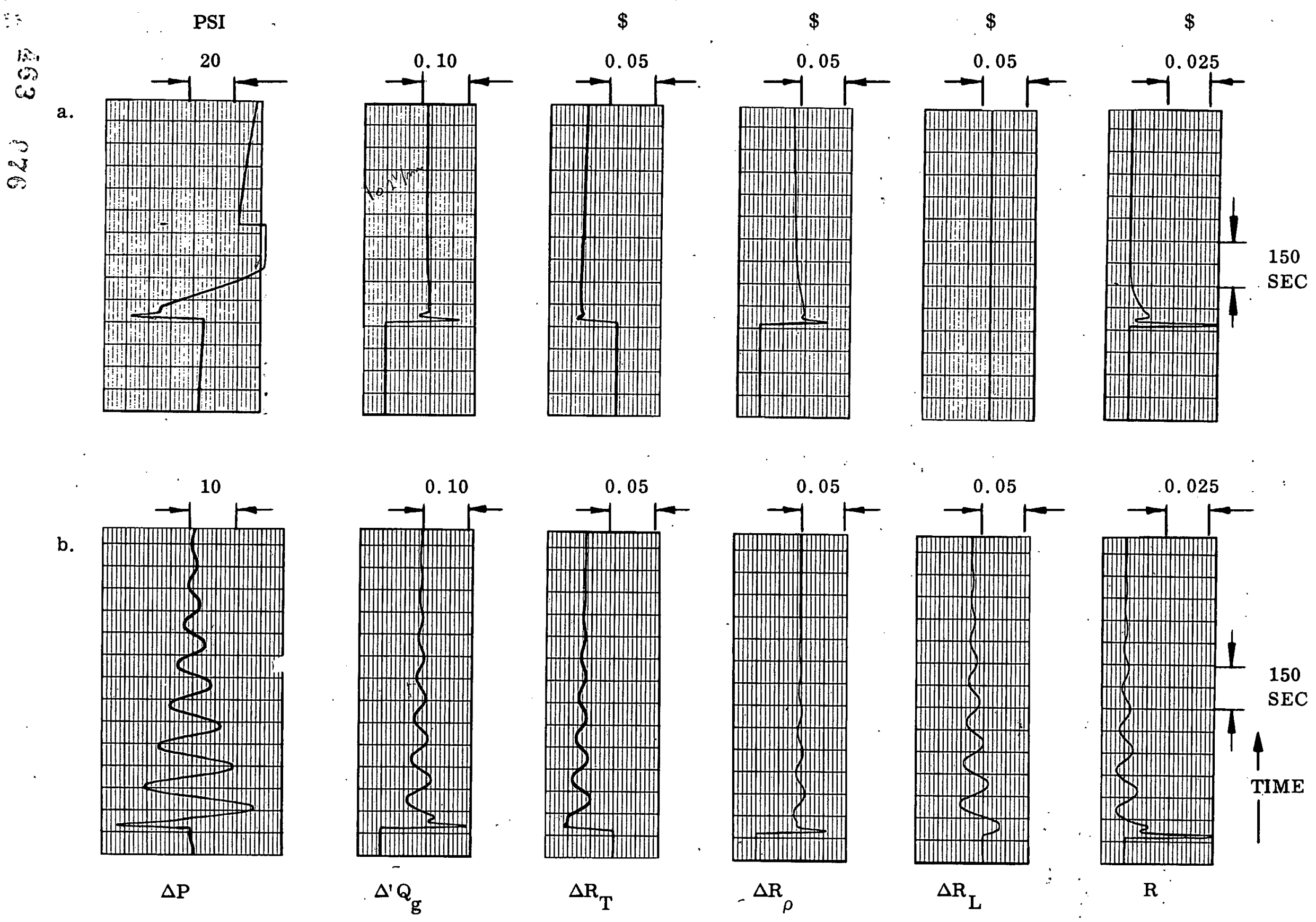

FIGURE 28 
FIGURE 28

(Poșitive Void Coefficient)

Control of the reference model is effected by making the rate of change of moderator level proportional to the departure of the pressure from a set pressure, $P_{0}$ :

$$
\frac{\mathrm{dL}}{\mathrm{dt}}=\mathrm{C}_{3}\left(\mathrm{P}-\mathrm{P}_{0}\right)
$$

Noting that $\partial \mathrm{R} / \partial \mathrm{L}=-\alpha_{2}$, the reactivity change due to changes in moderator level is given by

$$
\frac{{ }^{d R}}{d t}=-C_{3} \alpha_{2}\left(P-P_{o}\right),
$$

in which, for the reference conditions, $\mathrm{C}_{3}=10^{-6}$ and $\alpha_{2}=7.42 \$ / \mathrm{ft}$, giving $\mathrm{C}_{3} \alpha_{2}=7.42 \times 10^{-6}$ $\$ /$ sec-psi. Figures $28 \mathrm{a}$ and $28 \mathrm{~b}$ show model behavior when $\mathrm{C}_{3} \alpha_{2}$. is 0 and 10 times the reference value. For the case of no control $\left(C_{3}=0\right)$, it will be observed that the pressure continues to increase following a $10 \%$ increase in steam demand. The rate of pressure increase: after the initial transient is low, being less than $0.2 \mathrm{psi} / \mathrm{sec}$. 
$\infty$
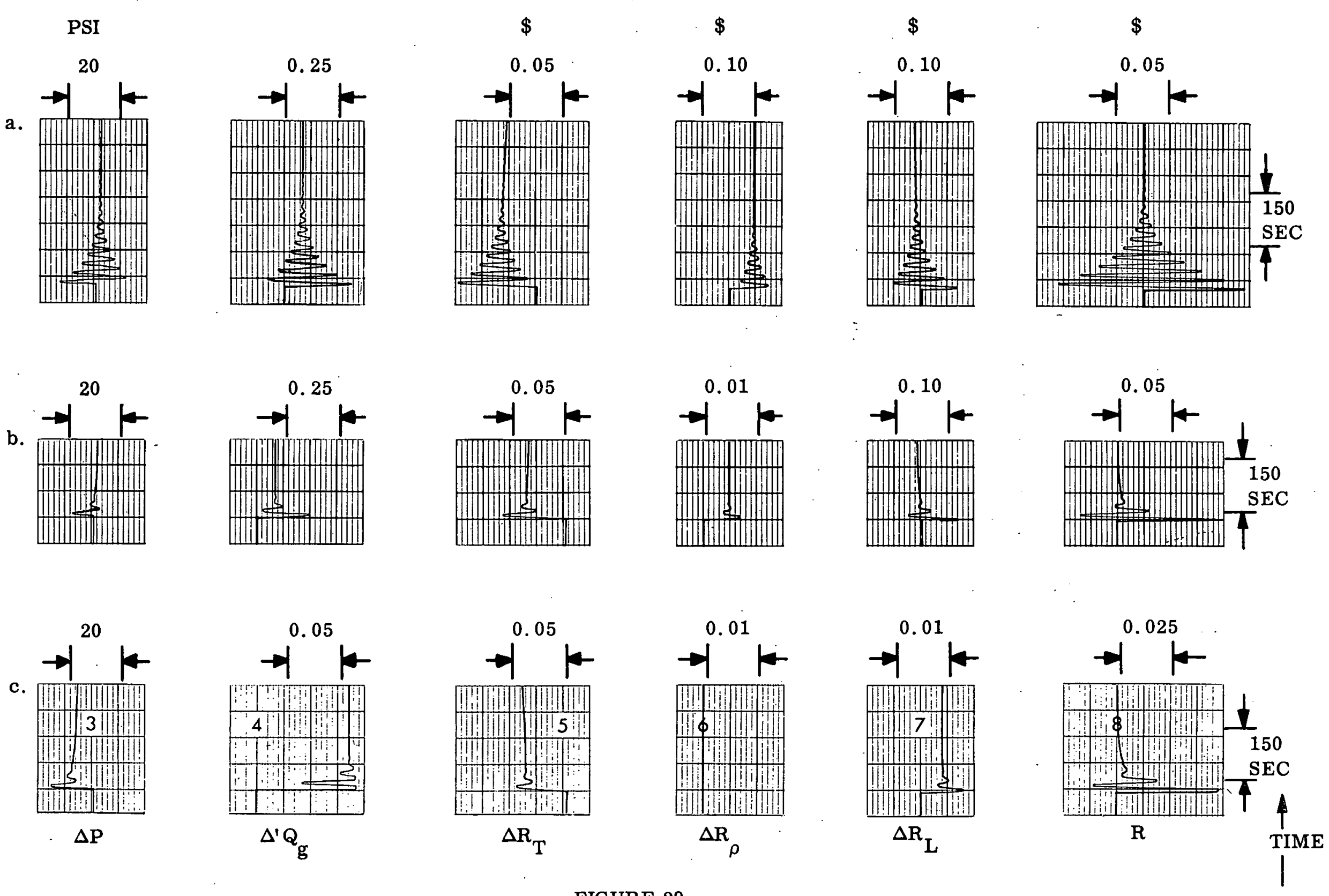
FIGURE 29

(Positive Void Coefficient)

The reference.control system was replaced with a control system described by: the following equation:

$$
\mathrm{d}_{2} \Delta \dot{\mathrm{P}}+\mathrm{d}_{3} \Delta \mathrm{P}+\mathrm{d}_{4} \int \Delta \mathrm{Pdt}=-\Delta \mathrm{R}_{\mathrm{L}}:
$$

With $d_{2}$ and $d_{3}$ set to zero, it will be noted that the original reference control system is obtained. The selected refe rence values of the coefficients are $d_{2}=0.125 . \$ /(\mathrm{psi} / \mathrm{sec})$, $\mathrm{d}_{3}=0.005 \$ / \mathrm{psi}$, and $\mathrm{d}_{.4}=7.42 \times 10^{-6} \$ / \mathrm{psi}-\mathrm{sec}$.

Figure 29a shows model response to a $10 \%$ increase in steam demand with $d_{2}=0$ and with $d_{3}$ and $d_{4}$ at reference values. Figure $29 \mathrm{~b}$ shows the same response but with $\mathrm{d}_{2}$ (as well as $\mathrm{d}_{3}$ and $\mathrm{d}_{4}$ ) at reference values. The large damping effect attributable to the pressurederivative control (i.e., to $\mathrm{d}_{2}$ ) is notable." Figure $29 \mathrm{c}$ shows model response with a void coefficient of zero $\left(\alpha_{3}=0\right)$ and $d_{2}=0$. By comparison with Figure 25a, it will be seen that addition of the $d_{3}$ term in the control equation permits stable operation with a zero void coefficent. Figures 30 and 31 show that the revised control system also permits stable operation with a negative void coefficient of reactivity. 


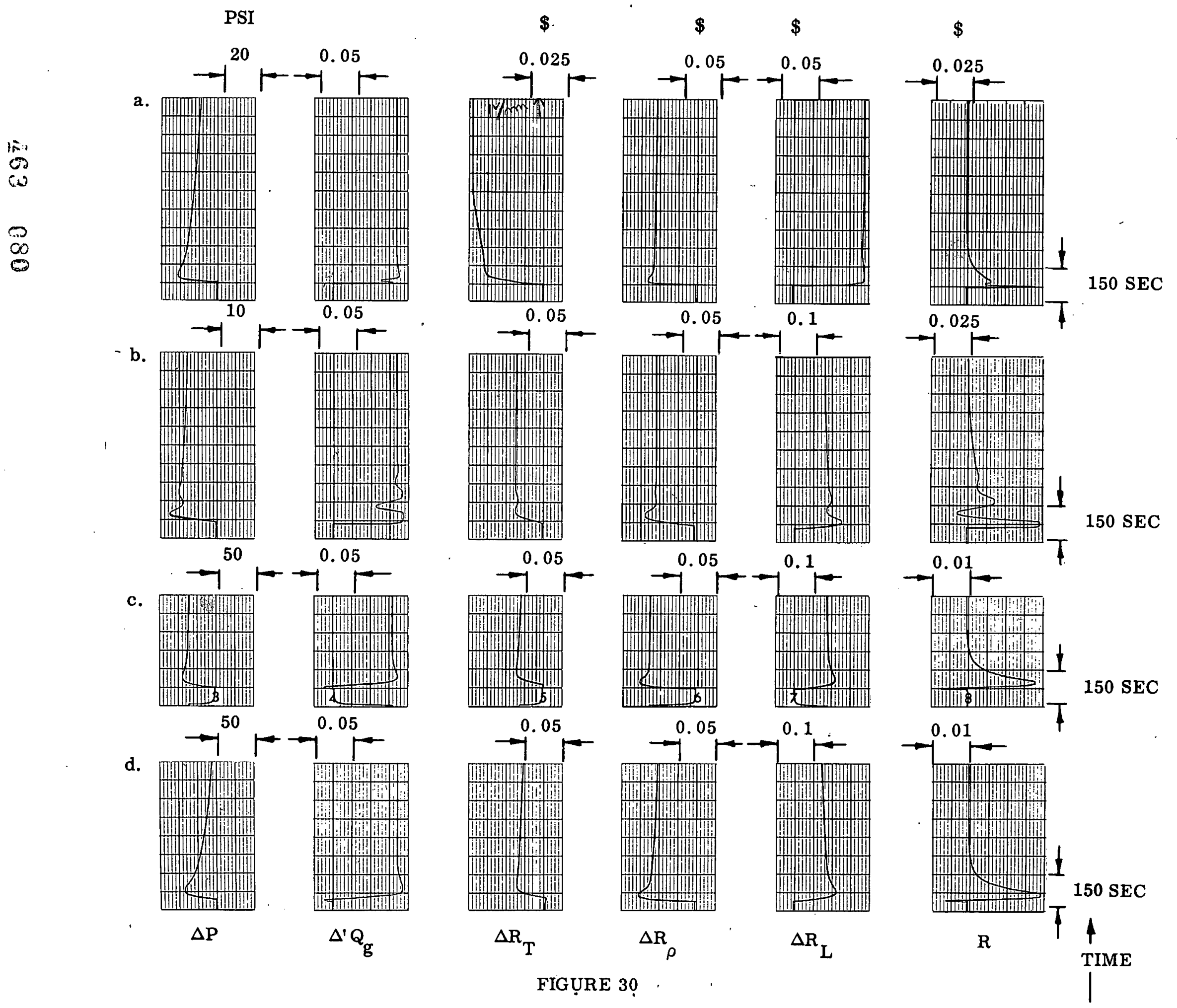


FIGURE 30

(Negative Void Coefficient)

For a reactor having a positive void coefficient of reactivity, the reactivity-void relation is likely to be similar to that shown in the sketch.

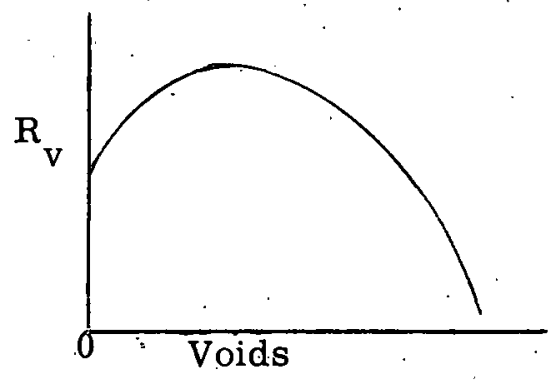

For sufficiently large voids, the derivative of reactivity. with respect to voids will be zero and; for a larger void fraction, negative. Thus, a control system which gives stable operation with positive, zero, and negative void coefficients of reactivity. is required. Figures 30 and 31 demonstrate that the control equations described opposite Figure 29 also permit stable operation with a negative void coefficient of reactivity. The magnitude of the reference negative void coefficient is the same as that of the reference positive coefficient.

The conditions applying to each set of traces is summarized by the following table.

\begin{tabular}{|c|c|c|c|c|}
\hline Coefficient & $d_{2}$ & $\mathrm{~d}_{\dot{3}}$ & $\mathrm{~d}_{4}$ & $\begin{array}{c}\alpha_{3} \\
\text { (void coef }\end{array}$ \\
\hline Figure & & . & & \\
\hline${ }^{30 a}$ & $\mathrm{~d}_{\text {ref }}$ & $\mathrm{d}_{3}$ & $\mathrm{~d}_{4}{ }_{\text {ref }}$ & ${ }^{\alpha}{ }_{\mathrm{r}}$ \\
\hline $30 \mathrm{~b}$ & $\mathrm{~d}_{2}$ & $2 d_{3}$ & $\mathrm{~d}_{4}$ ref & ${ }^{\alpha}{ }_{\mathrm{re}}$ \\
\hline $30 \mathrm{c}$ & 0 & $\begin{array}{c}1 / 2 d_{3} \\
\vdots\end{array}$ & 0 & ${ }^{\alpha} 3_{\text {ref }}$ \\
\hline $30 d$ & .0 & $1 / 2 \mathrm{~d}$ & ${ }^{d}{ }_{\text {ref }}$ & $\stackrel{\alpha}{3}_{3}$ \\
\hline
\end{tabular}




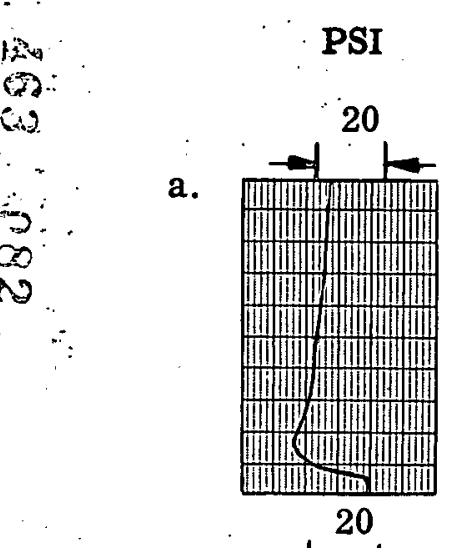

$\$$

0.05

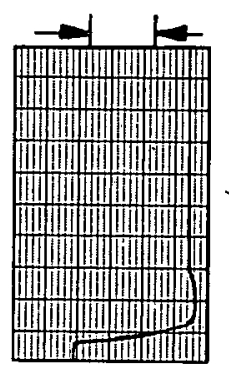

0.05

b.

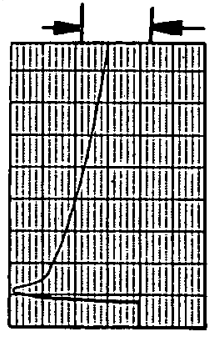

10

c. $\rightarrow-$ m.

(1)

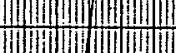

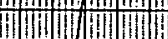

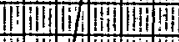

i. (1)

10

d.

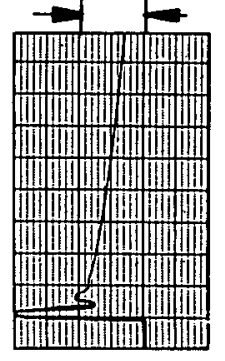

$\Delta \mathrm{P}$

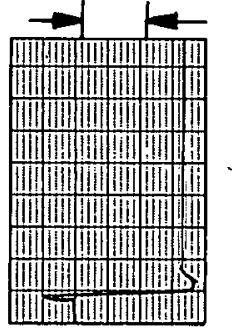

0.05

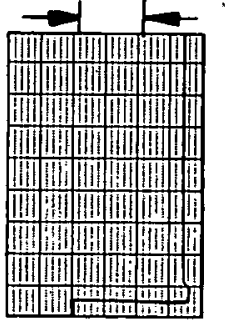

0.05

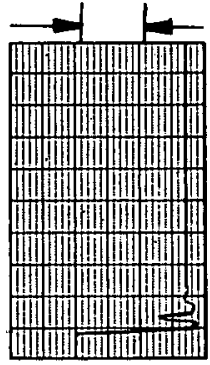

$\Delta^{\prime} \mathrm{Q}_{\mathrm{g}}$
0.05

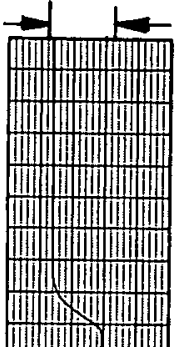

0.05

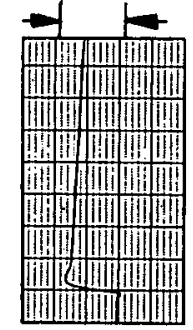

0.05

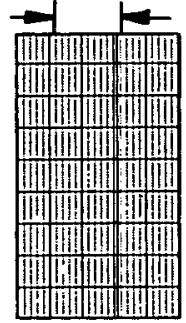

0.05

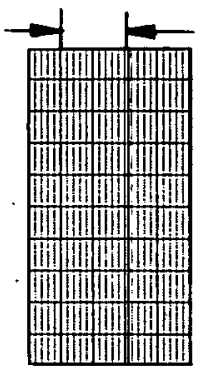

${ }^{\Delta R_{T}}$
$\$$

0.1

0.1

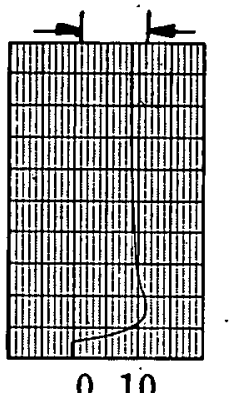

0.10

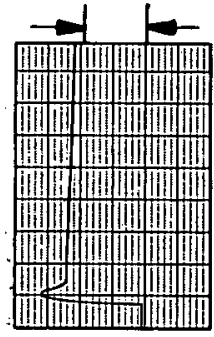

0.05

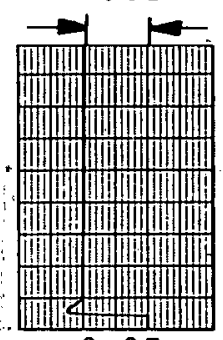

0.05

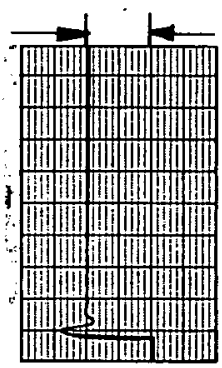

$\Delta_{\rho}$

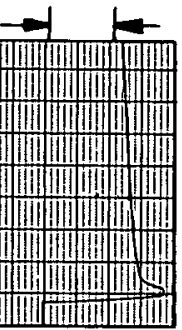

0.1
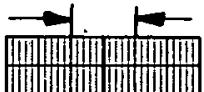

-

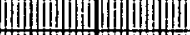

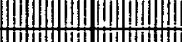

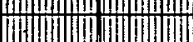

-

$\frac{1}{0.1}$

0.1

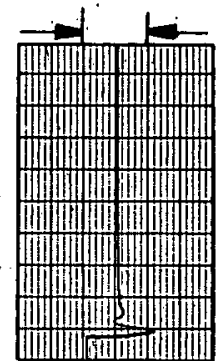

$\Delta \mathrm{R}_{\mathrm{L}}$
$\$$

0.025

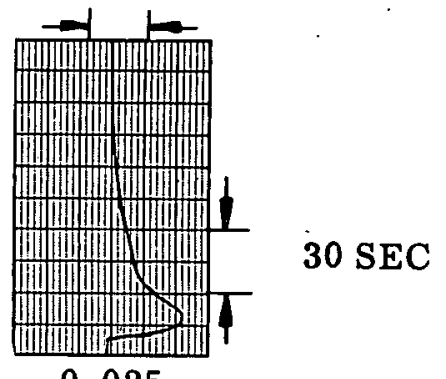

$$
0.025
$$

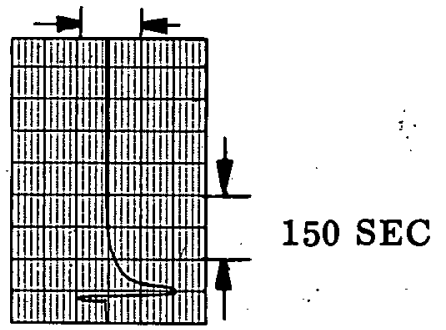

$$
0.05
$$

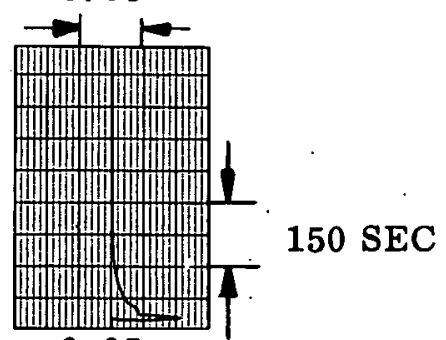

$$
0.05
$$

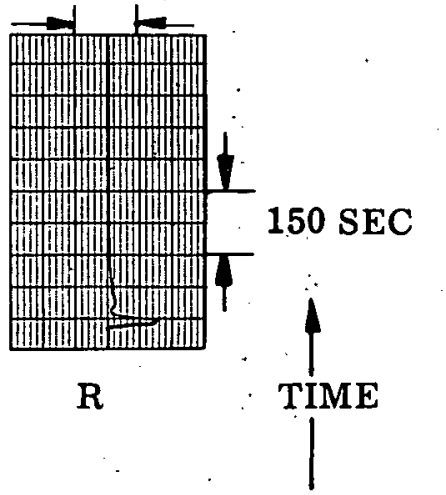


FIGURE 31

(Negative Void Coefficient)

The conditions applying to Figure 31 are summarized in the following table.

\begin{tabular}{|c|c|c|c|c|c|}
\hline Coefficient & $\mathrm{d}_{2}$ & $\mathrm{~d}_{3}$ & $\mathrm{~d}_{4}$ & $\alpha_{1}$ & $\alpha_{3}$ \\
\hline \multicolumn{6}{|l|}{ Figure } \\
\hline $31 a$ & 0 & $\mathrm{~d}_{3}$ ref & ${ }^{2 d_{4}}{ }_{\text {ref }}$ & ${ }^{\alpha} 1_{\text {ref }}$ & ${ }^{\alpha}{ }_{\text {ref }}$ \\
\hline $31 \mathrm{~b}$ & 0 & $\mathrm{~d}_{3_{\text {ref }}}$ & $\mathrm{d}_{4}{ }_{\text {ref }}$ & ${ }^{\alpha} 1_{\text {ref }}$ & ${ }^{2 \alpha}{ }^{3}$ ref \\
\hline $31 c$ & $\mathrm{~d}_{2}$ ref & $\mathrm{d}_{3 \text { ref }}$ & ${ }^{\mathrm{d}_{\text {ref }}}$ & $\dot{0}$ & ${ }^{\alpha}{ }_{\text {ref }}$ \\
\hline $31 d$ & 0 & $\mathrm{~d}_{3}$ & $\mathrm{~d}_{4}$ ref & 0 & ${ }^{\alpha}{ }_{\text {ref }}$ \\
\hline
\end{tabular}

In Figure $31 \mathrm{~b}$, it will be observed that the reactivity change due to fuel temperature (and thus fuel temperature) does not become constant after the initial transient. . The drift is caused by an analog computer difficulty and has no analog in the system represented.

Examination of Figure 10 of reference 6 shows that the fuel temperature is the time integral. of the difference between two signals. Thus, unless the two signals are exactly balanced in the steady state, the analog fuel temperature will continue to drift. The drift which can be noted in most of the preceding figures is slow and does not influence the transient performance indicated. 


\section{PUREE' PHYSICS ANA LYSIS, THERMAL GROUP}

\section{A. Blackness Computation}

Using the blackness iteration procedure described in the first quarterly progress report, ${ }^{13}$ a. series of cases was evaluated to demonstrate the effect of lattice pitch on blackness. The fuel rods used for these cases were one of those described by Kouts, et al 14 ; i.e. aluminumclad $\mathrm{UO}_{2}$ rods having a diameter of $0.493 \mathrm{in.}$ (fuel only) and $1.3 \%$ enrichment. Blackness was computed as a function of neutron velocity over the thermal energy range ( 20 groups) for four different lattice pitches. The results are plotted in Figure 32 along with the blackness, value determined by the method of Stuart ${ }^{15}$ which neglects the effects of neighbor rods.

It is seen that no significant variation from the Stuart blackness. value occurs except for very close lattices (i.e., pitch/diameter $\cong 1.02$ ).

A significant reference parameter for evaluating the effect of neighboring rods on blackness is the number of mean-free-paths between the adjacent surfaces, or more conveniently, the ratio (pitch-minus-diameter)/(mean-free-path). The curve of Figure 33 depicts the ratio of blackness $(\beta)$ involved by this method to that predicted by Stuart's method ( $\left.\beta_{0}\right)$. This curve may be assumed valid for a small $\operatorname{rod}(\sim 0.5 \mathrm{~cm})$ at low enrichments. No perceptible deviation from the Stuart value occurs until $(p-d) / \lambda_{c}$ drops below 0.3 . The three lattices proposed for the VMR critical experiment all have ratios (p-d)/ $\lambda_{c}$ greater than 0.6 ; hence, even with a water density of 0.5 , the effect of neighbor rods on blackness would be negligible.

\section{B. Spectral Shift Between Coolant and Fuel}

The matrix iteration program for the IBM 650. which computes the coolant spectrum by modifying the Wigner-Wilkins analysis ${ }^{16}$ to account for the presence of absorbing rods has been found to be in error. However ${ }_{g}$ the expression for neutron current into the rod is valid;

13. "Variable Moderator Reactor Development Program," Advanced Technology Laboratories, a Division of American-Standard, Quarterly Progress Report No.1, ATL-A-100, 31 August 1959.

14. H. Kouts, et a], "Physics of Slightly Enriched, Normal Water Lattices (Theory and Experiment)." Proceedings of the Second United Nations International Conference on Peaceful Uses of Atomic Energy, 12, Reactor Physics, (1958), P/466。 (Specific.case referred to is in table on page 451. )

15. G. W. Stuart, "Multiple Scattering of Neutrons, "Nuclear Science and:Engineering, $\underline{2}_{2}$ (1957), p 617.

16. E. P. Wigner and J. E. Wilkins, Jr., AECD-2275, "Effect of the Moderator on the Velocity Distribution of Neutrons with Numerical Calculations for H as Moderator, "September, 1944.

$$
-53-
$$$$
163 \quad 284
$$ 


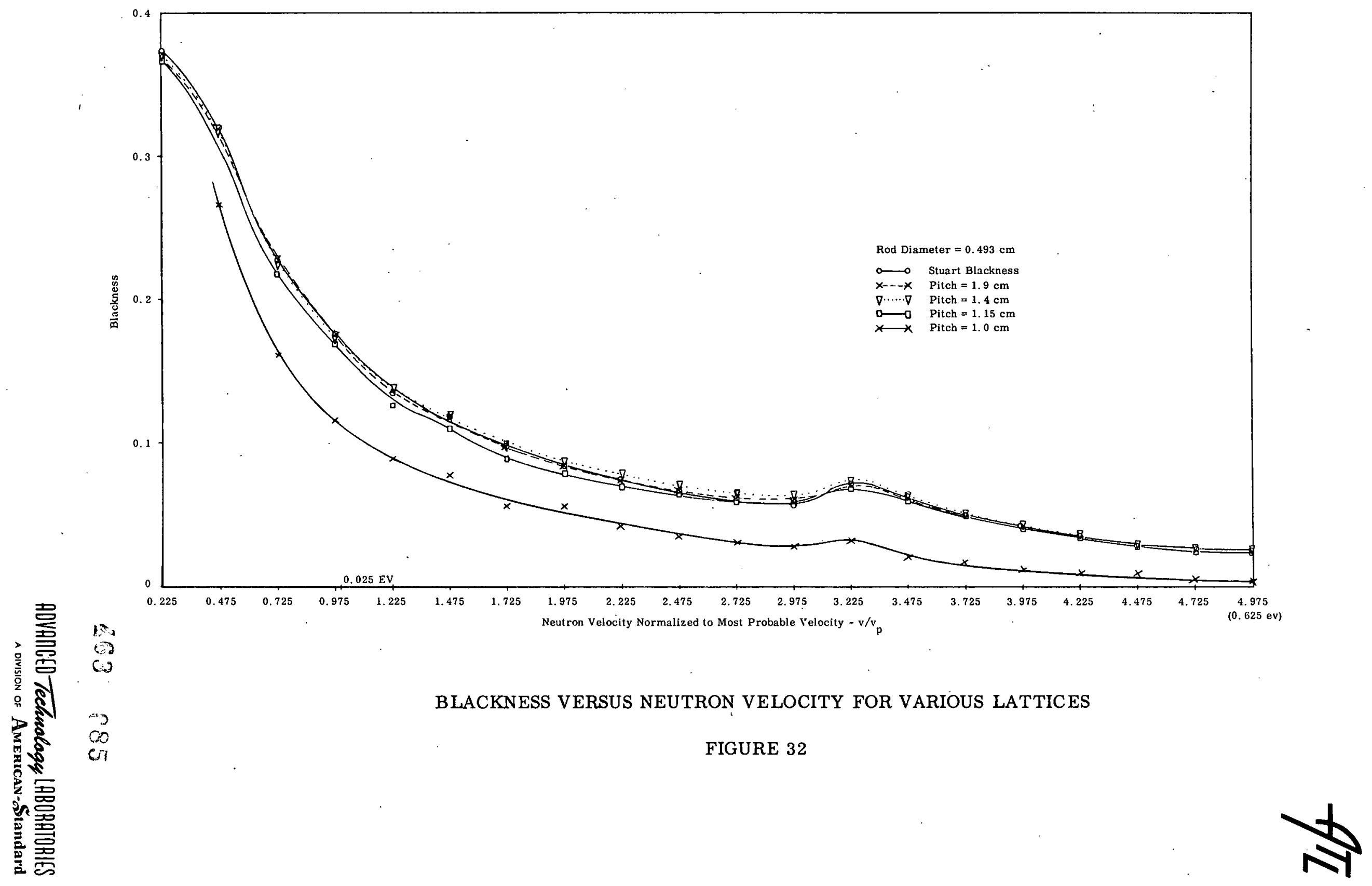




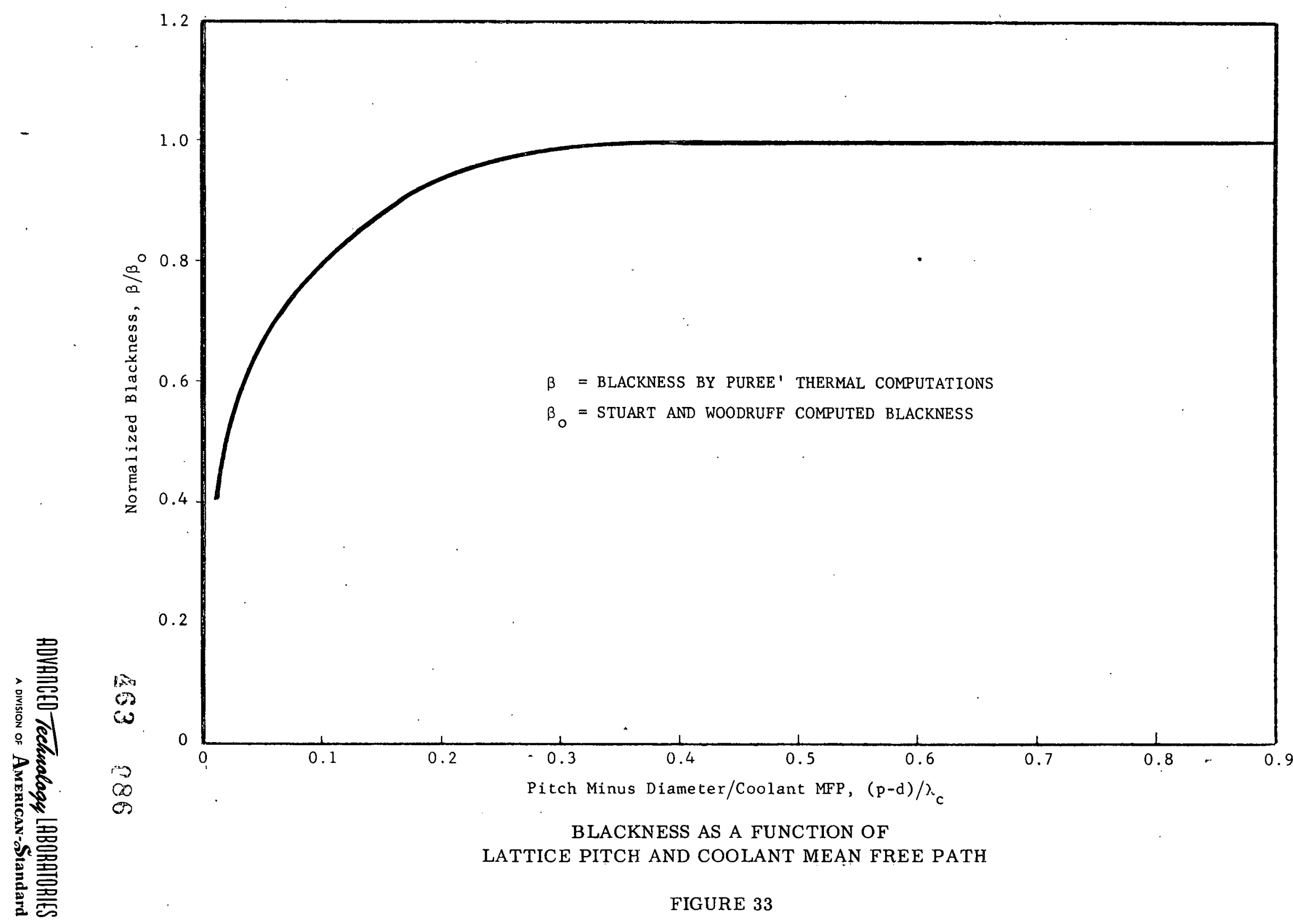

$\$$ 
hence, the ratio of fuel flux to coolant flux by energy group is attainable with the following relation:

$$
\frac{\bar{\phi}_{\mathrm{f}}}{\bar{\phi}_{\mathrm{c}}}=\frac{\mathrm{J}_{\mathrm{in}} \beta}{\sum_{\mathrm{a}} \mathrm{N}_{\mathrm{c}} \mathrm{v}_{\mathrm{c}}} \cdot \frac{2}{\mathrm{r}}
$$

where $\bar{\phi}_{f}, \bar{\phi}_{c}=$ average flux in fuel, coolant, respectively $\left(\frac{\mathrm{n}}{\mathrm{cm}^{2}-\mathrm{sec}}\right)$

$$
\begin{array}{ll}
\mathrm{J}_{\text {in }} & =\text { current into rod }\left(\frac{\mathrm{n}}{\mathrm{cm}^{2}-\mathrm{sec}}\right) \\
\beta & :=\text { blackness } \\
\Sigma_{\mathrm{f}_{\mathrm{f}}} & =\text { absorption cross. section for fuel }\left(\mathrm{cm}^{-1}\right) \\
\mathrm{N}_{\mathrm{c}} & =\text { neutron density in coolant }\left(\frac{\mathrm{n}}{\mathrm{cm}^{3}}\right) \\
\mathrm{v}_{\mathrm{c}} & =\text { neutron velocity for each group in coolant }(\mathrm{cm} / \mathrm{sec}) \\
2 / \mathrm{r} & =\text { surface-to-volume ratio for an infinite cylinder }\left(\mathrm{cm}^{-1}\right)
\end{array}
$$

Figure 34 depicts the thermal neutron spectrum in the coolant and fuel.for the Kouts 14 test lattice with an assumed.Wigner-Wilkins distribution in the coolant. Despite the fact that the true spectrum in the.coolant may not be represented in Figure 34 , the relative shift from coolant to fuel is evident.

The value measured for $\bar{\phi}_{\mathrm{c}} / \bar{\phi}_{\mathrm{f}}$ in the Kouts lattice is $1.0 \pm 0.01 .^{13}$ The spectra of Figure 34 indicate a value of $\bar{\phi}_{\mathrm{c}} / \bar{\phi}_{\mathrm{f}}$ of 1.13 , correcting for the $1 / \mathrm{v}$ detector used for the experimental determination. This is a reasonable check on the analytical determination of spectral shift.

\section{Conclusion}

The methods of obtaining properly. weighted cross sections for the PUREE' thermal group 13 have been adequately checked against experimental data and found to be valid. However, as seen by the negligible effect of neighbor rods on blackness (Figures.32 and 33) and by the small spectral shift between coolant and fuel for the VMR studies, it does not seem warranted at the present time to replace the "P-3" and "POP" 17 codes now in use for obtaining thermal constants by the more rigorous methods (the PUREE' thermal code - Reference 13).

17. "Variable Moderator Reactor Development Program," Advanced,Technology Laboratories, a Division of American-Standard, Guarterly Progress Report No. 2, ATL-A-103, 30 November 1959 (section III. B).

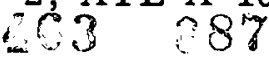




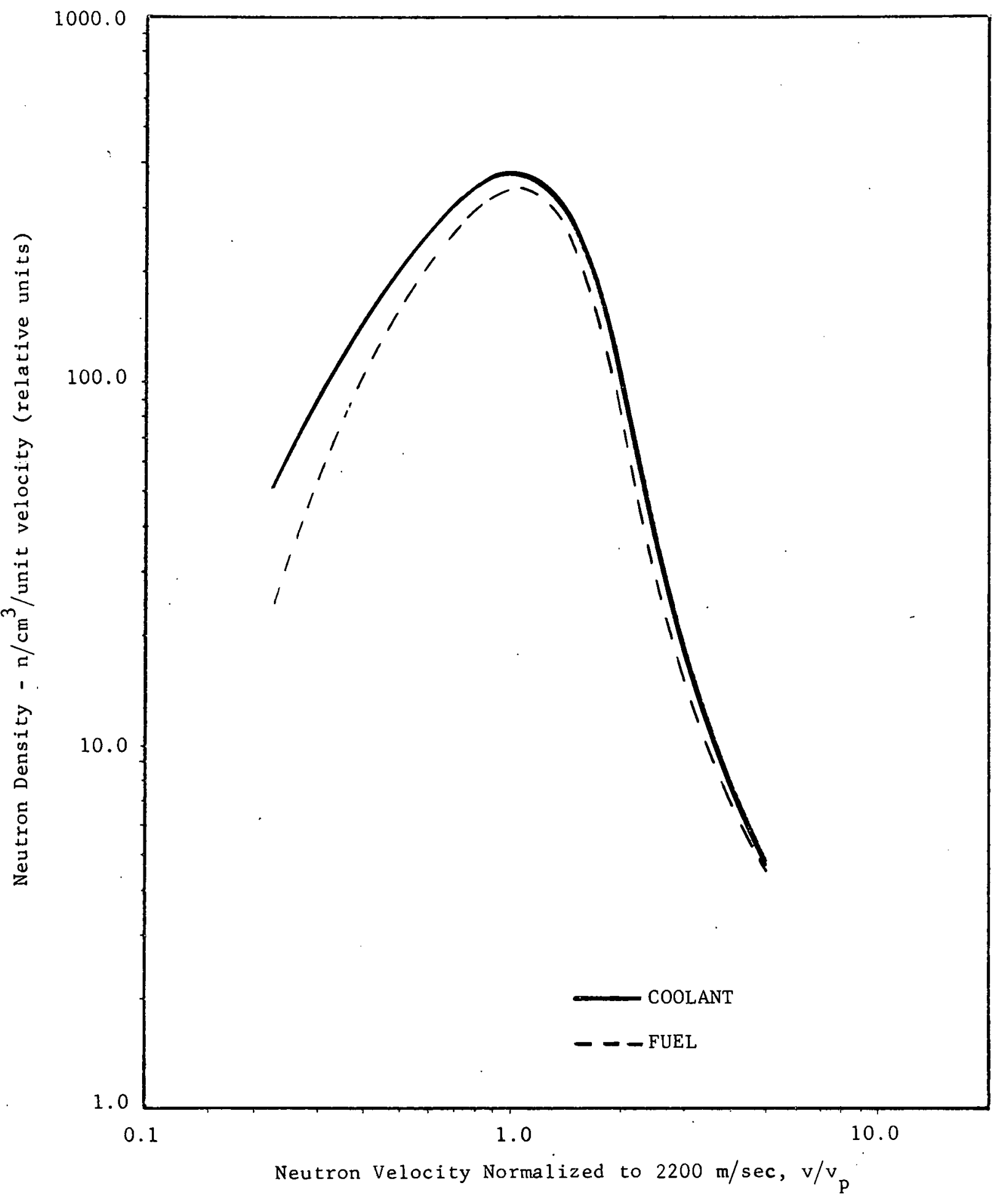

COOLANT AND FUEL SPECTRA

FIGURE 34

$1263 \quad \cap 88$ 


\section{VMR MECHANICAL AND SYSTEMS DESIGN}

\section{A. Reactor Arrangement}

1. Fuel

The fuel pins, consisting of $\mathrm{UO}_{2}$ pellets clad with type 348 stainless steel, are arranged in a triangular lattice to form a fuel element. The elements, of hexagonal form, are in turn arranged in a triangular pitch to form a rougly circular core. The triangular pin pitch and hexagonal fuel element were selected to minimize the disadvantage factor across a fuel cell, and to obtain a constant moderator gap between fuel cells. This arrangement also results in the maximum distance between fuel pins for a given water to $\mathrm{UO}_{2}$ volume ratio.

\section{Moderator Barrel}

The moderator barrel, consisting of a cylindrical core barrel, shrouds, grid plates, and miscellaneous piping, welded to form a single unit, performs the following functions:

a. Provides completely separate moderator region for control purposes.

b. Provides support for fuel elements and for a natural circulation riser.

c. Provides fuel element flow channels.

The shrouds are hexagonal and sized slightly larger than the fuel elements to permit refueling. A transition from hexagonal to circular section is made in the shrouds immediately above the lower grid plate. Thus the holes in the lower grid plate are circular, providing a small ledge at each shroud corner for fuel element support.

An annular reflector region is provided between the outer row of shrouds and the core barrel. The resulting solid annular section of the lower grid plate is used for making moderator inlet, outlet, and level-indicating pipe connections to the moderator barrel. The annular section of the upper grid plate is used for connection of pressure equalizing pipes, which extend above the water level in the steam generating portion of the pressure vessel.

The moderator inlet, outlet and level-indicating pipes are extended through pressure vessel nozzles to a point below the shielding beneath the pressure vessel, where they are welded to the vessel nozzles. As this is the only point at which the moderator barrel assembly is fastened to the vessel, the assembly may be removed from the vessel at any time during the life of the plant. 
There are four moderator outlet pipes distributed equally about the moderator barrel reflector region. These serve to allow for rapid moderator dump when scram action is required. The pipes have a sufficiently heavy wall thickness to permit their being used as core supports. This arrangement simplifies the pressure vessel and substantially eliminates problems caused by differential expansion of the moderator region pipes with respect to the pressure vessel.

The moderator barrel contains a moderator inlet flow distribution header and flow baffles to assure symmetrical moderator flow.

Attached to the outside of the moderator barrel is a thin boron-containing stainless steel cylindrical shell which serves to prevent reflection of neutrons to the core by the downcomer region water. This component is designed to allow its removal and replacement.

All components of the moderator barrel assembly are of type 304 stainless steel. The welded joints are designed with particular care to insure moderator region integrity throughout plant life.

\section{Coolant Riser}

A riser assembly, attached to the top surface of the upper grid plate, provides the increased driving head necessary for natural circulation. It is fabricated from type 304 stainless steel sheets arranged in a pattern providing individual channels above each fuel assembly to prevent cross-flow in the riser. The design also permits the riser to remain in place during the refueling operation.

\section{Pressure Vessel}

The reactor pressure vessel is a carbon steel, stainless steel-clad cylindrical shell with ellipsoidal heads. The upper head is removable. A feedwater distribution ring and a steam collecting ring are attached to the inside of the vessel. The inside diameter of the vessel is such that a large annular space is provided for the downcomer region, which results in low velocity flow in the downcomer, thereby minimizing entrainment of steam. This water space, together with the metal of the core barrel and the water in the reflector region of the moderator, provides sufficient shielding to avoid the need of additional neutron shielding for vessel wall protection.

The vessel shell may be tapered to a smaller diameter above the core region in order to reduce costs. The reduction in diameter is possible because of the smaller diameter of 
the riser as compared to the moderator barrel and also because of reduced shielding requirements above the core. The minimum pressure vessel diameter is that which permits field installation of the moderator barrel.

B. Reactor Component Stress Analysis

\section{Core Support Plate}

For various core configurations core support plate thicknesses have been determined. Since the plate is quite similar to a heat exchanger tube sheet, bending stresses have been treated in the matter recommended by Malkin: ${ }^{18}$ and Horvay ${ }^{19}$. This method treats plates perforated uniformly with circular (or hexagonal) holes as solid plates with fictitious values of Young's modulus and Poisson's ratio which are functions of the plate geometry. Bending moments are calculated for this "equivalent plate" and applied to the individual ligaments for the actual plate. However, for the core configurations presently under study, it appears that a close approximation of maximum ligament stresses may be made by application of the maximum radial bending moment fcund from standard plate formulae to a radial ligament. This observation is true only when a very large portion of the original plate has been removed, as is the case with the VMR grid plates.

Effects of gamma heating of VMR grid plates have been calculated and found to be negligible.

\section{Shrouds}

Calculations of stresses in the VMR shrouds have been made for the following:

a. Thermal stresses due to shroud gamma heating.

b. Thermal stresses due to core barrel gamma heating.

c. Thermal stresses due to moderator and coolant temperature transients.

d. Bending stresses due to grid plate deflections:

e. Membrane stresses due to differential pressures in coolant and moderator which would result from a pipe rupture accident.

f. Column and local buckling assuming fuel elements supported by upper grid plate.

18. "Notes on a Theoretical Basis for Design of Tube Sheets of Triangular Layout, "Trans. ASME .74 (1952), pp 382-396..

19. "Bending of Honeycombs and Perforated Plates, " Journal of Applied Mechanics, 19;. $\because$ : No. 1 (1952):, p 122 . 
Of the above the only stress which appears to be a potential problem is (e), the membrane stress resulting from an accident such as complete rupture of a steam or moderator outlet line. Because of the hexagonal form of the shrouds they have little resistance to deformation when differential pressures exist between the inner and outer surfaces, that is, between the coolant and moderator regions. In order to avoid deformation which might cause difficulty in removing fuel elements, the pressure equalizing pipes have been sized to prevent deformation of the shrouds under the worst possible conditions which could result from pipe rupture.

\section{Moderator Inlet Pipe}

Because of the differential expansion resulting from the dissimilar materials of the pressure vessel and the moderator inlet pipe and from the unequal temperatures of coolant and moderator, it appears that, with very conservative assumptions, the moderator inlet piping will experience stresses above yield. However, treating such stresses as transient stresses in accordance with the reference below, ${ }^{20}$ indicates no possibility of failure over a projected 30-year life. For example, temperature swings of $180^{\circ} \mathrm{F}$ in moderator inlet temperature correspond to an alternating stress of 24,000 psi as compared with a "yield" stress of 19,500 psi. The design curve on page 34 of reference 20 below indicates a life of $10^{6}$ cycles or, approximately 100 cycles per day, for the above condition. Since the moderator region inlet pipe will be subjected to far fewer cycles than this, the design is satisfactory.

\section{Pressure Vesse1}

The basic geometry and dimensions of the pressure vessel walls, heads, flanges, and nozzle reinforcements have been determined'using references, 21 and $20, \mathrm{below}$.

C. Economic Evaluation

Drawings for the VMR fuel elements Dwg, F-1712, and the pressure vessel, Dwg. F-1716, have been prepared for purposes of obtaining quotations as part of the VMR economic evaluation. Drawings for the reduced diameter pressure vessel described in Section $\mathrm{V}-\mathrm{A}$ and for the moderator barrel will be prepared in the near future for the saime purpose.

20. "Tentative Structural Design Basis for Reactor Pressure Vessels and Directly Associated Components";" U.S. Dept. of Commerce; Office of Technical Services, P. B. 151987,

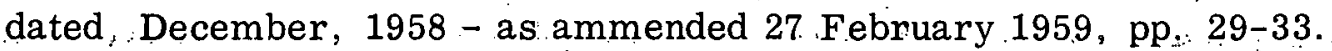

21. "Unified Pressure Vessel "ASME Boiler and Prèsüure Vès sèl Code., Section VIII, 1959 Edition, and Pertinent Case Rulings Applying to Nuclear Vessels. 


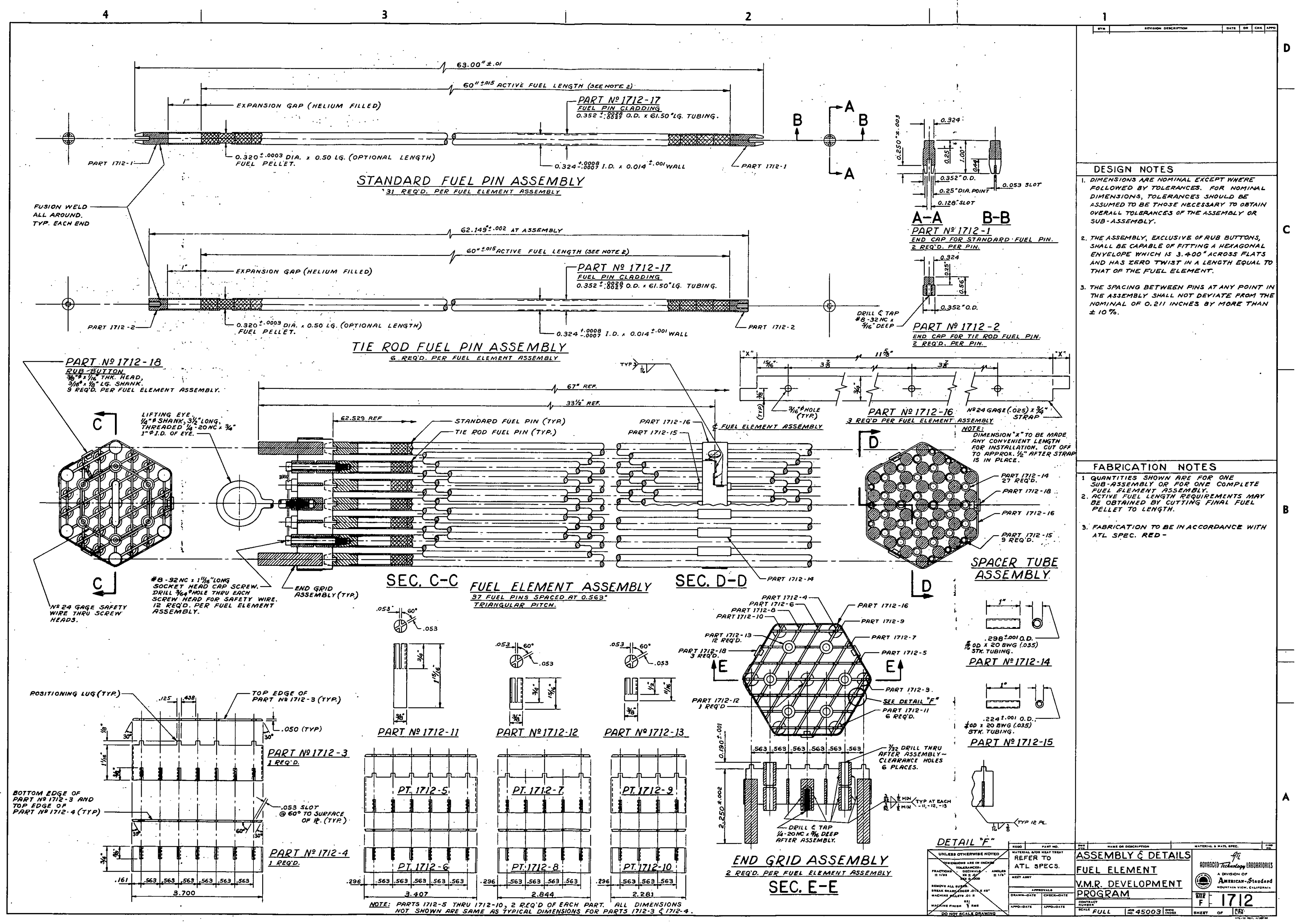

$\therefore 63 \quad 093$ 


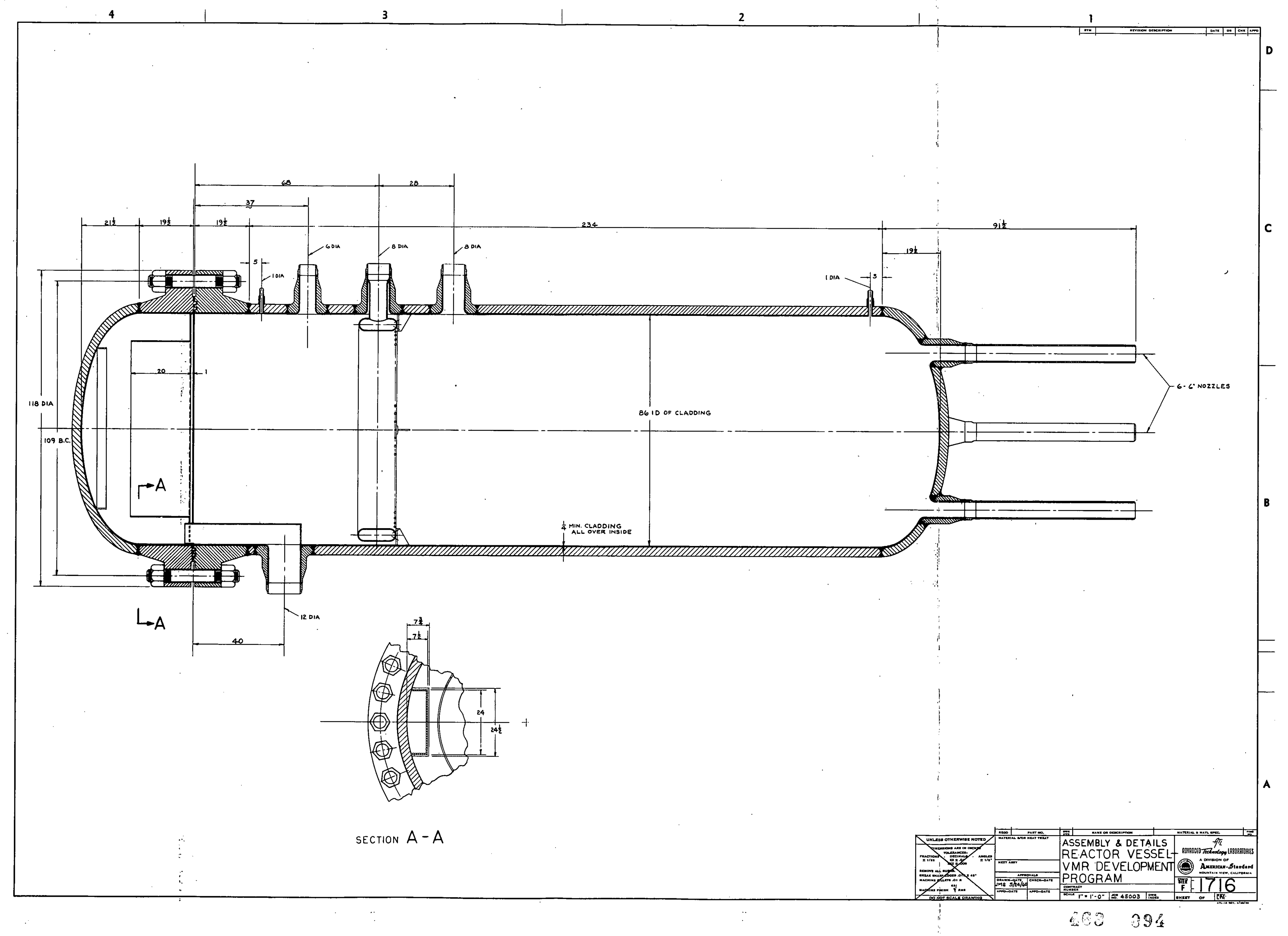




\section{Cleanup System for VMR Moderator Region}

It has been proposed that from 1 to 2 grams per liter of boric acid be used in the VMR moderator as a variable poison.

This will provide an acid medium with a $\mathrm{pH}$ of approximately 5.8 to 6.2 , and all corrosion is therefore likely to be acid corrosion.

At corrosion rates calculated to be $2.3 \times 10^{-3} \mathrm{lb} / \mathrm{hr}$. of stainless steel, the blowdown rate for a $1 \mathrm{ppm}$ impurity in the moderator water is $2300^{\mathrm{\prime}} \mathrm{lb} / \mathrm{hr}$. Assuming uniform acid corrosion of 18-8 stainless steel, the blowdown will produce 0.187 grams of chromium, 0.083 grams of nickel, and 0.883 grams of iron per hour in solution. This is equivalent to 0.0413 gram-equivalents of metal ion per hour, assuming trivalent chromium and divalent nickel and iron from corrosion in an acid medium. Since these materials exist as metal ions in acid solution and each equivalent of metal liberates one equivalent of molecular hydrogen in the corrosion process, the corrosion products can be removed and the acid balance of the solution can be restored to its original state by passage of the solution through a simple cation exchange in the hydrogen cycle.

The proposed system uțilizes an evaporator to remove the excess water. After cooling, the residue from this evaporator is passed through a filter, through the deionizing bed, and then returned to the reactor moderator region.

The blowdown being at $510^{\circ} \mathrm{F}$ will be partially flashed on expanding to atmospheric pressure in the evaporator. The evaporator is surmounted by a small demister supplied with a cold finger to produce approximately $10 \%$ reflux, thus eliminating the possibility of acid carryover in the steam. Steam issuing from the demister is then passed directly to the feedwater heaters of the power cycle. Condensate from the evaporator coils is also usable in the feedwater heaters.

A materials flow diagram of the system is shown in Figure 35, and heat flow is shown in Figure 36. Calculations by which the data were obtained are given in appendices A and B. Equipment sizing is shown in Appendix C. 
$2000 \mathrm{LB} / \mathrm{HR}$

STEAM TO FEEDWATER HEATERS

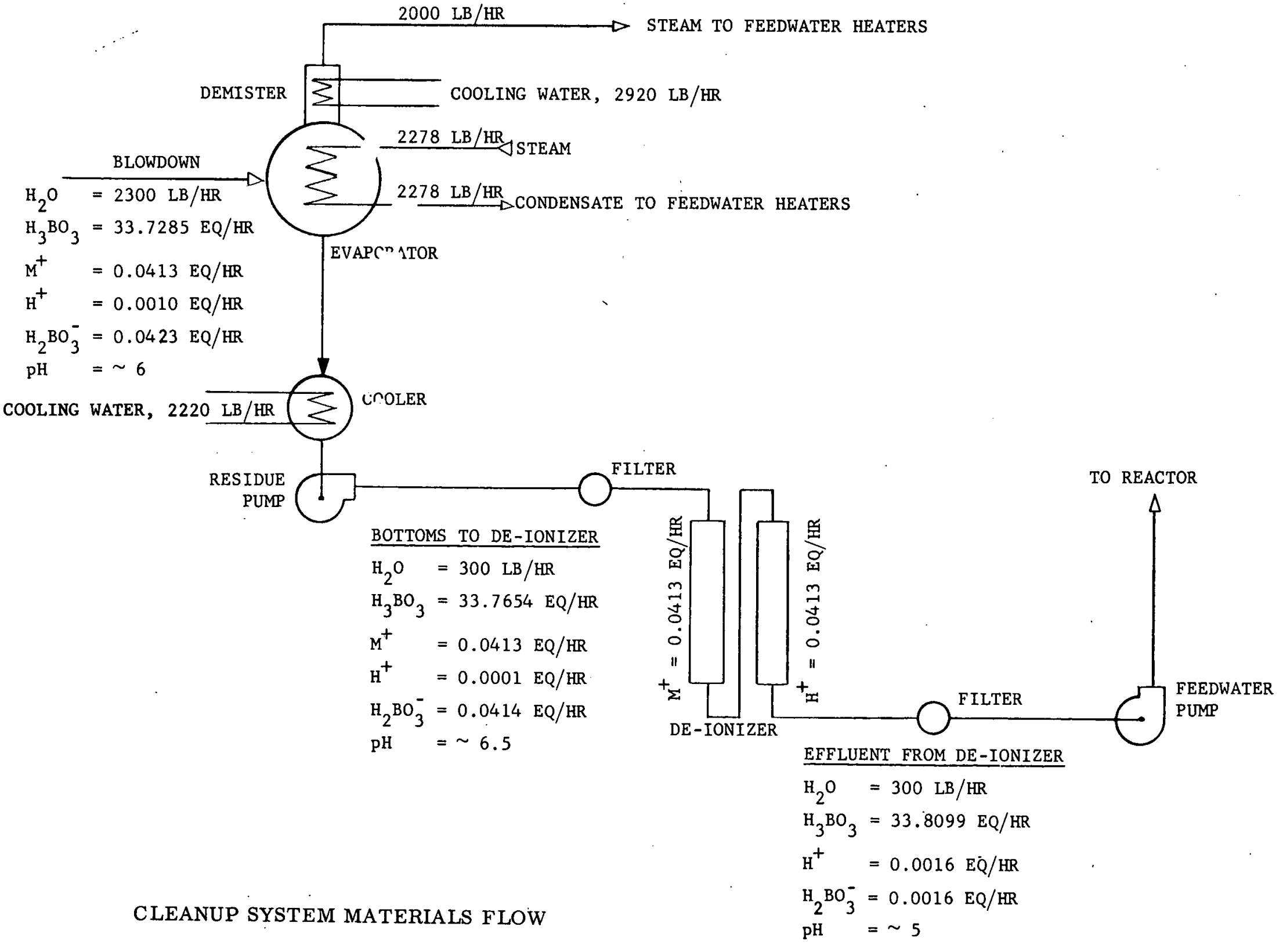

FIGURE 35 


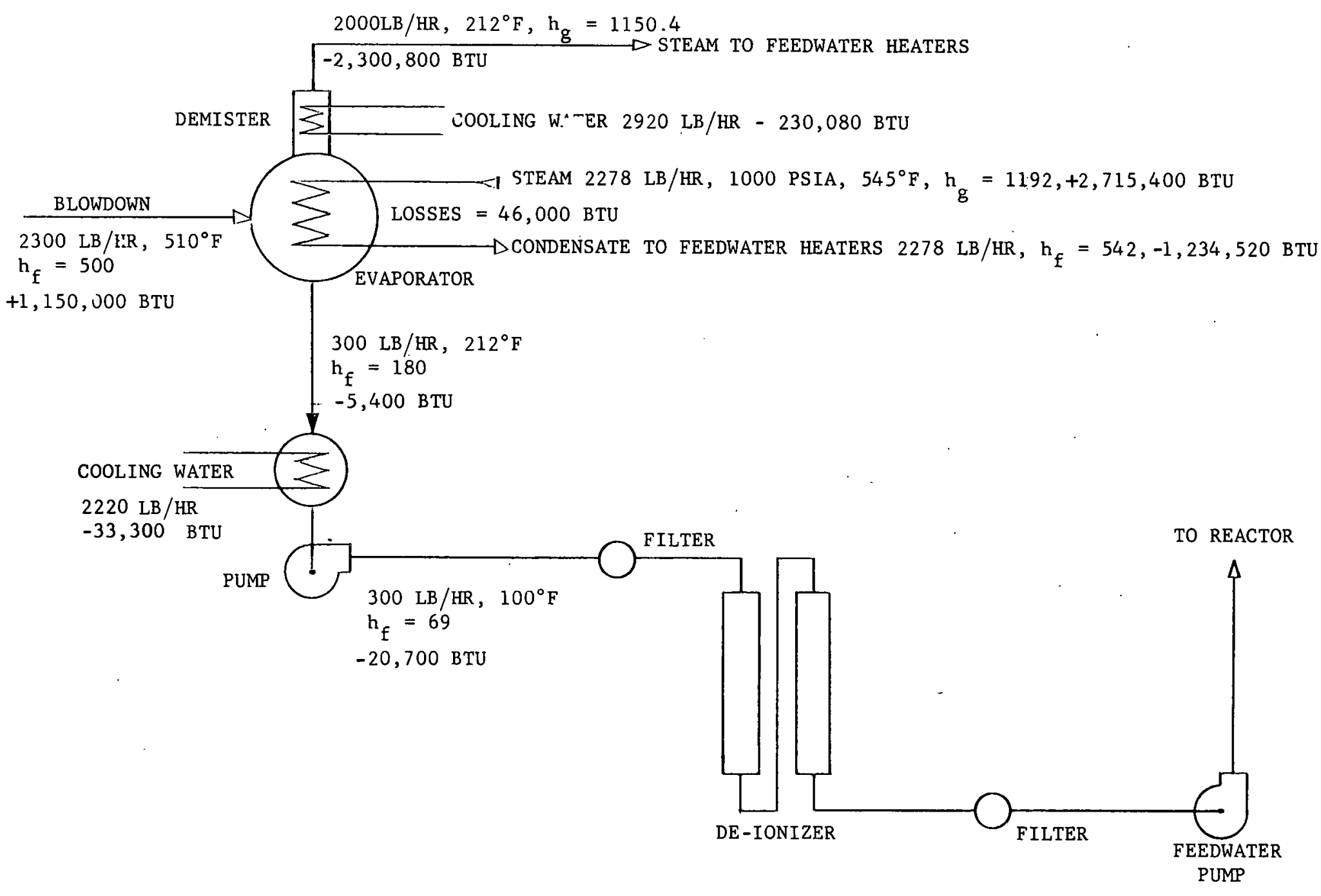

CLEANUP SYSTEM HEAT FLOW

FIGURE 36 


\section{THERMAL DESIGN OF FUEL ASSEMBLIES}

Certain data pertinent to the thermal design of the VMR fuel assemblies are tabulated in Tables IX and $\mathrm{X}$.

The "hot spot" factors shown in Table IX are based upon preliminary calculations and are subject to change as the design progresses. The fuel pin tolerances shown in Table $\mathrm{X}$ are those tolerances which can be obtained from fuel fabricators without severe penalty to the cost of the fuel assemblies.

Calculations of fuel pin temperature distribution have been made for the "maximum gap" and "minimum gap" cases shown in Table X. The results of these calculations are shown in Figure 37. Two conservative assumptions were made in the calculations. They are listed below.

1). The thermal conductivity of the $\mathrm{UO}_{2}$ was assumed to be invariant at $1.0 \mathrm{Btu} / \mathrm{hr}-\mathrm{ft}-{ }^{\circ} \mathrm{F}$.

2) The thermal conductivity of the gap was assumed to correspond to a $5 / 1$ mixture of $\mathrm{Xe}$ and $\mathrm{Kr}$ with the following properties:

$$
\begin{aligned}
\mathrm{k}\left(\mathrm{Btu} / \mathrm{hr}-{ }^{\circ} \mathrm{F}-\mathrm{ft}\right) & =0.0065 \text { at } 600^{\circ} \mathrm{F} \\
& =0.008 \text { at } 900^{\circ} \mathrm{F} \\
& =0.0095 \text { at } 1200^{\circ} \mathrm{F}
\end{aligned}
$$

The diametral gaps shown in Table IX correspond to the oxide-to-cladding clearances with the fuel pin in the cold condition. The actual clearances used in the calculations of the temperature distribution were determined for the hot condition of the fuel pins by an iterative process, balancing temperature distribution against gap thickness. 


\section{TABLE .IX}

\section{FUEL ASSEMBLY THERMAL DESIGN DATA}

Power per core, tmw (102\% of rated power)

77.5

No. of fuel pins/fuel assembly

39

No. of fuel assemblies/core

151

Fuel pin cladding material

Stainless steel

Fuel active length, inches

.60

"Hot Spot" factors

Eccentricity, gap variation, spacers, etc.

Large cell neutron flux (local flux factor).

1. 30

Axial neutron flux

1.50

Radial neutron flux

$\underline{1.40}$

Total "hot spot" factor

3.60

Average power density, $\mathrm{kw}$ per. foot of fuel pin

2.78

Maximum power density, kw per foot of fuel pin

10.0

Average surface heat flux, Btu/hr-sq ft

103,000

Maximum surface heat flux, Btu/hr-sq ft

370,000

Estimated burnout heat flux, Btu/hr-sq ft

$1,000,000$ 
TABLE X

FUEL CLADDING AND PELLET DIMENSIONS

(Cold Dimensions, inch)

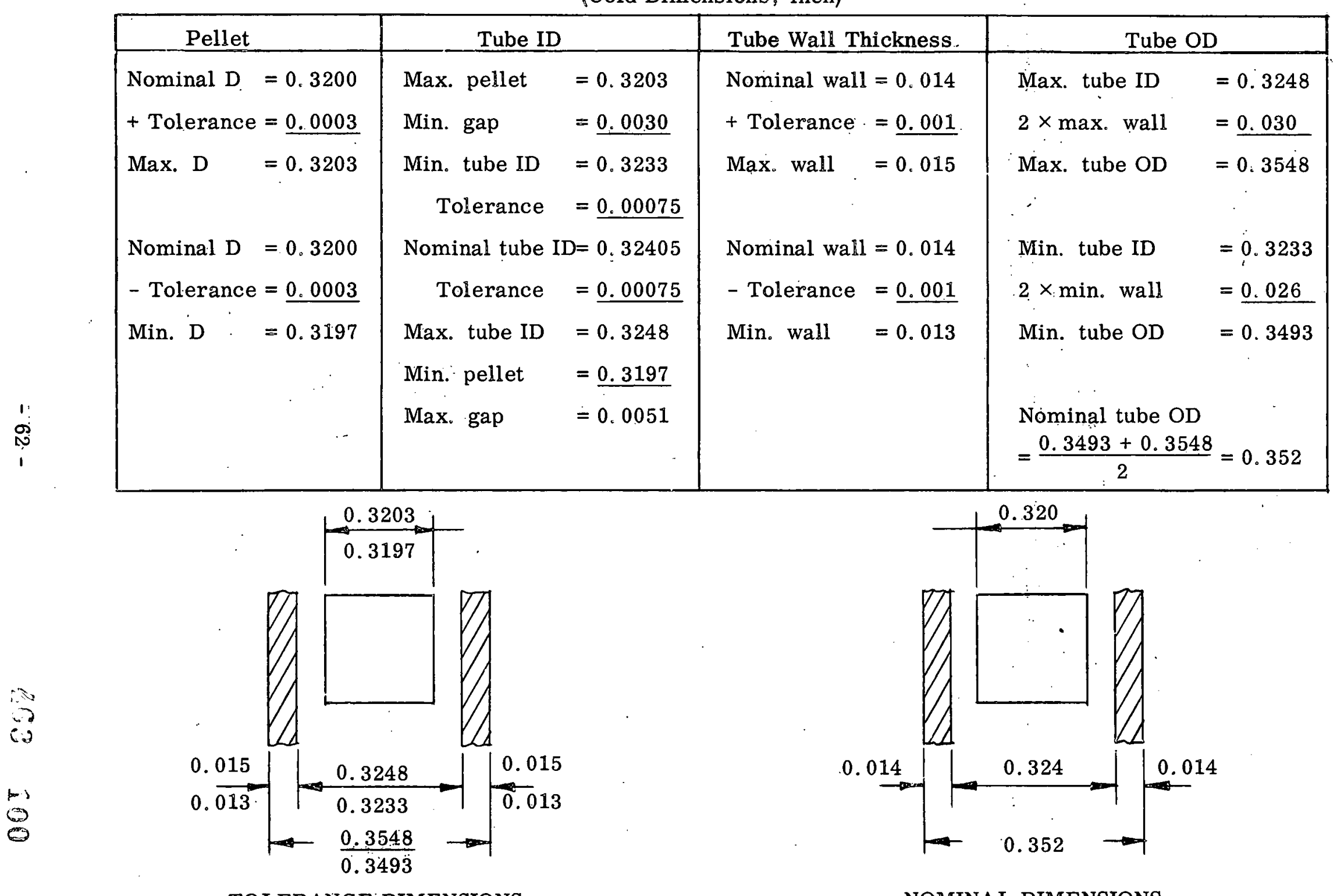

TOLERANCE DIMENSIONS

NOMINAL DIMENSIONS 


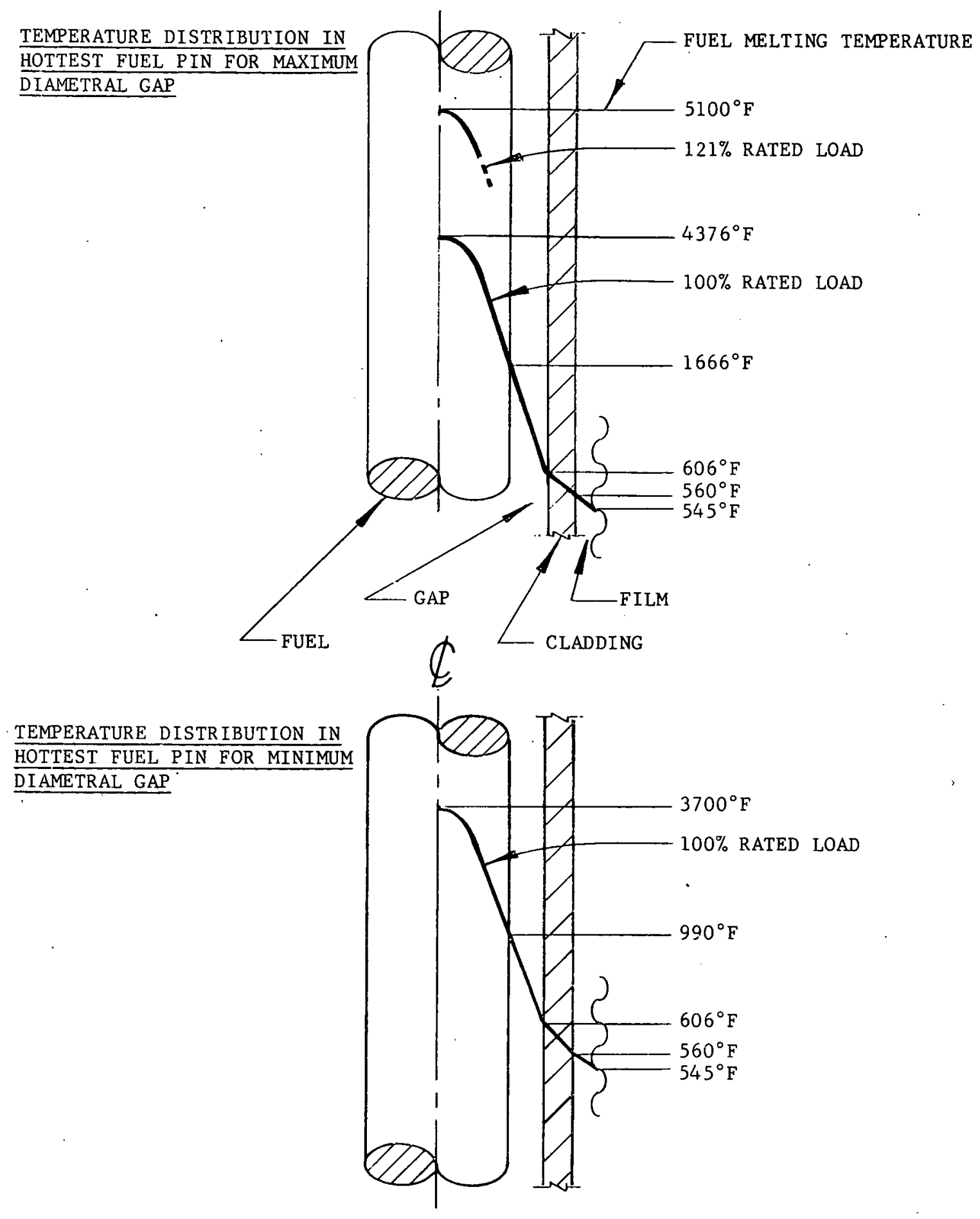

TEMPERATURE DISTRIBUTION IN VMR FUEL PIN

FIGURE 37

$283 \quad 101$

ADVANCED Techuology LABORATORIES 


\section{CRITICAL EXPERIMENT}

\section{A. Initial Critical Experiments}

Table XI contains a description of the proposed critical experiment configurations, and indicates the present status of these experimenț. To date two core.configurations have been tested in critical experiments. The first of these (case 104) did not become critical, but did achieve $\mathrm{k}_{\text {eff }}$ of 0.99 or more with the moderator and coolant levels at the top of the active portion of the fuel pins. Measurements.were made on this core of $\mathrm{k}_{\text {eff }}$ versus height of coolant and moderator for four coolant-moderator heights. For heights of 48, 46, 40 and 30 inches, the assembly. was within approximately $\$ 0.40, \$ 0.60, \$ 1.80$ and $\$ 5.50$, respectively, of being critical.

Calculated critical height for this assembly, was 29 inches. Thus, it appears that PUREE' results are.approximately $3 \% \mathrm{k}_{\text {eff }}$ greater than measured.

The second assembly (case 120) became.critical with water moderator and coolant at a. height of 27 inches. Detailed measurements of flux distributions; and of cadmium ratios for fịssion in U 235 and $U 238$, and capture in $U 238$ have been completed; but analysis of the results has not yet been completed. The assembly did not go critical with furfuryl alcohol or furfural in the coolant region. Attempts are being made to measure flux distributions in an assembly in which the seven inner elements contain furfuryl alcohol and the outer 28 contain water.

Moderator and coolant reactivity: worths per inch of height were measured at the justcritical heights of the water coolant assembly, giving results for the moderator of $\$ 0.144 /$ in. , for the coolant $\$ 0.216 / \mathrm{in}$, and for both simultaneously of $\$ 0.335 / \mathrm{in}$ 。

The calculations performed so far on the critical experiments have assumed that the thermal neutron spectrum is.essentially the same in all regions of the reactor. Checks of this method against results of other critical experiments in which the moderator and fuel are more homogeneous than in the VMR experiments (i.e. in which the moderator was.not separated into coolant and moderator regions) have been reasonably successful, (within approximately $1 \% \mathrm{k}_{\text {eff }}$ ). For some VMR reactor cores, calculations have been made assuming two different spectra in the cell, that in the fuel coolant region being a Wigner-Wilkins spectrum, and that in the moderator region being a Maxwellian. When the two spectra are used, the result is a decrease in thermal utilization (consequently in $\mathrm{k}_{\text {eff }}$ ) of up to $3 \%$

$$
-63-\quad 263 \quad 102
$$


TABLE XI

PROPOSED CRITICAL EXPERIMENT CONFIGURATIONS

\begin{tabular}{|c|c|c|c|c|c|c|c|c|c|c|c|c|c|c|}
\hline \multirow{2}{*}{$\begin{array}{l}\text { Case } \\
\text { No. }\end{array}$} & \multirow{2}{*}{$\begin{array}{l}\text { Has Been } \\
\text { Run }\end{array}$} & \multirow{2}{*}{$\begin{array}{l}\text { Will Be } \\
\text { Run }\end{array}$} & \multirow{2}{*}{$\begin{array}{c}\text { Did Not Go } \\
\text { Critical } \\
\end{array}$} & \multirow{2}{*}{ Deleted } & \multirow{2}{*}{ Config. } & \multicolumn{3}{|c|}{ Element } & \multicolumn{2}{|c|}{ Assembly } & \multicolumn{2}{|c|}{ Moderator } & \multicolumn{2}{|c|}{ Liquids } \\
\hline & & & & & & $\begin{array}{c}\text { Shroud } \\
\text { ID } \\
\text { (in.) } \\
\end{array}$ & $\begin{array}{l}\text { Pin } \\
\text { Pitch }\end{array}$ & $\begin{array}{l}\text { No. of } \\
\text { Pins }\end{array}$ & $\begin{array}{c}\text { Element } \\
\text { Pitch } \\
\text { (in.) } \\
\end{array}$ & $\begin{array}{c}\text { No. of } \\
\text { Elements }\end{array}$ & $\begin{array}{r}\text { Volume } \\
\mathrm{C} / \mathrm{UO}_{2}\end{array}$ & $\begin{array}{l}\text { Ratios } \\
\mathrm{M} / \mathrm{UO}_{2}\end{array}$ & Moderator & Coolant \\
\hline 104 & & & $\mathbf{x}$ & & 1 & 4.944 & .633 & 61 & 5.95 & 37 & 1.2 & 1.05 & $\mathrm{H}_{2} \mathrm{O}$ & $\mathrm{H}_{2} \mathrm{O}$ \\
\hline 105 & & & & $\mathrm{x}$ & $"$ & $"$ & $"$ & $\because$ & $"$ & $"$ & $"$ & $"$ & $"$ & FA \\
\hline 106 & & & & $x$ & $"$ & $"$ & $"$ & $"$ & $"$ & $"$ & $"$ & $n$ & $"$ & $F$ \\
\hline 107 & & $\mathrm{x}$ & & & 2 & 5.490 & .703 & 61 & 6.34 & 37 & 1.8 & 0.95 & $\mathrm{H}_{2} \mathrm{O}$ & $\mathrm{H}_{2} \mathrm{O}$ \\
\hline 108 & & $\mathbf{x}$ & & & $"$ & $"$ & $"$ & $"$ & $"$ & $"$ & $"$ & $"$ & $"$ & FA \\
\hline 109 & & $\mathbf{x}$ & & & $"$ & $"$ & $"$ & $"$ & $"$ & $"$ & $"$ & $"$ & $"$ & $\mathrm{~F}$ \\
\hline 120 & $\mathbf{x}$ & & & & 3 & 4.944 & .633 & 61 & 5.54 & 37 & 1.2 & 0.55 & $\mathrm{H}_{2} \mathrm{O}$ & $\mathrm{H}_{2} \mathrm{O}$ \\
\hline 121 & & & $x$ & & $"$ & $"$ & $"$ & $"$ & $"$ & $"$ & $"$ & $"$ & $"$ & $\mathrm{FA}$ \\
\hline 122 & & & $\mathbf{x}$ & & $"$ & $"$ & $"$ & $"$ & $"$ & $"$ & $"$ & $"$ & $"$ & $\mathrm{~F}$ \\
\hline 123 & & $x$ & & & 4 & 4.571 & .582 & 61 & 5.54 & 37 & 0.8 & 0.95 & $\mathrm{H}_{2} \mathrm{O}$ & $\mathrm{H}_{2} \mathrm{O}$ \\
\hline 124 & & $\mathbf{x}$ & & & $"$ & $"$ & $"$ & $"$ & $"$ & $"$ & $"$ & $"$ & $"$ & $\mathrm{FA}$ \\
\hline 125 & & $\mathrm{x}$ & & & $"$ & $"$ & $"$ & $"$ & $"$ & $"$ & $"$ & $"$ & $"$ & $\mathbf{F}$ \\
\hline 126 & & $\mathrm{x}$ & & & 5 & 5.490 & .703 & 61 & 5.95 & 37 & 1.8 & 0.45 & $\mathrm{H}_{2} \mathrm{O}$ & $\mathrm{H}_{2} \grave{\mathrm{O}}$ \\
\hline 127 & & $x$ & & & :" & $"$ & $"$ & $"$ & $"$ & $"$ & $"$ & $"$ & $"$ & $\mathrm{FA}$ \\
\hline 128 & & $\mathbf{x}$ & & & $"$ & $"$ & $"$ & $"$ & " & $"$ & " & $"$ & $"$ & $\mathbf{F}$ \\
\hline & & & & $x$ & 6 & 4.944 & .633 & 61 & 6.34 & 37 & 1.2 & 1.55 & $\mathrm{H}_{2} \mathrm{O}$ & $\mathrm{H}_{2} \mathrm{O}$ \\
\hline & & & & $x$ & $"$ & $"$ & $"$ & $"$ & $"$ & $"$ & $"$ & $"$ & " & $\mathrm{FA}$ \\
\hline & & & & $\mathbf{x}$ & $"$ & $"$ & $"$ & $"$ & $"$ & $"$ & $"$ & $"$ & $"$ & $\mathbf{F}$ \\
\hline & & & & $x$ & 7 & 4.571 & .582 & 61 & 5.95 & 37 & 0.8 & 1.45 & $\mathrm{H}_{2} \mathrm{O}$ & $\mathrm{H}_{2} \mathrm{O}$ \\
\hline & & & & $x$ & $"$ & $"$ & $"$ & $"$ & $"$ & $"$ & $"$ & $"$ & " & FA \\
\hline & & & & $x$ & " & $"$ & $"$ & $"$ & $"$ & $"$ & $"$ & $"$ & $"$ & $\mathrm{~F}$ \\
\hline & & & & $x$ & 8 & 4. 571 & .582 & 61 & 6.34 & 37 & 0.8 & 1.95 & $\mathrm{H}_{2} \mathrm{O}$ & $\mathrm{H}_{2} \mathrm{O}$ \\
\hline & & & & $\mathrm{x}$ & $"$ & $"$ & $"$ & $"$ & " & $"$ & $"$ & $"$ & " & $\mathrm{FA}$ \\
\hline & & & & $\mathrm{x}$ & $"$ & " & " & $"$ & $"$ & $"$ & $"$ & " & $"$ & $F$ \\
\hline
\end{tabular}


compared with the result obtained by using only one spectrum. Currently, calculations of the experiments that have been run are being performed assuming the two specträ.

\section{B. Current and Future Program}

Recent calculations performed for VMR reactor cores have indicated that, for a fixed overall water-to- $\mathrm{UO}_{2}$ ratio, configurations with relatively large coolant/UO $\mathrm{Uatios}_{2}$ were found to be more reactive than had been previously estimated. When the first assembly (case 104) did not become critical, it was theorized that a more reactive configuration could be obtained if either the amount of water within the element could be increased or the amount exterior to the element decreased. Hence, in the next experiment, the same element was retained but the interelement spacing was decreased, thus decreasing the amount of moderator exterior to the element. Since the assembly went critical the calculated results were at least qualitatively supported. The implications of this effect are that the assemblies in which the shroud diameter is 4.94 inches or less will not go critical for element spacings of either 5.95 inches or 6.34 inches.

It has become apparent that in order to check the PUREE' code, a considerable effort should be applied to determining microscopic reactor parameters such as disadvantage factors and epithermal to thermal capture and fission ratios; and that an effort should be made to determine, if possible, the gross thermal spectrum differences between coolant- . fuel and moderator regions. In view of this, and considering that the mechanical handling associated with changing of configurations requires more time than anticipated, it has been decided to perform a more detailed experimental program on those assemblies which have a high probability of being made critical. Table XI summarizes the eight proposed configurations of which one (configuration 3 ) has been partially investigated, and another (configuration 1) did not go critical. Two or three others (configurations 2,4 , and 5) will be investigated in detail, and the remaining ones (configurations 6, 7, and 8) are being deleted.

The measurements to be performed consist of two types, 1) reactivity and worth experiments, and 2) parameter measurements. The first of these consists of determination of critical heights and moderator and coolant worths for maximum coolant and moderator heights, and equal coolant and moderator heights; and if possible; sub-critical measurements of $\mathrm{k}_{\text {eff }}$ for several moderator heights. The parameter experiments consist of measurements of thermal flux distributions and regional average thermal fluxes; and of cadmium ratios for 
thermal capture in $U$ 238, and fission in $U 235$ and $U$ 238; and also axial and radial power distributions. The thermal flux measurements will be performed in some cases with both manganese and natural uranium foils. In a few selected cases, plutonium foils will also be used. The objective of such duplicate measurements will be to determine, if possible, any differences in the thermal neutron spectrum between fuel-coolant and moderator regions.

Figures 38 through 41 are photographs of the VMR critical experiment facilities.

\section{Deviations of the PUREE' Physics Code from Experimental Data}

As mentioned in section VII.A, the data available from VMR critical experiments at. this writing indicates that the predicted effective multiplication for case 104 was about $3 \%$ higher than the experimental value. Four approaches are presently being followed to determine the source or sources of this error.

1. As a portion of an ATL-sponsored project the method by which the VMR criticals are computed is being used to calculate parameters measured in a number of other critical experiments. Among these are the Yankee criticals in which the water-to- $\mathrm{UO}_{2}$ ratio varies from 2.2 to 3.9 , and in which a number of measures of spectrums, microscopic and macroscopic spatial flux, control and fuel,rod worth, etc., have been experimentally determined. Among the measurements are gold foil transits of the flux distribution in the core and reflector. These measurements should provide a test of the ability of our model to predict the flux distribution in the vicinity of the maderator of the VMR. Other experiments providing similar data are those on metal and oxide lattices performed at Brookhaven and Westinghouse. There are, in addition, Yankee measurements on two-region cores and on lattices in which the fuel elements contain some plutonium. The critical experiments on the N. S. Savannah are also of value. The tentative conclusions from the calculations performed so far are that the analytical model yields excellent agreement with Yankee, Brookhaven, and Westinghouse experiments, and that the sounce of the error appears to be a phenomenon which is emphașized in, and is unique to, the heterogeneous VMR core. Table XII indicates some of the results obtained in this study.

2. In another ATL-sponsored project, the effects on multiplication of some special phenomena are being estimated by approximate methods. These effects include the changes in the thermal neutron spectrum and hence in effective thermal microscopic cross sections between regions of different average composition. The application to the VMR is in analysis

$$
-66-
$$


TABLE XII

RESULTS OF COMPARISON OF CALCULATIONS

WITH YANKEE CRITICAL EXPERIMENTS

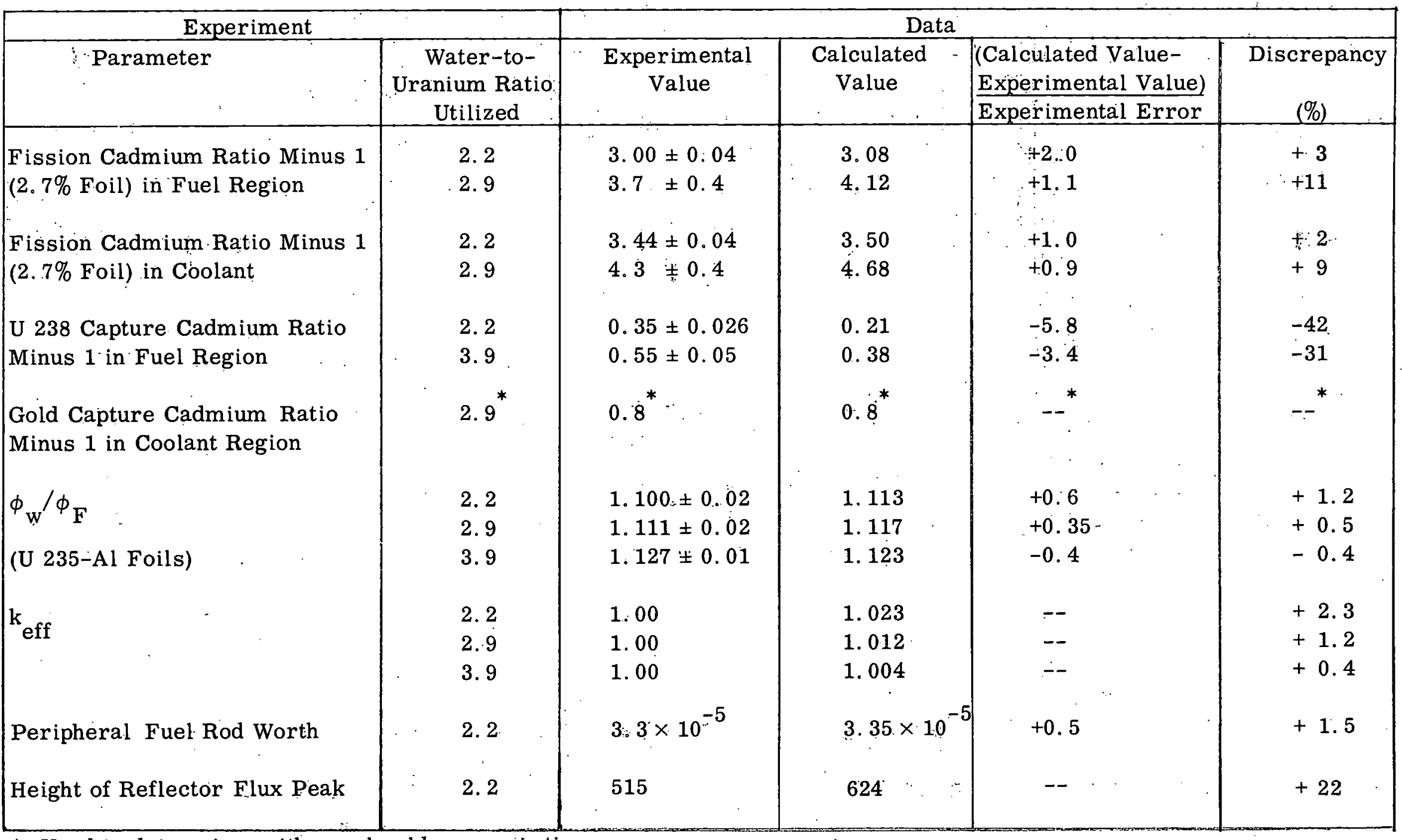

* Used to determine epithermal gold cross section. 


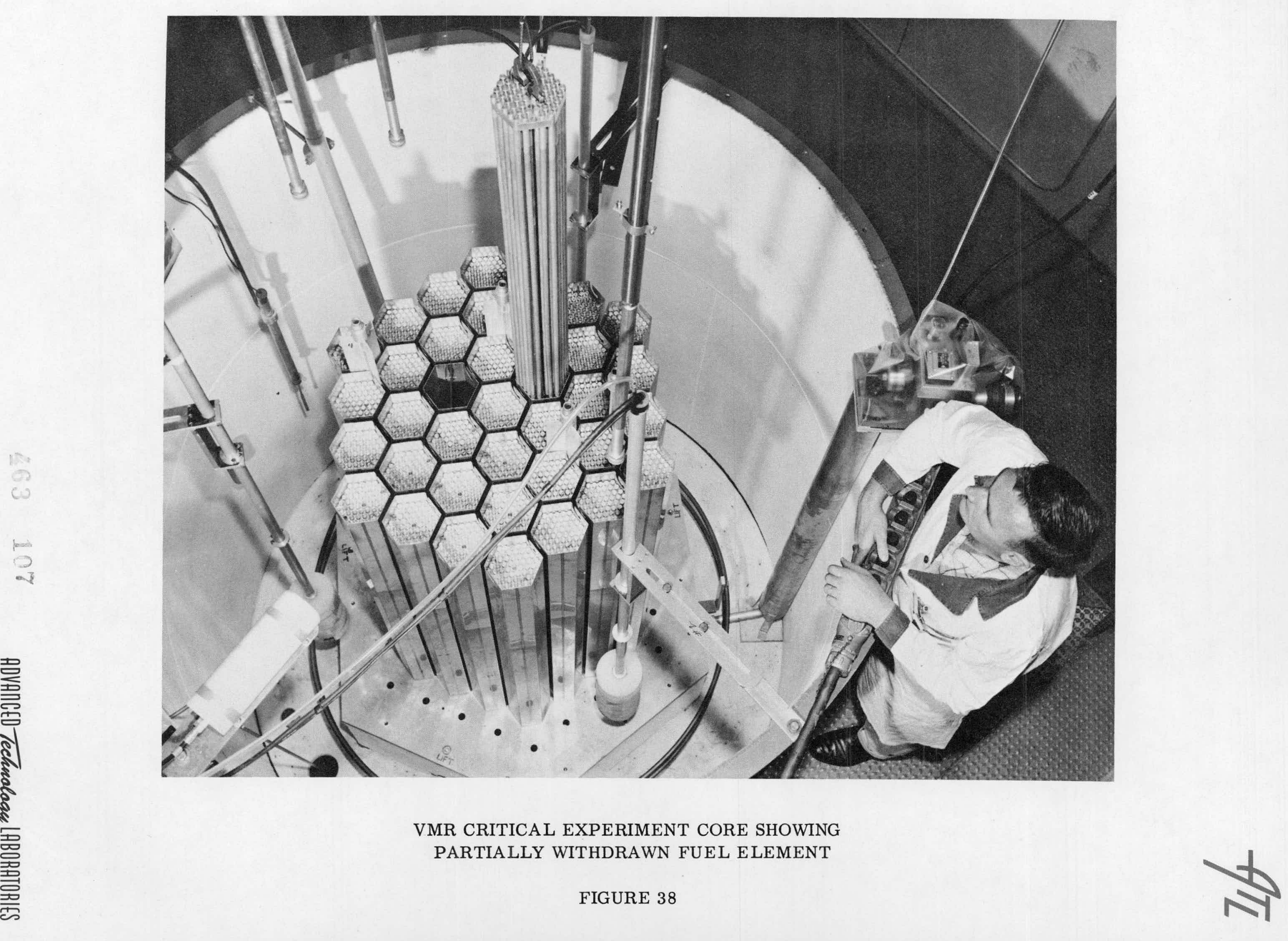




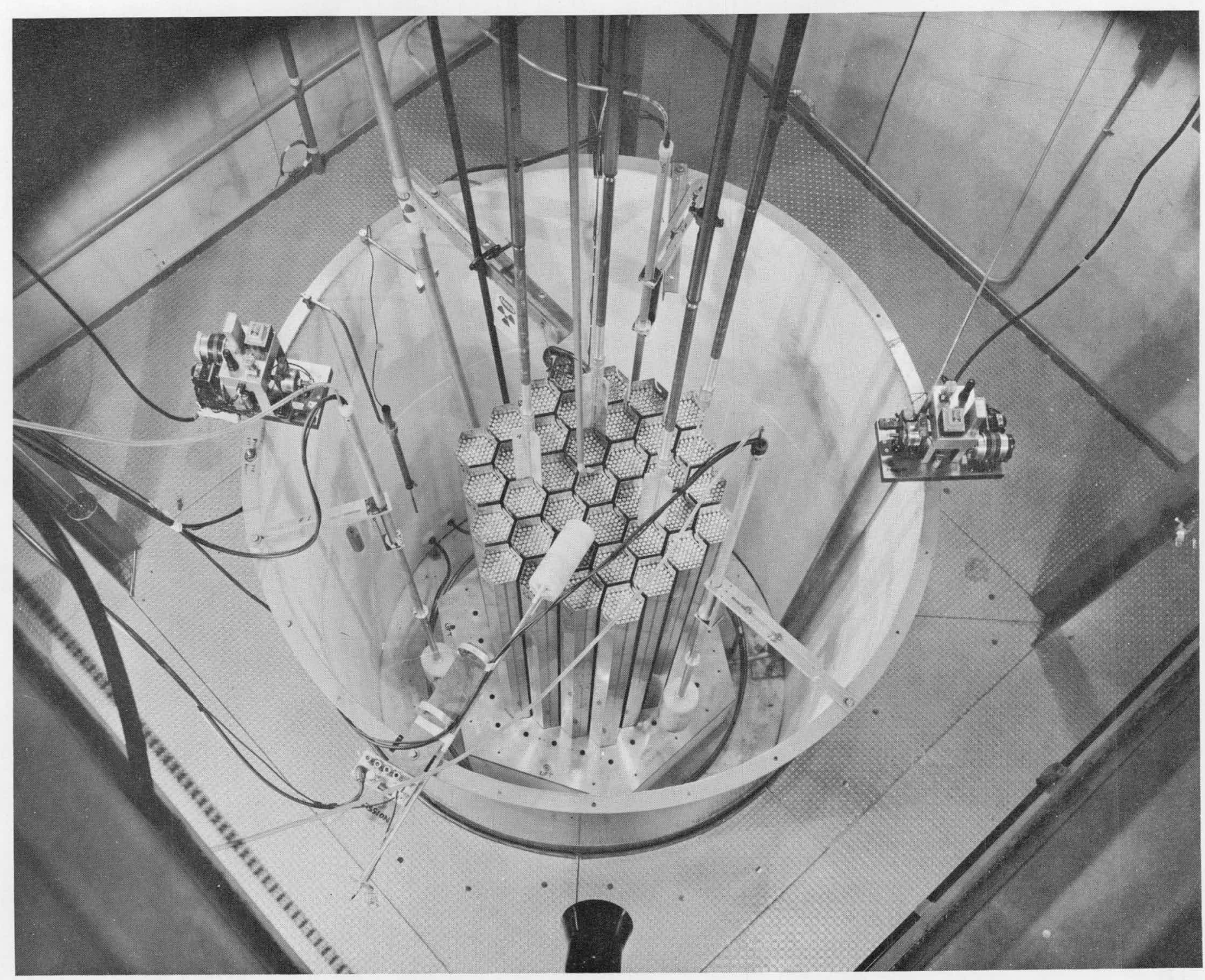

VMR CRITICAL ASSEMBLY CORE WITH

LIQUID LEVEL MEASURING DEVICES MOUNTED ON TANK WALL

FIGURE 39 


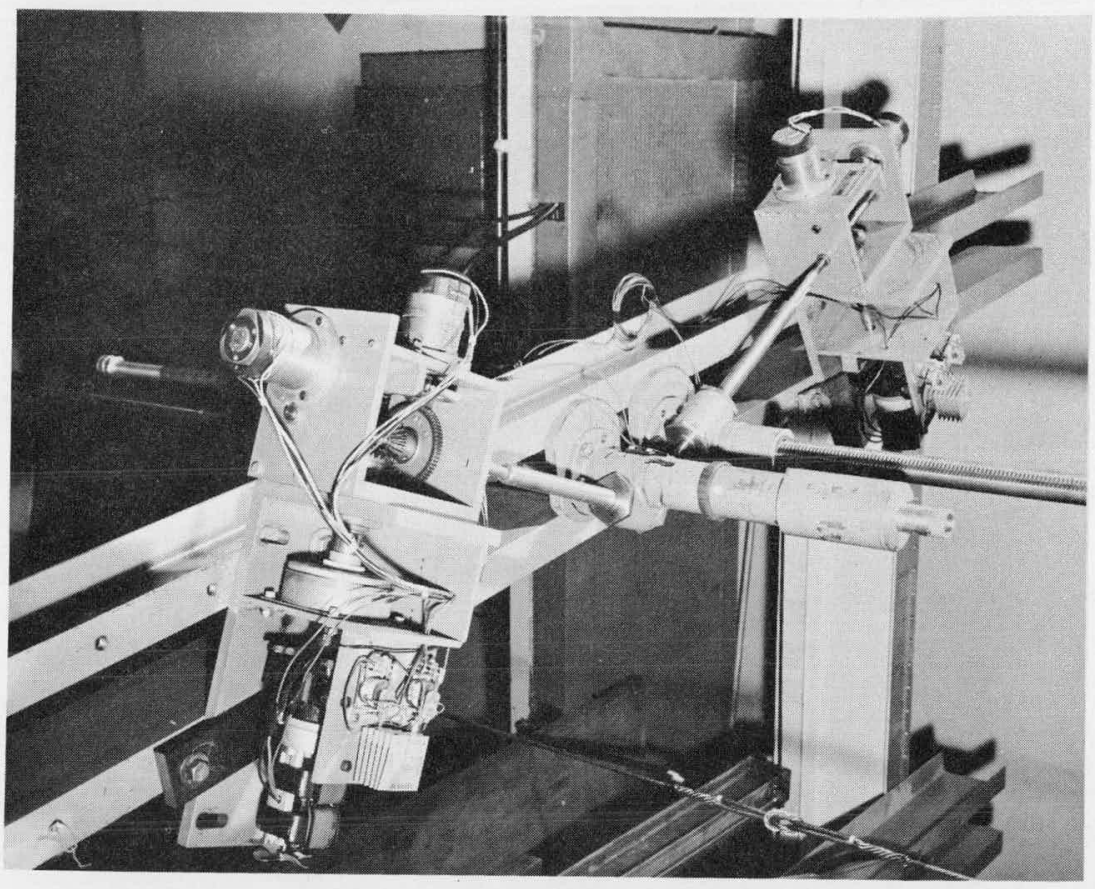

CONTROL ROD DRIVE MECHANISM

FIGURE 40

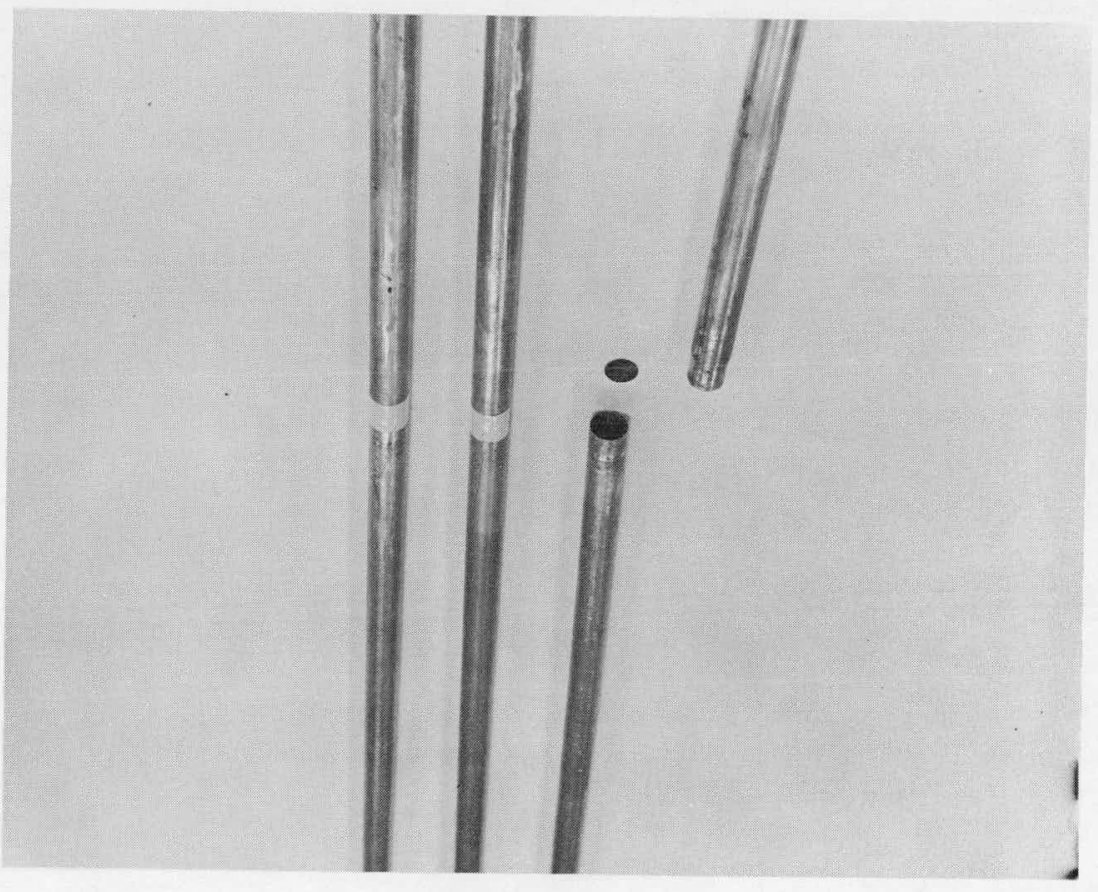

SPLIT FUEL PINS,

TWO ASSEMBLED WITH

CADMIUM COVERS OVER JOINT

FIGURE 41 
of the difference of thermal spectrum between the moderator region and the fuel-coolant region. Calculations performed so far indicate that this effect probably causes a decrease in multiplication af between 1 and $3 \%$ in a typical VMR design. Another phenomenon being investigated is the spatial variation in the intensity of the source into the thermal group due to the analogous variation in the epithermal flux. Again the application to the VMR is in the difference between moderator and coolant and the indications are that this may cause a decrease in $\mathbf{k}$. of between $1 / 4$ and $1 \%$ for a VMR lattice.

Other effects which will be studied as part of this project include the approximations made in obtaining effective cylindrical cells for our microscopic calculations on hexagonal lattices。

Some investigations of the effect of local variation of void density in the horizontal plane and of the effect of the difference between the binding energy of hydrogen in water and in organics are also being made.

3. Another approach to the discrepancy in case 104 is a direct examination of the nuclear data and the model used. A possible improvement in reflector (pure water) cross sections is presently being examined, and the resonance integrals of $U 238$ and $U 235$ fission and capture will again be compared with existing data. The oxygen cross sections also are open to question.

4. The last approach is the obvious one of performing calculations on the additional VMR critical experiment data in as much detail as possible. Such calculations on cases 120 and 121 are presently being made.

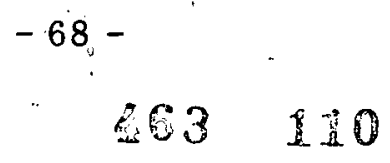




\section{APPENDIX A}

\section{MATERIALSBALANCE}

1: Blowdown

$2300 \mathrm{lb} \mathrm{H}_{2} \mathrm{O}+2.3 \times 10^{-3} \mathrm{lb} \mathrm{SS}+2091 \mathrm{~g} \mathrm{H}_{3} \mathrm{BO}_{3} \rightarrow$

1045. $5 \ell$

Assume $18-8 \mathrm{SS} ; 2.3 \times 10^{-3} \ddot{\mathrm{lb}}=1.043 \mathrm{~g}$

$0.18 \times 1.043=0.187 \mathrm{~g} \mathrm{Cr}^{+++}$

$0.08 \times 1.043=0.083 \mathrm{~g} \mathrm{Ni}^{++}$

$0.74 \times 1.043=0.773 \mathrm{~g} \mathrm{Fe}^{++}$

$\frac{0.187 \times 3}{52.01}=0.0108 \mathrm{eq} \mathrm{Cr}$

$\frac{0.083 \times 2}{58.71}=0.0028 \mathrm{eq} \mathrm{Ni}$

$=0.0413 \mathrm{eq} \mathrm{M}^{+}$

$\frac{0.773 \times 2}{55.85}=0.0277 \mathrm{eq} \mathrm{Fe}$

$\frac{2091}{61.84}=33.8131 \mathrm{eq} \mathrm{H}_{3} \mathrm{BO}_{3}$

$\mathrm{K}=5.8 \times 10^{-10}$ (International Critical Tables)

at $2 \mathrm{~g} / \mathrm{\ell}, \quad \mathrm{M}=\frac{.2}{61.84}=0.0323$

33. 8131 eq Total Boric Acid

$\frac{0.0413}{33.7718}$ eq $\mathrm{H}_{2} \mathrm{BO}_{3}^{-}$due to $\mathrm{M}^{+}$

First Approximation

$\frac{\left(\mathrm{H}^{+}\right)\left(\mathrm{H}_{2} \mathrm{BO}_{3}^{-}\right)}{\left(\mathrm{H}_{3} \mathrm{BO}_{3}\right)}=5.8 \times 10^{-10}$

$\left(\mathrm{H}^{+}\right)\left(\mathrm{H}_{2} \mathrm{BO}_{3}^{-}\right)=5.8 \times 10^{-10} \times 0.0323=18.7 \times 10^{-12}$

$\left(\mathrm{H}^{+}\right)=\left(\mathrm{H}_{2} \mathrm{BO}_{3}^{-}\right)=\sqrt{18.7 \times 10^{-12}}=4.33 \times 10^{-6}$

$4.33 \times 10^{-6} \times 1045.5=0.0045 \mathrm{eq} \mathrm{H}_{2} \mathrm{BO}_{3}^{-}$due to ionization

0.0413 eq $\mathrm{H}_{2} \mathrm{BO}_{3}^{-}$from neutralization

0.0045 eq 23 from ionization

$\overline{0.0458}$ eq $\mathrm{H}_{2} \mathrm{BO}_{3}^{-}$Total First Approximation

Note: $\left(\mathrm{H}^{+}\right)$indicates Hydrogen ion concentration.

$\mathrm{H}^{+}$indicates Total Hydrogen ion in system. 


$$
\begin{aligned}
& \frac{0.0458}{1045.5}=4.38 \times 10^{-5}\left(\mathrm{H}_{2} \mathrm{BO}_{3}^{-}\right) \\
& \left(\dot{\mathrm{H}}^{+}\right)=\frac{18.7 \times 10^{-12}}{4.38 \times 10^{-5}}=4.27 \times 10^{-7}
\end{aligned}
$$

Further approximations would give a $\mathrm{pH}$ of approximately 6

$$
1045.5 \times 10^{-6}=0.0010 \mathrm{H}^{+}
$$

Summation

$$
\begin{array}{ll}
\mathrm{M}^{+}= & 0.0413 \mathrm{eq} \\
\mathrm{H}_{3} \mathrm{BO}_{3}=33.8131-(2 \times 0.0413)-(2 \times 0.0010)= & 33.7285 \mathrm{eq} \\
\mathrm{H}^{+}= & 0.0010 \mathrm{eq} \\
\mathrm{H}_{2} \mathrm{BO}_{3}^{-}= & 0.0423 \mathrm{eq}
\end{array}
$$

2. Distillate - Neglect Acid Carryover

$2000 \mathrm{lb} \mathrm{\textrm {H } _ { 2 } \mathrm { O }}$

3. Bottoms to Cation Exchanger (De-ionizer)

$$
2300 \mathrm{lb}-2000 \mathrm{lb}=300 \mathrm{lb} \mathrm{H}_{2} \mathrm{O}=136.38 \ell
$$$$
\mathrm{M} \cdot=\frac{2300}{300} \times 0.0323=0.248
$$

First Approximation

$$
\begin{aligned}
& \left(\mathrm{H}_{2} \mathrm{BO}_{3}^{-}\right)=\frac{0.0423}{136.38}=3.10 \times 10^{-4} \\
& \left(\mathrm{H}_{3} \mathrm{BO}_{3}\right)=\frac{33.77}{136.38}=0.2476 \\
& \left(\mathrm{H}^{+}\right)=\frac{5.8 \times 10^{-10} \times 0.2476}{3.1 \times 10^{-4}}=4.63 \times 10^{-7}
\end{aligned}
$$

\section{Summation}

$$
\begin{array}{lr}
\mathrm{pH}=\text { approximately } 6.5 & \\
\mathrm{H}^{+}=4.63 \times 10^{-7} \times 136.38= & 0.0 .001 \mathrm{eq} \\
\mathrm{H}_{3} \mathrm{BO}_{3}=33.8131-(2 \times 0.0413)-(2 \times 0.0001)= & 33.7654 \mathrm{eq} \\
\mathrm{H}_{2} \mathrm{BO}_{3}^{-}= & 0.0414 \mathrm{eq} \\
\mathrm{M}^{+}= & 0.0413 \mathrm{eq}
\end{array}
$$


4. Effluent from Cation Exchanger (De-ionizer)

$$
\begin{aligned}
& 300 \mathrm{lb} \cdot \mathrm{H}_{2} \mathrm{O}=136.38 \ell \\
& \mathrm{M}^{+}=\quad 0.0000 \mathrm{eq} \\
& \mathrm{H}_{3} \mathrm{BO}_{3}+\mathrm{H}_{2} \mathrm{BO}_{3}^{-}+\mathrm{H}^{+}=33.8131 \mathrm{eq} \\
& M=.0 .248 \\
& \left(\mathrm{H}^{+}\right)\left(\mathrm{H}_{2} \mathrm{BO}_{3}^{-}\right)=5.8 \times 10^{-10} \times 0.248=1.438 \times 10^{-10} \\
& \left(\mathrm{H}^{+}\right)=\left(\mathrm{H}_{2} \mathrm{BO}_{3}^{-}\right)=\sqrt{1.438 \times 10^{-10}}=1.2 \times 10^{-5} \text {. } \\
& \mathrm{pH}=\text { approximately } 5 \\
& \mathrm{H}^{+}=\mathrm{H}_{2} \mathrm{BO}_{3}^{-}=1.2 \times 10^{-5} \times 136.38=163.66 \times 10^{-5}=0.0016 \mathrm{eq}
\end{aligned}
$$

Resin bed must accommodate flow of $300 \mathrm{lb} / \mathrm{hr}=0.6 \mathrm{gpm}$, and must absorb $0.0413 \mathrm{eq} / \mathrm{hr}$ Resin consumption at $50 \mathrm{eq} / \mathrm{cf}$

$\frac{0.0413}{50}=0.000826 \mathrm{cf} / \mathrm{hr}^{:}=0.0198 \mathrm{cf} / \mathrm{d}=7.24 \mathrm{cf} / \mathrm{yr}$

Use 6" pipe $=5 \mathrm{ft} / \mathrm{cf}$.

Use 1 cf beds and change 8 times/yr

Flow rate $=\frac{0.6}{0.19635}=3 \mathrm{gpm} / \mathrm{ft}^{2}$ 


\section{APPENDIX B}

\section{HE AT BALANCE}

Blowdown $\quad 2300 \mathrm{lb} / \mathrm{hr}, \mathrm{h}_{\mathrm{f}}=500 \mathrm{Btu} / \mathrm{lb}$

$$
2300 \times 500=\quad+1,150,000 \mathrm{Btu} / \mathrm{hr}
$$

Steam out $\quad 2000 \mathrm{lb} / \mathrm{hr}, \mathrm{h}_{\mathrm{g}}=1150 \mathrm{Btu} / \mathrm{lb}$

$$
2000 \times 1150.4=\quad: \quad-2,300,800
$$

Reflux $\quad 10 \%$

- 230,080

Bottoms out $\quad 300 \mathrm{lb} / \mathrm{hr}, \mathrm{h}_{\mathrm{f}}=180 \mathrm{Btu} / \mathrm{lb}$

$$
300 \times 180=
$$

- $\quad 54,000$

Losses

$$
3 \%
$$

$-\quad 46,000$

Required for evaporation

$+1,480,880 \mathrm{Btu} / \mathrm{hr}$

Steam available. 1000 pssia dry and saturated

$$
\begin{aligned}
& \mathrm{h}_{\mathrm{g}}=1192 \mathrm{Btu} / \mathrm{lb} \\
& \mathrm{h}_{\mathrm{f}}=542 \\
& \mathrm{~h}_{\mathrm{v}}=650 \\
& 1,480,880 / 650=2278 \mathrm{lb} / \mathrm{hr} \\
& 2278 \times 1192= \\
& 2278 \times 542=
\end{aligned}
$$$$
+2,715,400
$$

$-1,234,520$

$+1,480,880 \mathrm{Btu} / \mathrm{hr}$ 


\section{APPENDIX C}

\section{EQUIPMENT SIZES}

1. Evaporator Surface

Assume $\mathrm{U}=300$

$\Delta \mathrm{T}=544-212=332^{\circ} \mathrm{F}$

$A=\frac{\mathrm{g}}{\mathrm{U} \Delta \mathrm{T}}=\frac{1,480,880}{300 \times 332}=15 \mathrm{ft}^{2}$

2. Tower

Assume 3 plates or equivalent packing

3. Cooling Finger

$10 \%$ reflux of $2000 \mathrm{lb} \mathrm{H}_{2} \mathrm{O}, \mathrm{sh}_{\mathrm{g}}=1150$

$2000 \times 1150=2,300,800 \mathrm{Btu}$

Assume $U=300$

Assume cooling $\mathrm{H}_{2} \mathrm{O}$ at $75^{\circ} \rightarrow 154^{\circ}$

$\Delta \mathrm{T}_{1}=137^{\circ}, \Delta \mathrm{T}_{2}=58^{\circ}, \operatorname{lm} \Delta \mathrm{T}=92^{\circ} \mathrm{F}$

$A=\frac{2,300,800 \times .1}{300 \times 92}=8.4 \mathrm{ft}^{2}$

$\mathrm{H}_{2} \mathrm{O}$ required $\doteq 230,080 / 79=2920 \mathrm{lb} / \mathrm{hr}$

4. Bottoms Cooler

$300 \mathrm{lb} / \mathrm{hr} \mathrm{H}_{2} \mathrm{O}$ from $212^{\circ} \mathrm{F}$ to $100^{\circ} \mathrm{F}$

$\mathrm{h}_{\mathrm{f} 1}=180$

$\mathrm{h}_{\mathrm{f} 2}=\underline{69}$

$\Delta h_{f}=111$

$300 \times 111=33,300 \mathrm{Btu}$

Assume cooling $\mathrm{H}_{2} \mathrm{O}$ at $75^{\circ} \rightarrow 90^{\circ}$

$\left.\begin{array}{l}\Delta \mathrm{T}_{1}=137^{\circ} \mathrm{F} \\ \Delta \mathrm{T}_{2}=10^{\circ} \mathrm{F}\end{array}\right\} \quad \operatorname{lm} \Delta \mathrm{T}=49^{\circ} \mathrm{F}$ 
Assume $\mathrm{U}=200$
$\mathrm{A}=\frac{33,300}{200 \times 49}=3.4 \mathrm{ft}^{2}$
$\mathrm{H}_{2} \mathrm{O}$ required $=\frac{33,300}{15}=2220 \mathrm{lb} / \mathrm{hr}$

5. Filter

$\frac{300}{8.345 \times 60}=0.6 \mathrm{gpm}$

6. Feed Water Pump

$0.6 \mathrm{gpm}-1000$ psia delivery

7. Deionizer Feed Pump

$0.6 \mathrm{gpm} 20 \mathrm{lb}$, head 
No. of Copies

8

U. S. Atomic Energy Commisșion

Contracts Division

San Francisco Operations Office

Attn: Walter H. Brummett Jr., Director

2

Technical Services Division

San Francisco Operations Office

Attn: R. W. Hughey, Director

1

Battelle Memorial Institute

Attn: David Dingee, Supervisor

1 Critical Assembly Lab.

Chicago Operations Office

U. S. Atomic Energy Commission

Attn: Claude Pursell

1

Technical Information Service Extension

U. S. Atomic Energy Commission

ATL Files

8 